\title{
Variance Risk Premia in Commodity Markets*
}

\author{
Marcel Prokopczuk ${ }^{\dagger, \ddagger}$ and Chardin Wese Simen ${ }^{\ddagger}$
}

January 14, 2013

\begin{abstract}
In this paper, we study variance risk premia in commodity markets. Using synthetic variance swaps, we find significant variance risk premia in 18 out of 21 markets. Typically, variance risk premia are negative, time-varying and their magnitudes increase with variance. Consistent with theory, we find a significant relation between variance risk premia and macroeconomic factors. Furthermore, we evaluate the information content of commodity variance risk premia for future returns. We show that gold's variance risk premium has predictive power for returns in most of the markets considered. This economically significant predictive power is robust to the inclusion of traditional predictors.
\end{abstract}

\section{JEL classification: G12, G13}

Keywords: Commodities, Variance risk premia, Variance swaps

* Marcel Prokopczuk gratefully acknowledges financial support from the British Academy. We thank Lazaros Symeonidis for helpful comments. Contact: marcel.prokopczuk@zu.de (M. Prokopczuk) and c.wesesimen@icmacentre.ac.uk (C. Wese Simen).

${ }^{\dagger}$ Chair of Empirical Finance and Econometrics, Zeppelin University, 88045 Friedrichshafen, Germany.

¥ICMA Centre, Henley Business School, University of Reading, Reading, RG6 6BA, United Kingdom. 


\section{Introduction}

Over the past decade, commodity markets have not only witnessed substantial growth but also tremendous increases in prices and volatility. Given their role as consumption goods, factors of production and financial assets, managing commodity price volatility is crucial for a wide number of market participants such as commercial hedgers and investors. Arguably, these developments have motivated the successful launch of commodity related volatility derivatives such as oil and gold VIX futures contracts. The rapid proliferation of these derivatives raises several questions. Chief among them include: how large is the compensation required by investors to bear variance risk in commodity markets? To what degree are commodity variance risk premia time-varying? What are the determinants of variance risk premia in commodity markets? In this paper we seek to answer these questions.

We study variance risk premia in 21 commodity markets between 1989 and 2011, a period which includes the run-up to the recent financial crisis. In doing so, we contribute to the literature in at least three ways. To start with, we are, to the best of our knowledge, the first to comprehensively examine the extent to which variance risk is priced in a wide variety of commodity markets. Our large data set enables us to investigate variance risk premia in diverse commodities including the grains, energy and metals markets. Additionally, by analyzing variance swaps of different maturities, we shed some light on the shape and behavior of the term-structure of variance risk premia.

Second, we thoroughly investigate the determinants of commodity variance risk premia. In particular, we examine the link between commodity variables, macroeconomic factors and variance risk premia. Moreover, the different volatility behaviors of commodities highlighted by Brooks and Prokopczuk (2011) 
make commodity markets well-suited to clearly distinguish between two popular rationalizations of the sign of variance risk premia: the diversification benefit and the insurance premia hypotheses.

Third, we evaluate the predictive power of commodity variance risk premia for returns across multiple horizons and markets. Here, our focus differs from existing studies in that we also investigate whether a commodity's variance risk premium predicts not only its own returns but also those of other commodities.

Our main findings can be summarized as follows. Variance risk is significantly priced in 18 out of 21 commodity markets. Generally, the evidence points to negative variance risk premia with magnitudes rising in variance levels. These findings hold for different maturities and also over the recent financial crisis. Furthermore, our results support the insurance premia hypothesis, implying a strong link between macroeconomic factors and variance risk premia. Consistent with the predictions of Bakshi and Madan (2006), we find that individual macroeconomic factors explain as much as $20.4 \%$ of movements in variance risk premia. Commodity specific factors can help too: the basis, hedging pressure and open interest complement the explanatory power of macroeconomic factors by $34 \%$ on average. Finally, we demonstrate that gold's variance risk premium predicts returns with significantly negative coefficients for as many as 13 markets. Typically, the predictive power manifests itself at all horizons and is robust to the inclusion of traditional predictors such as the basis and open interest.

Most existing papers studying variance risk premia focus on the question of whether variance risk is priced in equity markets. Applying hedging-based tests, Bakshi and Kapadia (2003b) and Coval and Shumway (2001) present evidence of priced volatility risk in equity indices. Hafner and Wallmeier (2007), Carr and Wu 
(2009) and Driessen et al. (2009) implement a model-free approach and document negative variance risk premia in leading European and US stock indices. In contrast, the evidence for individual stocks is somewhat mixed. While Carr and Wu (2009) report significantly negative variance risk premia in 8 out of 35 individual equities only, Driessen et al. (2009) find marginally positive variance risk premia for some stocks.

Some studies investigate the market price of variance risk in other traditional asset classes. Estimating the Heston (1993) model for the Dollar/Mark market, Guo (1998) reports that, between 1987 and 1992, the market price of variance risk ranges from -4.1 to 1.3. Low and Zhang (2005) reach similar conclusions for other currencies. They show that investors writing straddles earn as much as $2.4 \%$ per annum in the British Pound market and conclude that volatility risk is negatively priced in currency markets during the period 1996-2003. Additionally, their evidence suggests that the performance of this strategy decreases as the horizon increases. Similarly, Simon (2010) finds that short straddles in fixed-income markets are highly profitable. Mueller et al. (2011) synthesize variance swaps and provide evidence of negative variance risk premia in the US Treasury bond market.

In contrast to traditional asset classes, the literature on variance risk premia in commodity markets is somewhat scant. ${ }^{1}$ Employing relatively simple parametric models, Doran and Ronn (2008) estimate variance risk premia of $-0.9,-0.4$ and -1.4 for crude oil, heating oil and natural gas, respectively. Similarly, Trolle and Schwartz (2010) show that long variance swap positions lose $2.96 \%$ and $3.58 \%$ on average in the crude oil and natural gas markets, respectively. In a related study,

\footnotetext{
${ }^{1}$ Similar observations can be made for other emerging asset classes such as credit and volatility. Wang et al. (2010) and Barnea and Hogan (2012) are the only studies on variance risk premia in the credit default swap (CDS) and VIX markets we are aware of.
} 
Wang et al. (2011) find that corn variance swaps are unprofitable, indicating a negative price of variance risk for corn.

Overall, existing studies unanimously point to negative variance risk premia in financial markets, which contrasts with the positive compensation required by investors for price risk. This seemingly counterintuitive result raises several questions: why do investors pay a premium for taking on variance risk? What are the determinants of variance risk premia?

The literature proposes two main hypotheses: the diversification benefit and the insurance premia against bad economic states. On the one hand, the diversification benefit hypothesis argues that the sign of variance risk premia is determined by the correlation between returns and volatility. Specifically, if returns and volatility are negatively correlated as is the case for equities, variance swaps provide good hedges for price risk. Investors are willing to pay a variance risk premium to obtain this diversification benefit. Conversely, if returns and volatility are positively correlated, it is plausible that investors will require a compensation for bearing this extra risk.

On the other hand, the insurance premia hypothesis links with the insights of Bakshi and Madan (2006), who argue that volatility risk premia arise because "rational risk-averse investors are sensitive to extreme loss states and are willing to counteract these exposures by buying protection". This statement assimilates variance risk premia to insurance premia against bad states of the economy. Drechsler and Yaron (2011) formalize this intuition by developing an equilibrium model in which investors are not only averse to uncertainty but also have a preference for early uncertainty resolution. Their intuition is simple: if investors dislike increases in economic uncertainty, they will pay a premium to hedge variance risk. Drechsler (2012) and Mueller et al. (2011) provide empirical evidence in support 
of this conjecture. It is important to note that, unlike the diversification benefit argument, this hypothesis always predicts a negative price of variance risk.

Another strand of the literature explores the information content of variance risk premia for future returns. Bollerslev et al. (2009) show that, between 1990 and 2007, the S\&P 500 variance risk premium accounts for as much as $7 \%$ of variations in its returns. Using a more recent sample (2000-2011), Bollerslev et al. (2011b) confirm this finding: the S\&P 500 variance risk premium explains $13.02 \%$ of changes in quarterly returns. Moreover, the authors document analogous predictive patterns for major international stock markets.

Although the above studies significantly enhance our understanding of variance risk premia, they suffer from several limitations. First, commodity related studies are limited in scope. Together, Trolle and Schwartz (2010) and Wang et al. (2011) merely cover 3 markets. In light of the mixed evidence for equities, it may be that their findings are market specific: thus the necessity to study variance risk premia in a large number of commodity markets. Second, because of their relatively short and uneventful sample period, existing studies do not shed light on the dynamics of variance risk premia during the recent boom in commodity prices or the run-up to the recent financial crisis. Third, most studies invariably focus on one horizon, overlooking crucial information in the term-structure of variance risk premia. Examining variance risk premia across different maturities could provide insights into the term-structure of variance risk premia. Fourth, to date, no empirical study has ascertained which of the two hypotheses put forward to explain the sign of variance risk premia is more likely. Indeed, the negative correlation between price and volatility that prevails in traditional markets makes it difficult to clearly distinguish between the two conjectures. Brooks and Prokopczuk (2011) show that 
commodities such as gold and silver exhibit a positive price/volatility correlation, making commodity markets a perfect testing ground to distinguish between the two hypotheses. Fifth, the literature has only considered systematic factors in its analysis of the determinants of variance risk premia. Despite the empirical evidence of Mueller et al. (2011), it is possible that market specific conditions such as inventories and open interest affect variance risk premia. Sixth, we examine whether the predictive power of variance risk premia for future returns is validated in commodity markets. More important, we assess whether a commodity variance risk premium contains information not only for its returns but also for other commodity returns.

This paper proceeds as follows. In Section II we introduce our methodology and describe the data set employed. In Section III we present and discuss the empirical results of our study. Finally, Section IV concludes.

\section{Methodology and Data}

\section{A. Methodology}

Empirical studies on variance risk premia are usually anchored around one of the following three estimation approaches: parametric, semi-parametric or model-free. The parametric approach consists of specifying a data-generating process for the underlying. In this framework, the variance risk premium is usually a parameter to be estimated by exploiting information from the underlying and options prices. This approach is not only computationally intensive but also subject to specification errors since it explicitly assumes a specific data-generating process

for the underlying. Consequently, parametric estimates of variance risk premia 
are joint tests of model specification and variance risk premia. Broadie et al. (2007) empirically examine the impact of model misspecification on risk premia. They conclude that the significance of variance risk premia depends crucially on assumptions about the presence of jumps in the data-generating process. $^{2}$

Bakshi and Kapadia (2003a) propose to study variance risk premia in a semiparametric way through option hedging errors by analyzing the profitability of deltahedged at-the-money (ATM) straddles. This approach is motivated by financial theory, which argues that option prices are affected by changes in implied volatility and the underlying's price. Since delta-neutral ATM straddles are insensitive to small movements of the underlying's price, their profitability is mainly driven by changes in implied volatility. Hence, the profitability of delta-neutral ATM straddles may shed light on the existence of variance risk premia. Though intuitive, this approach is subject to the criticism that it does not allow for jump risk. Given the evidence discussed by Eraker et al. (2003) and Pan (2002), this omission is likely to be a serious issue. Echoing this concern, Branger and Schlag (2008) warn that hedging-based tests may mistakenly attribute the combined effect of volatility and jump risk premia to volatility risk premia, potentially leading to wrong inferences on the sign, significance and size of volatility risk premia.

To overcome these problems, the more recently introduced model-free approach builds on variance swaps defined as swap contracts in which the floating leg corresponds to the realized variance of the underlying over a predetermined period. The underlying idea is that variance risk premia are equal to the pay-offs of variance swaps which are the differences between the realized variance and the risk-neutral expectation of variance. No-arbitrage arguments imply that the rate of a variance

\footnotetext{
${ }^{2}$ Pan (2002) reaches similar conclusions. She shows that once jumps are allowed for, the variance risk premium becomes insignificant in her data set.
} 
swap, $S V_{t, T}$, must be equal to the risk-neutral expectation of variance $\mathbb{E}_{t}^{Q}\left(V_{t, T}\right)$ over the life of the swap. Thus, the variance risk premium at date $t$ and horizon $T$, $V R P_{t, T}$, is given by:

$$
V R P_{t, T}=R V_{t, T}-S V_{t, T}
$$

where $R V(t, T)$ denotes the realized variance between $t$ and $T$ under the physical measure. $^{3}$

Consequently, quantifying variance risk premia reduces to estimating realized variance and variance swap rates. Whilst realized variance estimators have been extensively studied (see, e.g., Andersen et al. (2009) and the references therein), until recently, little has been known about the latter. In a seminal study, Britten-Jones and Neuberger (2000) elaborate a replicating strategy to estimate the variance swap rate under the assumption that the underlying follows a continuous process. ${ }^{4}$ More precisely, they derive the following estimator:

$$
\mathbb{E}_{t}^{Q}\left(V_{t, T}\right)=M F I V_{t, T}=\frac{2 e^{r_{t}(T-t)}}{T-t}\left[\int_{0}^{F} \frac{P(K)}{K^{2}} d K+\int_{F}^{+\infty} \frac{C(K)}{K^{2}} d K\right]
$$

where $\mathbb{E}_{t}^{Q}\left(V_{t, T}\right)$ and $M F I V_{t, T}$ refer to the risk-neutral expectation of variance and model-free implied variance between $t$ and $T$, respectively. The annualized risk-free rate is denoted by $r_{t}$, and $P(K)$ and $C(K)$ denote European put and call options struck at $K$.

Subsequently, Jiang and Tian (2005) extend this approach to a broader class of models by formally showing that Equation (2) holds for jump diffusion models

\footnotetext{
${ }^{3}$ This implicitly assumes, of course, that the expectation of realized variance under the physical measure is an unbiased estimate of realized variance.

${ }^{4}$ See Demeterfi et al. (1999) for an excellent treatment of the replicating strategy.
} 
also. Although jumps introduce errors in the replicating strategy, the numerical analysis of Carr and Wu (2009) indicates that these biases are negligible. Together, these results lead to the conclusion that the variance swap approach for estimating variance risk premia is robust and, more importantly, model-free in the sense that it does not require assumptions about the underlying data-generating process.

Therefore, we employ a methodology that is similar to that of Carr and Wu (2009). Assume we want to synthetically create a 60 day variance swap. On each trading day, we obtain and sort all out-of-the-money (OTM) options by time to maturity. We identify the two maturities $T_{1}$ and $T_{2}$ that are closest to and cover 60 days. We retain options of maturities $T_{1}$ and $T_{2}$ only. As in Trolle and Schwartz (2010), we truncate the first and second integrals in Equation (2) at $K_{l}$ and $K_{u}$ respectively:

$$
\begin{gathered}
K_{l}=S_{t} \exp ^{-10 \sigma T} \\
K_{u}=S_{t} \exp ^{10 \sigma T}
\end{gathered}
$$

where $K_{l}$ and $K_{u}$ refer to the lower and higher truncated strikes. $S_{t}$ refers to the underlying price on day $t, \sigma$ is the average implied volatility of all OTM options and $T$ denotes the time to maturity of the synthetic variance swap. For each maturity, we linearly interpolate available implied volatilities across moneyness. ${ }^{5}$ For strikes higher (lower) than the highest (lowest) listed strike price but lower (higher) than $K_{u}\left(K_{l}\right)$, we assume constant implied volatility. Pursuing this approach, we obtain a grid of 1,000 equidistant implied volatilities for strikes between $K_{u}$ and $K_{l}$. To ensure that our interpolated implied volatilities are realistic, we require the existence of at least two OTM put and two OTM call options for each of the two maturities.

\footnotetext{
${ }^{5}$ We obtain similar results with a spline interpolation. These results are available upon request.
} 
We exclude from our sample all trading days that do not meet this requirement.

We then convert implied volatilities into European option prices using the Black (1976) option pricing formula. We evaluate the integrands at each of the 1,000 points and numerically approximate (trapezoidal rule) the integrals in Equation (2) to estimate the variance swap rate. Finally, we linearly interpolate between the two swap rates to obtain the 60 day variance swap rate. We repeat the above steps every day to obtain time series of 60 day variance swap rates.

As is common in empirical studies, we estimate realized variance as follows:

$$
R V_{t, t+N}=\frac{252}{N} \sum_{i=t+1}^{t+N}\left(\log \frac{F_{i, t+N}}{F_{i-1, t+N}}\right)^{2}
$$

where $N$ is the time to maturity of the variance swap, $F_{i, t+N}$ denotes the futures contract observed at time $i$ and expiring at time $t+N$.

Note that, contrary to individual equities, commodity options are written on futures contracts which life span is finite. As a result, the time series of the first nearby contract could exhibit spikes at rollover dates especially in markets characterized by steep term-structure of futures. Given that these spikes could bias our estimates of realized variance upward, we construct a constant maturity futures time series by linear interpolation of futures contracts maturing at $T_{1}$ and $T_{2}$.

\section{B. Data}

We obtain futures and option settlement prices from the Commodity Research Bureau (CRB). Table 1 lists the 21 commodities included in our sample. To mitigate the effect of micro-structure related issues such as infrequent trading and stale prices, we only retain options with time-to-maturity of at least 12 days. We further delete 
options with prices lower than five times the minimum tick size reported in the last column of Table 1. Given that our data set comprises American options and that our estimation approach requires European option prices, we follow Trolle and Schwartz (2009) and convert the American options prices into European prices employing the approximation of Barone-Adesi and Whaley (1987).

In light of our focus on variance swaps that mature in 60 or 90 days, we retain only OTM options on the first two futures contracts. For energy commodities, we retain OTM options on the second and third futures contracts. ${ }^{6}$ Table 2 gives an overview of the final data set of option prices. It shows that our sample period spans more than 20 years including the recent financial crisis. The last two columns report the average number of OTM call and put options per trading day. These numbers vary a lot across commodities. In particular, the number of OTM options for energy commodities is substantially higher than for the other sectors. On average across all commodities, there are 17 and 14 OTM call and put options per day, respectively.

\section{Empirical Results}

Prior to discussing our empirical results, it is instructive to visually examine the dynamics of realized variance (RV) and model-free implied variance (MFIV). Figure 1 plots the time series of RV and MFIV for 6 commodities drawn from different sectors. This figure highlights several interesting features. First, RV and MFIV trend together. Second, MFIV is usually higher than RV, suggesting that long variance swaps investments are generally unprofitable. However, by visually inspecting these plots, it is impossible to ascertain whether these losses

\footnotetext{
${ }^{6}$ The reason for selecting the second and third nearby futures contracts is that, unlike other commodities, energy commodities have a monthly expiration schedule.
} 
are significantly different from zero or whether similar results are obtained for other commodities. Third, the top right panel (soybean) reveals seasonal patterns in the two estimates of variance, raising questions as to whether variance risk premia are seasonal? Fourth, the scales of the vertical axes indicate that some commodities are more volatile than others, prompting us to explore the connection between variance risk premia and variance level. Finally, the figure shows that the two variance estimates exhibit considerable temporal variations, leading us to analyze the drivers of variance risk premia. We elaborate on each of the above observations in the ensuing paragraphs.

\section{A. Is Variance Risk Priced in Commodity Markets?}

We start our empirical analysis by ascertaining whether variance risk is priced in commodity markets. If variance risk is not priced, we expect one or a combination of the following scenarios. First, the average pay-off to variance swaps is of small magnitude, a few basis points at best. Second, the average pay-off is not statistically distinguishable from zero.

\section{A.1 Evidence of Variance Risk Premia}

Table 3 presents summary statistics of the estimated commodity variance risk premia. The average 60 day variance risk premia reported in Panel A ranges from $-10.2 \%$ (natural gas) to $2.6 \%$ (cotton), suggesting that variance risk is priced in commodity markets and also that the market price of variance risk exhibits large cross-sectional variations. To assess the significance of variance risk premia, we report Newey-West t-statistics in the fourth column of Table 3. The evidence for 60 day variance risk premia (Panel A) suggests that variance swaps generate significant 
pay-offs in all markets except coffee, silver and soybean meal. Unlike individual stocks, we find clear evidence of significantly negative variance risk premia in 17 of the 21 markets; only cotton exhibits a positive variance risk premium.

The volatility of 60 day variance risk premia is generally low, with values usually below $7 \%$. However, natural gas and coffee variance risk premia exhibit volatilities that are an order of magnitude higher (15\% and $17 \%$, respectively). The high volatility of silver's variance risk premia could explain why its market price of variance risk is not statistically different from zero. Examining the higher moments of variance risk premia, we find evidence of positive skewness which contrasts with the negative skewness often found in returns. The positive skewness indicates that, though short variance swap positions earn significant profits, these strategies could incur severe losses. Variance risk premia are leptokurtic with kurtosis as high as 24.48 in the soybeans market. Summarizing, the magnitudes and signs of higher moments bring us to the conclusion that variance risk premia are not normally distributed. Moreover, the positive skewness and high kurtosis are compatible with the idea that variance risk premia are compensation for crash risk.

To gain insights into the term-structure of variance risk premia, we repeat the above analysis for 90 day variance risk premia and present the results in Panel B of Table 3. There are a few notable differences from the findings for the 60-day variance risk premia reported in Panel A. In contrast to the bimonthly horizon, variance risk is not priced in the soybeans and oats markets at quarterly horizons. We observe the opposite pattern for silver and soybean meal: variance risk is priced at quarterly but not bimonthly horizons. Moreover, the short-end of the term-structure of variance risk premia appears to be very steep in the lean hogs market as evidenced by the substantial rise in the variance risk premium from $-1.2 \%$ at a 60 day horizon 
to $4.3 \%{ }^{7}$ Together, these results highlight important differences in the pricing of variance risk across maturities.

In summary, Table 3 unequivocally points to significant variance risk premia in commodity markets. Our conclusions tie in with previous work. By showing that variance risk is negatively priced in energy markets, we extend the findings of Trolle and Schwartz (2010) to longer horizons (60 and 90 days). Similarly, our results for corn (90 day) corroborate and supplement the evidence of Wang et al. (2011). However, our evidence of significant variance risk premia for most commodities differs from that of individual equities reported in Carr and Wu (2009) and Driessen et al. (2009). This result underscores the differences across asset classes.

Moreover, Table 3 has a more profound implication in that it provides evidence against the diversification benefit hypothesis. As previously discussed, this hypothesis posits that the sign of variance risk premia is determined by the price/volatility correlation of the underlying asset. Given the findings of Brooks and Prokopczuk (2011) that several commodities, such as gold, silver and soybeans, exhibit positive price/volatility correlation, we would expect a positive variance risk premium in these 3 markets. Table 3 rejects this hypothesis. In contrast, it documents significantly negative premia for gold, silver and soybeans (for soybeans only the 90 day premium is insignificant). Moreover, the evidence points to negative variance risk premia in most markets at either 2 or 3 month horizons. We interpret these results as empirical evidence against the diversification benefit hypothesis. We formally explore the insurance premium hypothesis which links macroeconomic expectations, uncertainty and variance risk premia in Subsection $C$.

\footnotetext{
${ }^{7}$ Further analysis reveals that the difference between the two premia is essentially driven by realized variance.
} 


\section{A.2 Cross-market Comparisons}

The highly negative variance risk premia of natural gas (at both maturities) potentially indicates that more volatile commodities exhibit higher variance risk premia. If confirmed, this feature could complicate cross-market comparisons. To control for the overall volatility level, we compute the Log Variance Risk Premium (LVRP) defined as $L V R P_{t, T}=\log \left[\frac{R V_{t, T}}{M F I V_{t, T}}\right]$. An alternative approach consists in calculating changes in daily variance risk premia. However, we favour LVRP because it can be interpreted as the return of a variance swap. Moreover, LVRP are conducive to cross-market comparisons since traditional performance measures such as Sharpe ratios (SR) can be computed for returns series.

Table 4 displays the results of the analysis for the LVRP. Again, we report results for 60 and 90 day variance swaps in Panels A and B, respectively. The mean LVRPs reported in Panel A of Table 4 range from $-86.5 \%$ (oats) to $66.9 \%$ (cotton). ${ }^{8}$ The standard deviation of the LVRP is fairly homogenous across commodities with values typically below $50 \%$, the only exception being silver with a high volatility of $121 \%$. The relatively low higher moments indicate that LVRPs are better approximated by a Gaussian distribution than variance risk premia.

To evaluate the performance of commodity variance swaps, we report absolute values of annualized, Newey-West corrected SRs in the penultimate column of Table 4. We present absolute values of SR because the negative returns on variance swaps complicate cross-market comparisons of SRs. Koijen et al. (2012) show that long passive commodity investments earn SRs of about $10 \%$ for the period 1980-2011. Table 4 demonstrates that 60 day commodity variance swaps outperform long passive strategies with SRs varying between $9.4 \%$ and $63.4 \%$. The high variability in

\footnotetext{
${ }^{8}$ Note that under the null of no variance risk premium, LVRP will be negative due to Jensen's inequality.
} 
SRs within and across sectors is striking. At 2 month horizons, SRs fluctuate between $34 \%$ and $47 \%$ in energy markets. This variability carries over to grains and livestocks. For example, a short variance swap position in live cattle earns an annualized SR of $50.2 \%$, almost three times higher than the $17.4 \%$ of lean hogs. These large differences provide further support to the heterogeneity of commodity markets.

Cotton's remarkable $63.4 \%$ reward to variability ratio is noteworthy. First, it is the highest SR across all commodities and maturities. Second, cotton variance swaps outperform equity variance swaps. For example, Carr and Wu (2009) report SRs that vary between $0 \%$ and $55 \%$ for US listed stocks. Third, and more important, in order to earn this SR, an investor must initiate long rather than short variance swap positions in the cotton market. This subtle yet crucial difference enhances the attractiveness of cotton variance swaps. The enhancement stems from the asymmetric pay-offs to variance swaps; while the maximum loss on long variance swap positions is equal to the swap premia, short variance swap positions carry significant downside risk with unlimited losses possible.

We further compare the performances of commodity variance swaps of different maturities. We repeat the above analysis for 90 day variance risk premia. Panel B of Table 4 points to a rapid deterioration of Sharpe ratios from a peak of $63.4 \%$ (cotton) to a peak of $34.9 \%$ (natural gas) as the maturities of variance swaps increase from 2 to 3 months. This result links with the work of, Low and Zhang (2005) who conclude that volatility risk premia decrease with maturities. 


\section{B. Time Variation in Variance Risk Premia}

In the following paragraphs, we analyze time variations in variance risk premia. First, we examine seasonal patterns in variance risk premia. Second, we study the link between variance and variance risk premia.

\section{B.1 Affine Premium}

It is possible that the large cross-sectional variations in variance risk premia reported in Table 3 are the results of a negative relationship between variance risk premia and variances. In fact, several stochastic volatility models (e.g. Heston (1993)) specify the variance risk premium as an affine function of volatility. We formally test this possibility by regressing realized variance on model-free implied variance:

$$
R V_{t, T}=\alpha+\beta M F I V_{t, T}+\epsilon
$$

The null hypothesis is that of a one-to-one relationship between realized and modelfree implied variance, i.e. the slope coefficient is not significantly different from 1.

The first five columns of Table 5 report the results from Regression (6). Starting with 60 day variance risk premia, we find that, except for soybeans and soybean meal, the slope estimates are always significantly lower than 1. In line with our conjecture, this result confirms a negative relationship between $V R P$ and $M F I V$. We also assess whether relative variance risk premia are time-varying by estimating the following regression:

$$
\log \left(R V_{t, T}\right)=\alpha+\beta \log \left(M F I V_{t, T}\right)+\epsilon
$$


In the last five columns of Panel A, we report the coefficients, t-statistics and $R^{2}$ of the above regression. The main findings do not change. We cannot reject the null hypothesis at the $5 \%$ level for corn and soybeans only.

Panel B of Table 5 presents our findings for variance swaps that mature in 3 months. There are a few minor differences compared to Panel A. For example, we cannot reject the null hypothesis $(\beta=1)$ for cotton, soybeans, soybean meal, wheat, lean hogs and oats. Nevertheless, our main conclusion is unaltered: the profitability of short variance swaps positions increases with variance.

Contrary to Trolle and Schwartz (2010), we find that natural gas LVRP decreases with variance. The divergence of results is most likely due to our different sample period and horizon. In addition, our evidence for commodity LVRP differs from that of Carr and $\mathrm{Wu}$ (2009), who find that log variance risk premia are independent of log realized variance in equity markets.

\section{B.2 Calendar Effects}

Many commodities exhibit seasonal patterns. Suenaga et al. (2008) document the seasonality of realized variance in the natural gas market whereas Back et al. (2013) document seasonality in implied volatilities. A priori, it is not clear whether this pattern carries through to variance risk premia. On the one hand, if MFIV is a forward looking measure of realized variance, it should capture the seasonal pattern and therefore both, RV and MFIV vary with the seasonal cycle. This reasoning is borne out by the plots of RV and MFIV for soybeans (Figure 1). Following this argument, it is possible that variance risk premia do not exhibit any seasonality. On the other hand, if the market price of variance risk is equivalent to an insurance risk premium, its magnitude may be seasonal, varying with market related factors 
such as crop cycles and weather conditions. Hence, we can reasonably expect sizable variance risk premia at times when commodities are most sensitive to demand and/or supply factors.

In order to establish which of the two conjectures applies, we compute monthly averages of variance risk premia which we report in Table $6 .^{9}$ In most markets, the signs of variance risk premia are remarkably stable across months. However, the month-by-month analysis also highlights large fluctuations in the magnitude and significance of variance risk premia. In line with Trolle and Schwartz (2010), we uncover economically large differences in natural gas's variance risk premium. In particular, the variance risk premium is considerably higher during the period JulyJanuary than the period February-June. Further statistical tests indicate that the difference between the 60 day variance risk premia of March $(-4.3 \%)$ and September $(20.5 \%)$ is significant at the $5 \%$ level. Together, these findings provide evidence of time regularities in the market price of natural gas's variance risk. Orange juice is another interesting case: its variance risk premium is significant in October--January and July only. Economically, these months coincide with periods when orange juice crops are most vulnerable to weather conditions. Notice also that results for soybean meal and coffee indicate that variance risk is priced for a few months only. However, the unconditional results reported in Table 3 do not provide evidence of significant variance risk premia. Together, these results show that there is significant scope for timing commodity variance swaps investments.

In summary, we document important time variations in commodity variance risk premia. This finding is of great interest for academics and investors alike.

\footnotetext{
${ }^{9}$ For brevity, we report and discuss only the results pertaining to bimonthly variance risk premia. Results for variance swaps that mature in 90 days are similar and are available upon request.
} 
First, we demonstrate the importance of timing commodity variance swaps (e.g. natural gas, orange juice, soybean meal). Second, our results are important for commodity pricing. For example, the finding that orange juice's variance risk premium is only significantly negative when crops are most vulnerable to weather conditions, indicates that commodity specific factors such as inventories and weather may play an important role in enhancing our understanding of variance risk premia, as it is likely that variance risk premia are not only affected by systematic but also commodity specific factors.

\section{Determinants of Variance Risk Premia}

Having documented the existence of time-varying variance risk premia, we now turn to the question of identifying the determinants of commodity variance risk premia.

\section{C.1 Macroeconomic Expectations}

Bollerslev et al. (2011a) relate variance risk premia to time-varying risk aversion, suggesting that variations in variance risk premia may be attributable to the state of the economy. Motivated by this insight, we investigate whether macroeconomic expectations can account for variations in variance risk premia.

We proxy time-varying risk aversion with 2 financial variables: the default spread (DFSPD) defined as the difference between AAA and BAA and the term spread (TSPD) calculated as the difference between 10 year and 2 year bond yields. We download these data from the Federal Reserve website. Additionally, expectations of macroeconomic activity are obtained from Blue Chip Economic Indicators (BCEI). This data set presents three distinct advantages over traditional data sources of economic expectations such as the Survey of Professional Forecasters 
(SPF) and the Livingstone Survey. First, BCEI surveys more than 40 experts from leading academic institutions, banks, consultancies and insurers. Moreover, respondents provide forecasts for several variables, ranging from GDP to net exports. Second, these surveys are conducted at a monthly frequency. By contrast, the SPF and the Livingston Survey are only available at quarterly and semi-annual frequencies, respectively. Third, BCEI presents forecasts for the current and following calendar years, making this data set well-suited for studies on long-run uncertainty. $^{10}$

To obtain consensus expectations for each month, we obtain individual forecasts of different variables closely linked to economic activity and compute the cross-sectional median. ${ }^{11}$ More precisely, we obtain consensus forecasts for real gross domestic production (RGDP), the consumer price index (CPI) and industrial production (IP). Each of these variables reveals information about different facets of the economy. For example, RGDP and CPI are informative about the real and nominal economy, respectively. Similarly, industrial production is closely linked to commodity demand.

If variance risk premia are interpreted as insurance premia, positive macroeconomic expectations will translate into less negative variance risk premia. As a result, RGDP and IP should be positively related with variance risk premia in all commodity markets where they are negative. Table 7 summarizes the results of regressions of variance risk premia on each macroeconomic forecast. ${ }^{12}$ In the interest

\footnotetext{
${ }^{10}$ Unfortunately the BCEI surveys are only available in PDF format. Therefore, we manually extracted and digitized the data.

${ }^{11}$ Note that the fixed forecasting horizon introduces some seasonality in individual series. For example, in January 2004, the current year forecast refers to the period January-December 2004. In July, it still relates to the period January 2004-December 2004. To get around this issue, we fit an X-12 ARIMA filter to individual series.

${ }^{12}$ We report the results of univariate regressions only as these allow us to evaluate the individual explanatory power (the $\operatorname{Adj} R^{2}$ ) of each variable. Using all variables at the same time introduces multicollinearity due to the high correlation between RGDP and IP.
} 
of brevity, we focus our discussion on the 60 day premia only. Consistent with our predictions, the slope coefficients of RGDP and IP are positive and statistically significant. In line with previous studies, we find that energy and metal commodities are the most sensitive to RGDP forecasts. The high slope estimates and explanatory power of copper and gold substantiate this finding. As previously discussed, IP is more closely associated to commodity demand than RGDP. Hence, we expect the results for industrial production to be stronger. This intuition is supported by the data. Unlike, RGDP, which yield only 7 significant slope estimates, 10 commodities exhibit significantly positive slope estimates when IP is used as explanatory variable. Moreover, the explanatory power records modest improvements as illustrated by the rise in gold's Adj $R^{2}$ from $5.9 \%$ (RGDP) to $7 \%$ (IP).

We observe that inflation expectations account for substantial variations in variance risk premia. This is best illustrated by the impressive Adj $R^{2}$ of $20.4 \%$ and $16.8 \%$ recorded for crude and heating oil. Additionally, the slope estimates are statistically distinguishable from zero in 17 markets, implying that changes in expected inflation affect the market price of variance risk in commodity markets. Interestingly, the point estimates indicate that increases in inflation lead to smaller variance risk premia. This result accords with studies that document the role of commodities as an inflation hedge. In particular, increases in inflation lead to capital inflows into commodity markets thus reducing the cost of insurance.

Turning to default spread, we anticipate that a widening of the spread, which indicates deteriorating credit conditions, leads to more negative variance risk premia. Columns "DFSP" validate our intuition. Several commodities (e.g. crude oil and gold) display significantly negative t-statistics. Moreover, the very high explanatory power for gold $(18.5 \%)$ reinforces the view of gold as a safe haven asset. 
Finally, Table 7 shows that increases in term spread increase the magnitude of variance risk premia of 5 commodities. If the economy is under performing, the FED will cut short interest rates, thus leading to a steepening of the yield curve. Hence, steep yield curves may be associated with challenging economic conditions and a higher insurance premium. ${ }^{13}$

\section{C.2 Macroeconomic Uncertainty}

Motivated by the theoretical model predictions of Drechsler and Yaron (2011), who link variance risk premia with macroeconomic uncertainty, we investigate the effects of macroeconomic uncertainty on commodity variance risk premia. To measure uncertainty around an economic variable, we compute the monthly cross-sectional standard deviation of individual forecasts for the current and subsequent year. Thus, we obtain 2 series of monthly cross-sectional standard deviations. We then extract the first principal component from the 2 series which we use as proxy for economic uncertainty. ${ }^{14}$ Following this approach, we obtain variables measuring uncertainty about real GDP (URGDP), inflation uncertainty (UCPI) and uncertainty about industrial production (UIP). We then regress the commodity variance risk premia on the macroeconomic uncertainty variables.

Panel A of Table 8 summarizes the results of univariate regressions of 60 day variance risk premia on individual uncertainty measures. To facilitate comparisons, we standardize all variables. Our evidence suggests that URGDP does not significantly explain changes in variance risk premia. We observe only 4 significant coefficients and low explanatory power. In contrast, the evidence in

\footnotetext{
${ }^{13}$ Of all 5 significant coefficients, only cotton has a positive point estimate. However, it is important to bear in mind that cotton has a positive VRP.

${ }^{14}$ See Buraschi and Whelan (2011) for a similar approach.
} 
favor of industrial production uncertainty is more compelling as 12 coefficients are significantly different from zero and the adjusted $R^{2}$ s generally higher than $4 \%$. The strongest effect — both in terms of magnitude (0.26) and explanatory power $(6.7 \%)$ — is observed in the gold market. Notwithstanding the differences in significance and explanatory power, we observe that both UIP and URGDP are generally positively related to commodity variance risk premia. This positive association is most likely due to the role of commodity prices as hedges against macroeconomic uncertainty. A concurrent study by Mueller et al. (2011) provides support for this explanation. The authors show that URGDP is positively related to the market price of variance risk in the S\&P 500 market. ${ }^{15}$ In our context, their finding implies a negative link between the S\&P 500 and URGDP, indicating that our results might be due to the role of a commodity as a hedge against increased macroeconomic uncertainty. ${ }^{16}$

Additionally, we uncover a significantly positive relationship between commodity variance risk premia and CPI uncertainty (UCPI) for cocoa, gold, orange juice and sugar. The economic significance of this result is noteworthy: a unit increase in UCPI decreases gold's variance risk premium by as much as 0.26. In comparison, Mueller et al. (2011) report a significantly positive relationship between UCPI and variance risk premia in the fixed-income and equity markets. Again, their results lend support to the intuition that commodity markets are effective hedges against inflation uncertainty. However, it is also worth noting that inflation expectations affect the market price of variance risk more strongly than uncertainty about inflation, which can be seen by comparing the results in Table 7 and 8 .

Although not discussed for the sake of brevity, results for the 90 day variance

\footnotetext{
${ }^{15}$ Note that Mueller et al. (2011) define the variane risk premium opposite to the definition employed in this paper, i.e. as implied minus realized variance.

${ }^{16}$ Interestingly, Mueller et al. (2011) show that bond variance risk premia are not affected by URGDP, suggesting that commodities provide better hedges against URGDP than bond markets.
} 
risk premia reported in Panel B of Table 8 draw a similar picture overall.

\section{C.3 Commodity Specific Determinants}

In addition to macroeconomic factors, we analyze the impact of commodity specific variables on variance risk premia. We evaluate 3 variables considered to be important in commodity markets: the basis, hedging pressure and open interest.

First, the theory of storage postulates that commodity prices are more volatile when inventories are low, which motivates the inclusion of the basis. Given the difficulties inherent in global inventory data (e.g. measurement errors, low reporting frequency), we proxy inventories with the futures basis (BAS), defined as the ratio of the second nearby futures contract over the first nearby contract. Note that the theory of storage predicts the impact of inventory on realized variance only. The theory is silent about implied variance, let alone variance risk premia. Hence, evaluating the impact of inventory levels on variance risk premia is an empirical question.

Second, it is also possible that the balance of short and long commercial hedgers affects the market price of variance risk. Specifically, if variance risk premia are negatively correlated with futures risk premia, we expect the slope estimate of hedging pressure (HP) to be negative. ${ }^{17}$

Third, the recent debate on the causes of commodity price volatility points to increased trading activities due to a growing number of financial investors. Hong and Yogo (2012) have recently reported that open interest (OI) has strong predictive power for subsequent price changes. However, some would argue that increased open interest should reduce the cost of insurance as market participants are trading in

\footnotetext{
${ }^{17}$ This flows from the hedging pressure hypothesis, which predicts a positive relationship between hedging pressure and risk premia.
} 
a fairly liquid market. A priori, it is not clear what effect open interest should have on the market price of variance risk. Hence, it is interesting to investigate its impact on variance risk premia as well. Both, the hedging position of commercial and non-commercial traders and the open interest information are obtained from the Commodity Futures Trading Commission (CFTC) and computed following the methodology described in Hong and Yogo (2012). ${ }^{18}$

Table 9 reports results of univariate regressions of variance risk premia on the commodity specific variables. Starting with the 60 day variance risk premia, we observe that the basis is the most important commodity specific determinant of variance risk premia with 11 significant coefficient estimates, 6 of which are positive. Moreover, the basis can explain more than $11 \%$ of variations in variance risk premia of soybeans and silver. As previously discussed, a positive relationship between bases and variance risk premia, as reported for lumber and sugar, for example does not necessarily invalidate the theory of storage but rather suggests that risk-neutral variance is more responsive to changes in inventories than realized variance. ${ }^{19}$

Our evidence also indicates that hedging pressure significantly affects the market price of variance risk of 3 commodities namely soybean oil, gold and orange juice. In each of these markets, the coefficient estimates are negative, implying that variance risk premia become "more" negative as short commercial hedgers outnumber their long counterpart. It is instructive to bear in mind that the hedging pressure theory predicts a positive relationship between hedging pressure and futures risk premia. Hence, the weak negative correlation uncovered provides some evidence of a negative correlation between futures risk premia and variance risk premia in

\footnotetext{
${ }^{18}$ The CFTC publishes several reports including futures only, and futures and options combined reports. We use the futures report because of its longer sample period.

${ }^{19}$ The relationship between inventories and realized volatility has been studied among others by Symeonidis et al. (2012).
} 
some commodity markets. However, it is also noteworthy that the sign of the hedging pressure variable changes across markets.

Interestingly, we find that open interest growth has very little explanatory power for explaining variations in variance risk premia. Thus the results obtained by Hong and Yogo (2012) regarding open interest and futures prices do not carry over to variance risk premia.

Overall, Panel A indicates that inventory levels are the most important commodity specific determinants of variance risk premia. Panel B presents results for 90 day variance risk premia leading to similar conclusions regarding the relative importance of each commodity variable.

Together, Tables 7 through 9 reveal that both commodity and macroeconomic factors determine variations in variance risk premia. Yet, we know little about the relative contribution of each set of factors. To address this question, we combine CPI, IP, DFSPD, TSPD, BAS, HP and OI in a single regression and evaluate their respective contributions through the marginal $R^{2}$ also employed by Longstaff et al. (2011). ${ }^{20,21}$ More precisely, we divide the $R^{2}$ of the regression with commodity specific regressors only by that obtained with both commodity and macroeconomic variables. By construction, a high marginal $R^{2}$ indicates a high information content of commodity specific variables for variance risk premia and vice versa. Column "Marg $R^{2}$ " of Table 10 reveals that some commodities are highly affected by commodity specific factors with marginal $R^{2}$ reaching $82.1 \%$ for oats. We obtain analogous, albeit more modest, results for natural gas $(66.2 \%)$, soybeans $(55.2 \%)$

\footnotetext{
${ }^{20}$ We discard RGDP because of collinearity concerns. Using either RGDP or IP, we obtain very similar results. These results are available upon request.

${ }^{21}$ Results based on macroeconomic uncertainty instead of expectations yield similar results and are available upon request.
} 
and soybean meal $(61.6 \%) .{ }^{22}$ On average and across markets, commodity specific factors supplement the explanatory power of macroeconomic factors by $34 \%(41.2 \%)$ for variance risk premia over 60 (90) days.

In summary, our empirical results provide some support to the theoretical predictions of Drechsler and Yaron (2011): variance risk premia respond to macroeconomic uncertainty. Moreover, macroeconomic expectations account for a substantial level of variations in the market price of variance risk. Notwithstanding the prominence of macroeconomic factors, commodity specific variables enhance our understanding of variance risk premia in some markets as highlighted by the marginal $R^{2}$ reported in Table 10 .

\section{Do Variance Risk Premia Predict Returns?}

Over the past few years, gold has been widely considered as a safe haven, a store of value and hedge against inflation. Tables 7 through 10 unequivocally show that gold's variance risk premium is mainly influenced by macroeconomic forecasts. These observations brings us to ask an important question: does gold variance risk premium contain information for future returns?

We focus specifically on gold for several reasons. First, Table 7 shows that unlike most commodities, its variance risk premia is sensitive to each macroeconomic variable employed. Second, the results obtained by combining macro and commodity specific factors suggest that almost a quarter of variations in the variance risk premium of gold can be explained. Moreover, almost $80 \%$ of the explanatory power stems from macroeconomic rather than from commodity specific factors.

In the following, we assess the predictive power of gold's 90 day variance risk

\footnotetext{
${ }^{22}$ Since the calculations involve $R^{2}$ instead of its adjusted counterpart, the marginal $R^{2}$ must be viewed as an upper limit of explanatory power gained by adding commodity specific factors.
} 
premium for commodity returns over 4 horizons: 3, 6, 9 and 12 months. The most closely related study to ours is that of Pan and Kang (2011), who demonstrate that crude oil's variance risk premium contains information for its future returns. Though related, our aim is to investigate whether gold's variance risk premium predicts not only the returns of gold but also those of other commodities.

Studies on return predictability are often criticized on the grounds that their findings suffer from either overlapping observations biases or the use of persistent regressors. $^{23}$ In order to address these concerns, we use non-overlapping variance risk premia obtained by estimating 90 day variance risk premia once every quarter. ${ }^{24}$ Given our interest in predicting returns, we need a strictly ex-ante forecast of variance risk premia. So far, the expected realized variance under the physical measure has been estimated by using ex-post realized variance. However, to avoid look ahead biases, we estimate expected realized variance by using an exponentially weighted moving average model (EWMA) with smoothing constant $\lambda$ equal to 0.94 . In this way, we rely on historical data only yielding truly out-of-sample forecasts.

\section{D.1 Univariate Analysis}

To start, we conduct univariate analyses by simply regressing commodity spot returns on gold's variance risk premia:

$$
R_{t, t+h}=\alpha+\beta V R P_{t}+\epsilon_{t}
$$

where $R_{t, t+h}$ is the excess return over the period $t$ to $t+h$ of the commodity considered. $V R P_{t}$ refers to non-overlapping variance risk premia of gold at time

\footnotetext{
${ }^{23}$ See Ang and Bekaert (2007) and the references therein.

${ }^{24}$ We show in Subsection E.1 that gold's 90 day non-overlapping variance risk premium has a first order auto-correlation close to zero, making it suitable for multi-period analyses.
} 
t. $\epsilon_{t}$ denotes the error term.

The intuition is simple. If variance risk premia are equivalent to insurance premia, we anticipate a negative relationship between variance risk premia and returns: $\beta<0$. The reason for this is that rational risk-averse investors purchase insurance because they anticipate difficult macro-economic conditions for which, they require higher expected returns. Table 11 summarizes the results of Regression (8). For ease of comparison, we standardize all variables. We interpret a significant slope coefficient as evidence for predictability. The predictive ability of gold's variance risk premium for its own returns manifests at all horizons. The strongest results - in terms of magnitude, goodness of fit and significance - are obtained for quarterly returns which is plausible as the variance risk premia employed have a quarterly horizon as well.

Moreover, Table 11 shows that gold's variance risk premium contains information for future returns in as many as 13 other commodity markets. The significantly negative coefficient estimates indicate that the predictive power is apparent at all horizons for copper, soybeans, soybean oil and rough rice. The explanatory power is also remarkable. For instance, gold's variance risk premium explains as much as $10 \%$ of the variations in copper's returns, which is economically sizable.

\section{D.2 Multivariate Analysis}

In the second step, we augment our baseline model with the basis and open interest, two variables that have been shown to successfully predict commodity returns:

$$
R_{t, t+h}=\alpha+\beta V R P_{t}+\gamma B A S_{t}+\delta O I_{t}+\epsilon_{t}
$$


where $R_{t, t+h}$ is the excess return over the period $t$ to $t+h$ of the commodity considered. $V R P_{t}$ refers to non-overlapping variance risk premia of gold at time t. $B A S_{t}$ and $O I_{t}$ denote the basis and open interest of the commodity considered calculated as in Hong and Yogo (2012). $\epsilon_{t}$ denotes the error term.

Since commodity prices are often considered to be mean-reverting, we anticipate a positive (negative) relationship between the basis (inventory) and spot returns. Recent evidence by Hong and Yogo (2012) points to the predictive power of open interest growth for commodity returns. Therefore it is important to ascertain whether open interest crowds out the information content of gold's variance risk premium found in the univariate regressions. Three outcomes are possible. First, gold's variance risk premium remains significant, indicating that it contains important information for future returns. Second it becomes insignificant, implying that traditional predictors crowd out its information content. Finally, it could become significant even though insignificant in univariate regressions. Though unlikely, this scenario may be due to omitted variable biases.

Table 12 indicates that despite the inclusion of traditional predictors, gold's variance risk premium remains significant for most commodities. The similaritiesboth in terms of magnitude and sign - with the univariate regressions are striking. The significance of gold's variance risk premium, observed across all horizons in copper, gold, soybeans, soybean oil and rough rice, is robust to the inclusion of traditional predictors. Clearly, this result indicates that gold's variance risk premium contains useful information for returns above and beyond that of the basis and open interest. We detect little evidence to suggest that the two predictors subsume gold's variance risk premium. In fact, this scenario occurs only for silver's 12-month returns. We also observe that gold's variance risk premium becomes significant in the 
coffee (12-month returns) and soybean meal (6 and 9 month returns) markets. The positive signs of the basis and open interest are consistent with previous studies. Surprisingly, we obtain somewhat weak evidence in favor of open interest. This result is rather puzzling as Hong and Yogo (2012) demonstrate that open interest has strong predictive power for commodity returns. We attribute these differences to our shorter time period.

We further evaluate the contribution of gold's variance risk premium by comparing adjusted $R^{2}$ s of the augmented regression with and without gold's variance risk premium, which we report in the columns $\operatorname{Adj} R_{1}^{2}$ and $\operatorname{Adj} R_{2}^{2}$, respectively. Intuitively, if the variance risk premium predicts future returns, we anticipate that $\operatorname{Adj} R_{1}^{2}$ is greater than $\operatorname{Adj} R_{2}^{2}$. The evidence is compelling: significant test statistics for gold's variance risk premium are always accompanied by improvements in explanatory power. The importance of gold's variance risk premium is most visible for copper: the explanatory power for 9-month returns surges from $-1.6 \%$ to $8.7 \%$ as we add gold's variance risk premium to the regression.

In summary, Tables 11 and 12 document that gold's variance risk premium contains information for commodity future returns above and beyond that of traditional predictors. Moreover, the predictive power extends to commodities within and beyond the metal sector. These results might provide guidance for a successful trading strategy that extracts signals from gold's variance risk premium.

\section{E. Robustness Analysis}

In this section, we evaluate the robustness of our findings. To begin with, we analyze the effect of overlapping observations on our main conclusions. Subsequently, we focus on the temporal stability of the variance risk premia estimates. 


\section{E.1 Non-Overlapping Samples}

Although the various statistics displayed in Table 3 are compelling, they are subject to a potential problem: we estimated realized variance on a rolling window basis. It could be argued that because of the substantial amount of overlap in sampling periods, our results may not be particularly informative. To address such concern, we present summary statistics of non-overlapping variance risk premia in Table 13 . Overall, the results are quite similar to those reported in Table 3. Of course, some differences are also observed. For some commodities such as lean hogs (60 day horizon) and silver (90 day horizon), we find that variance risk is no longer priced which might be a result of the substantially decreased number of observations.

It is interesting to note the sharp reduction in the autocorrelation of variance risk premia. In particular, the fall in autocorrelation of gold's 90 day variance risk premium, from 0.97 to 0 , provides further justification for using gold's variance risk premium as independent variable in the return predictability analysis presented in Subsection $D$.

\section{E.2 Subsample Analysis}

In order to analyze the robustness of our results with respect to the observation period, we partition our sample into 3 distinct periods: the first period ends in November 2000, the second extends from December 2000 to November 2006 and the third subsample runs from December 2006 onward. These periods are selected because of their economic importance. The first subsample corresponds to a calm and relatively uneventful period. The second period coincides with the increasing financialization of commodities. Finally, the last subsample provides insights into the dynamics of variance risk premia during the recent financial crisis. 
We observe some differences between pre-crisis and post-crisis samples. For example, in Table 13, variance risk (60 day) is priced in the soybeans market from 2006 onward only. For silver, we find that its variance exhibits changes sign over the subperiods. The 60 day variance risk premium is positive $(1.2 \%)$ in the first subsample and negative in the following subsamples $(-1 \%$ and $-2.6 \%$ for the growth and crisis periods, respectively). These findings can explain why no significant variance risk premium was found for the entire sample period. For some commodities (e.g. soybean meal), the magnitude of variance risk premia during the recent crisis is about twice as large as during the pre-crisis sample. This observation confirms our finding that variance risk premia are negatively related to $M F I V$. Overall, our conclusion of negative variance risk premia holds over the recent economic downturn.

\section{Conclusion}

This paper investigates the market price of variance risk in 21 commodity markets from 1989 to 2011. Using synthetically constructed variance swaps that mature in 60 and 90 calendar days, we present evidence of significantly negative variance risk premia. Although generally similar, we detect sign-switching behavior across maturities (e.g. lean hogs) or subsamples (e.g. silver) in some markets, most likely due to term-structure effects or time variations in variance risk premia.

We further analyze the economic determinants of variance risk premia and document a strong relation between macroeconomic expectations, uncertainty and variance risk premia. Moreover, we find that commodity specific variables enhance our understanding of variance risk premia dynamics, indicating that both systematic 
and idiosyncratic factors impact variance risk premia.

Assessing the information content of gold's variance risk premium for commodity returns, we find evidence of predictability in several markets. The large and negative slope coefficients observed in most markets underline the economic significance of the relationship. The information contained in gold's variance risk premium are above and beyond that of traditional predictors such as the basis and open interest.

Our study can be extended in several directions. First, as commodity option markets become more liquid, it would be interesting to study the term-structure of variance risk premia by considering variance risk swaps of longer maturities. Second, our study does not address the issue of jump risk premia. Finally, our analysis reveals large cross-sectional variations in variance risk premia. Understanding the determinants of these variations is another interesting research question. 


\section{References}

Andersen, T., Bollerslev, T., and Diebold, F. (2009). Parametric and nonparametric volatility measurement. Handbook of Financial Econometrics: Tools and Techniques, 1:67.

Ang, A. and Bekaert, G. (2007). Stock return predictability: Is it there? Review of Financial Studies, 20(3):651-707.

Back, J., Prokopczuk, M., and Rudolf, M. (2013). Seasonality and the valuation of commodity options. Journal of Banking \& Finance, 37(2):273-290.

Bakshi, G. and Kapadia, N. (2003a). Delta-hedged gains and the negative market volatility risk premium. Review of Financial Studies, 16(2):527-566.

Bakshi, G. and Kapadia, N. (2003b). Volatility risk premiums embedded in individual equity options. Journal of Derivatives, 11(1):45-54.

Bakshi, G. and Madan, D. (2006). A theory of volatility spreads. Management Science, 52(12):1945-1956.

Barnea, A. and Hogan, R. (2012). Quantifying the variance risk premium in VIX options. Journal of Portfolio Management, 38(3):143-148.

Barone-Adesi, G. and Whaley, R. (1987). Efficient analytic approximation of american option values. Journal of Finance, 42(2):301-320.

Black, F. (1976). The pricing of commodity contracts. Journal of Financial Economics, 3(1):167-179.

Bollerslev, T., Gibson, M., and Zhou, H. (2011a). Dynamic estimation of volatility 
risk premia and investor risk aversion from option-implied and realized volatilities. Journal of Econometrics, 160(1):235-245.

Bollerslev, T., Marrone, J., Xu, L., and Zhou, H. (2011b). Stock return predictability and variance risk premia: statistical inference and international evidence. Duke University Working Paper Series.

Bollerslev, T., Tauchen, G., and Zhou, H. (2009). Expected stock returns and variance risk premia. Review of Financial Studies, 22(11):4463-4492.

Branger, N. and Schlag, C. (2008). Can tests based on option hedging errors correctly identify volatility risk premia? Journal of Financial and Quantitative Analysis, 43(4):1055-1090.

Britten-Jones, M. and Neuberger, A. (2000). Option prices, implied price processes, and stochastic volatility. Journal of Finance, 55(2):839-866.

Broadie, M., Chernov, M., and Johannes, M. (2007). Model specification and risk premia: Evidence from futures options. Journal of Finance, 62(3):1453-1490.

Brooks, C. and Prokopczuk, M. (2011). The dynamics of commodity prices. ICMA Centre Discussion Paper.

Buraschi, A. and Whelan, P. (2011). Macroeconomic uncertainty, difference in beliefs, and bond risk premia. Imperial College Discussion Paper.

Carr, P. and Wu, L. (2009). Variance risk premiums. Review of Financial Studies, $22(3): 1311-1341$.

Coval, J. and Shumway, T. (2001). Expected option returns. Journal of Finance, 56(3):983-1009. 
Demeterfi, K., Derman, E., Kamal, M., and Zou, J. (1999). A guide to volatility and variance swaps. Journal of Derivatives, 6(4):9-32.

Doran, J. and Ronn, E. (2008). Computing the market price of volatility risk in the energy commodity markets. Journal of Banking \& Finance, 32(12):2541-2552.

Drechsler, I. (2012). Uncertainty, time-varying fear, and asset prices. Forthcoming in Journal of Finance.

Drechsler, I. and Yaron, A. (2011). What's vol got to do with it. Review of Financial Studies, 24(1):1-45.

Driessen, J., Maenhout, P., and Vilkov, G. (2009). The price of correlation risk: Evidence from equity options. Journal of Finance, 64(3):1377-1406.

Eraker, B., Johannes, M., and Polson, N. (2003). The impact of jumps in volatility and returns. Journal of Finance, 58(3):1269-1300.

Guo, D. (1998). The risk premium of volatility implicit in currency options. Journal of Business \& Economic Statistics, 16(4):498-507.

Hafner, R. and Wallmeier, M. (2007). Volatility as an asset class: European evidence. European Journal of Finance, 13(7):621-644.

Heston, S. (1993). A closed-form solution for options with stochastic volatility with applications to bond and currency options. Review of Financial Studies, $6(2): 327-343$.

Hong, H. and Yogo, M. (2012). What does futures market interest tell us about the macroeconomy and asset prices? Journal of Financial Economics, 105(3):473490. 
Jiang, G. and Tian, Y. (2005). The model-free implied volatility and its information content. Review of Financial Studies, 18(4):1305-1342.

Koijen, R., Moskowitz, T., Pedersen, L., and Vrugt, E. (2012). Carry. Working Paper.

Longstaff, F., Pan, J., Pedersen, L., and Singleton, K. (2011). How sovereign is sovereign credit risk? American Economic Journal: Macroeconomics, 3(2):75103.

Low, B. and Zhang, S. (2005). The volatility risk premium embedded in currency options. Journal of Financial and Quantitative Analysis, 40(4):803-832.

Mueller, P., Vedolin, A., and Yen, Y. (2011). Bond variance risk premia. LSE Working Paper.

Pan, J. (2002). The jump-risk premia implicit in options: Evidence from an integrated time-series study. Journal of Financial Economics, 63(1):3-50.

Pan, X. and Kang, S. (2011). Do the variance risk premia predict commodity futures returns? Evidence from the crude oil market. McGill University Working Paper.

Simon, D. (2010). Examination of long-term bond iShare option selling strategies. Journal of Futures Markets, 30(5):465-489.

Suenaga, H., Smith, A., and Williams, J. (2008). Volatility dynamics of NYMEX natural gas futures prices. Journal of Futures Markets, 28(5):438-463.

Symeonidis, L., Prokopczuk, M., Brooks, C., and Lazar, E. (2012). Futures basis, inventory and commodity price volatility: An empirical analysis. Economic Modelling, 29(6):2651-2663. 
Trolle, A. and Schwartz, E. (2009). Unspanned stochastic volatility and the pricing of commodity derivatives. Review of Financial Studies, 22(11):4423-4461.

Trolle, A. and Schwartz, E. (2010). Variance risk premia in energy commodities. Journal of Derivatives, 17(3):15-32.

Wang, H., Zhou, H., and Zhou, Y. (2010). Credit default swap spreads and variance risk premia. Working Paper.

Wang, Z., Fausti, S., and Qasmi, B. (2011). Variance risk premiums and predictive power of alternative forward variances in the corn market. Journal of Futures Markets, 32(6):587-608. 

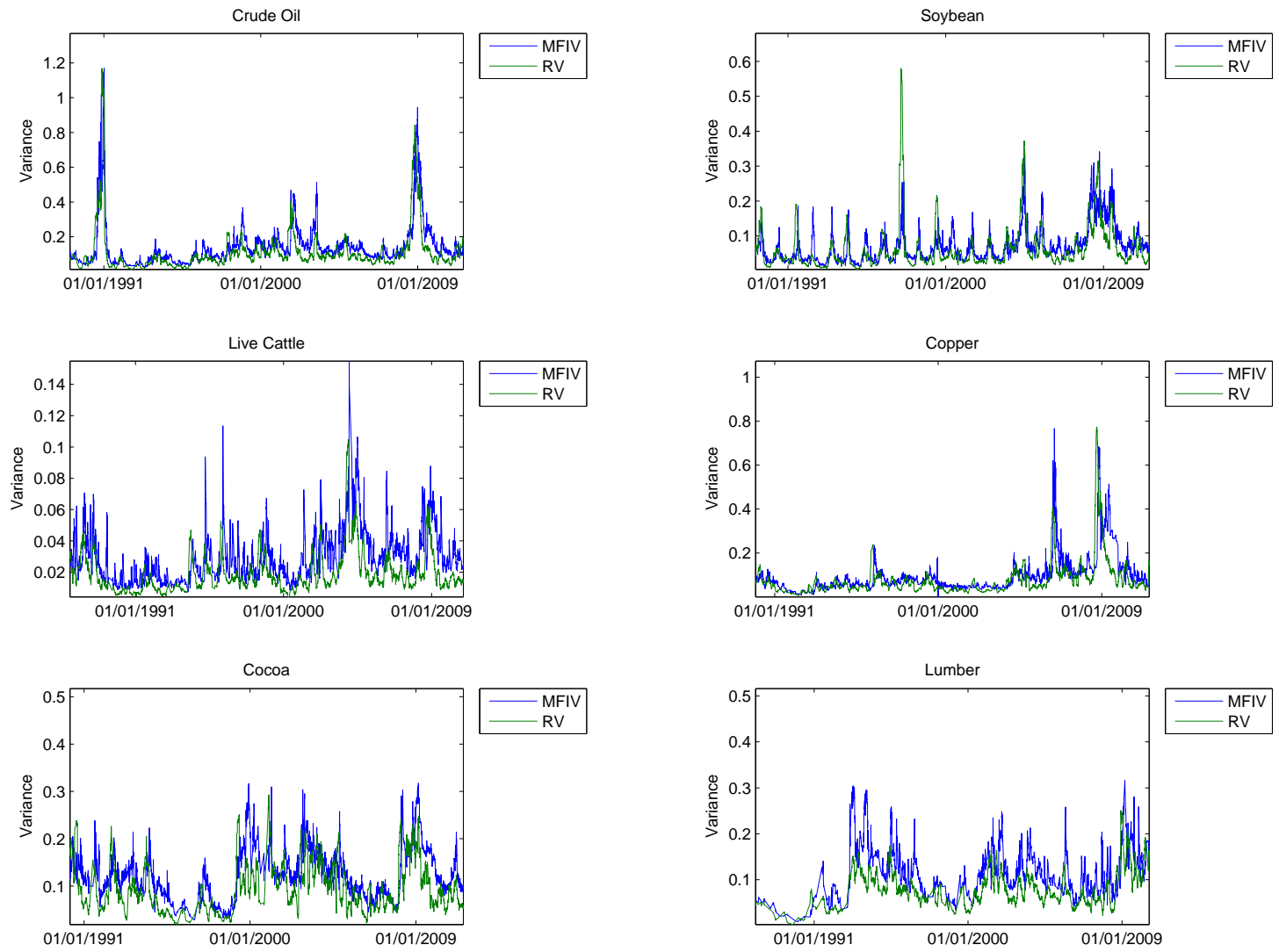

Figure 1: Time Series of Realized Variance and Model-Free Implied Variance

This figure displays time series of realized and model-free implied variances for crude oil, soybean, live cattle, copper, cocoa, lumber over a 60 day horizon. The blue and green lines represent model-free implied and realized variances, respectively. The difference between realized and implied variance is the variance risk premium. 


\section{Table 1: Overview of Commodities}

This table lists all commodities considered. The first two columns report the sector and name of specific commodities. The third column displays the exchange where the futures and options contracts of the commodity are traded. The last two columns contain the available maturity months and minimum tick sizes of the options contracts as reported by the relevant exchange.

\begin{tabular}{|c|c|c|c|c|}
\hline Sector & Commodity & Exchange & Maturity Months & Tick Size \\
\hline \multirow{3}{*}{ Energy } & Crude Oil & NYMEX & January-December & 0.01 \\
\hline & Heating Oil & CME & January-December & 0.0001 \\
\hline & Natural Gas & NYMEX & January-December & 0.001 \\
\hline \multirow{7}{*}{ Grains } & Corn & $\mathrm{CBOT}$ & January, March, May, July, September, November, December & 0.25 \\
\hline & Cotton & ICE & March, May, July, October, December & 0.01 \\
\hline & Soybeans & CBOT & January, March, May, July, August, September, November & 0.25 \\
\hline & Soybean Meal & CBOT & January, March, May, July, August, September, October, December & 0.1 \\
\hline & Soybean Oil & CBOT & January, March, May, July, August, September, October, December & 0.01 \\
\hline & Sugar & ICE & March, May, July, October, December & 0.01 \\
\hline & Wheat & CBOT & March, May, July, September, December & 0.25 \\
\hline \multirow{2}{*}{ Livestock } & Lean Hogs & CME & Febuary, April, June, July, August, October, December & 0.025 \\
\hline & Live Cattle & CME & Febuary, April, June, August, October, December & 0.025 \\
\hline \multirow{3}{*}{ Metals } & Copper & COMEX & March, May, July, September, December & 0.0005 \\
\hline & Gold & COMEX & Febuary, April, June, August, October, December & 0.1 \\
\hline & Silver & COMEX & March, May, July, September, December & 0.5 \\
\hline \multirow{5}{*}{ Tropical } & Cocoa & ICE & March, May, July, September, December & 1 \\
\hline & Colombian Coffee & $\mathrm{ICE}$ & March, May, July, September, December & 0.05 \\
\hline & Oats & CBOT & March, May, July, September, December & 0.25 \\
\hline & Orange Juice & $\mathrm{ICE}$ & January, March, May, July, September, November & 0.05 \\
\hline & Rough Rice & CBOT & January, March, May, July, September, November & 0.05 \\
\hline Wood & Lumber & CME & January, March, May, July, September, November & 0.1 \\
\hline
\end{tabular}




\section{Table 2: Description of Options Data}

This table summarizes information about the OTM options data. For each commodity, we only retain OTM options that mature between 30 and 120 calendar days. The first two columns report the sector and name of specific commodities. Columns "Starting Date" and "Ending Date" indicate the beginning and end of the sample, respectively. "Days" reports the number of observation days in the sample. The last two columns show the average number of OTM calls and puts on each trading day, respectively.

\begin{tabular}{llccccc}
\hline \hline \multirow{2}{*}{ Sector } & Commodity & Starting Date & Ending Date & Days & Calls & Puts \\
\hline \multirow{3}{*}{ Energy } & Crude Oil & 16 Jan 89 & 02 Sep 11 & 5640 & 27 & 22 \\
& Heating Oil & 11 Jan 89 & 14 Sep 11 & 5660 & 29 & 24 \\
& Natural Gas & 02 Oct 92 & 14 Sep 11 & 4740 & 51 & 27 \\
\hline \multirow{5}{*}{ Grains } & Corn & 24 Feb 89 & 07 Oct 11 & 5691 & 19 & 13 \\
& Cotton & 30 Jan 90 & 16 Nov 07 & 4449 & 20 & 15 \\
& Soybeans & 24 Feb 89 & 07 Oct 11 & 5692 & 20 & 14 \\
& Soybean Meal & 24 Feb 89 & 14 Oct 11 & 5686 & 8 & 5 \\
& Soybean Oil & 24 Feb 89 & 07 Oct 11 & 5651 & 13 & 11 \\
& Sugar & 06 Mar 90 & 04 Oct 11 & 5372 & 26 & 17 \\
& Wheat & 24 Feb 89 & 07 Oct 11 & 5692 & 18 & 13 \\
\hline \multirow{2}{*}{ Livestock } & Lean Hogs & 01 Feb 85 & 13 May 11 & 6612 & 7 & 12 \\
& Live Cattle & 30 Oct 84 & 28 Feb 11 & 6630 & 9 & 11 \\
\hline \multirow{3}{*}{ Metals } & Copper & 12 Dec 89 & 11 Oct 11 & 5461 & 12 & 14 \\
& Gold & 03 Jan 89 & 11 Oct 11 & 5704 & 16 & 13 \\
& Silver & 03 Mar 89 & 26 Oct 11 & 5673 & 24 & 32 \\
\hline \multirow{5}{*}{ Tropical } & Cocoa & 06 Mar 90 & 23 Sep 11 & 5384 & 10 & 6 \\
& Colombian Coffee & 05 Mar 90 & 30 Sep 11 & 5390 & 5 & 19 \\
& Oats & 01 May 90 & 12 Aug 11 & 5344 & 7 & 5 \\
& Orange Juice & 02 Mar 90 & 07 Oct 11 & 5370 & 8 & 4 \\
& Rough Rice & 10 Apr 92 & 14 Jul 11 & 4832 & 9 & 6 \\
\hline Wood & Lumber & 05 Jun 87 & 15 Nov 10 & 5680 & 10 & 7 \\
\hline \hline \hline
\end{tabular}




\section{Table 3: Variance Risk Premia}

This table presents summary statistics of the estimated commodity variance risk premia. Columns entitled Mean, T-Stat, Median, AR(1), Min and Max report the average, Newey-West corrected t-statistic (same lag length as the maturity of the swap), median, first order auto-correlation, minimum and maximum variance risk premia. The last four columns display the standard deviation, skewness, kurtosis and number of observations, respectively. Panel A presents the results for a horizon of 60 days, Panel $B$ for a horizon of 90 days.

Panel A: 60 Day Variance risk premia

\begin{tabular}{llllllllllll}
\hline \hline Sector & Commodity & Mean & T-Stat & Median & AR(1) & Min & Max & Std Dev & Skew & Kurt & Obs \\
\hline \multirow{3}{*}{ Energy } & Crude Oil & $-3.4 \%$ & -5.96 & $-3.2 \%$ & 0.96 & -0.62 & 0.71 & 0.08 & 1.28 & 18.72 & 5025 \\
& Heating Oil & $-3.0 \%$ & -7.48 & $-2.6 \%$ & 0.94 & -0.63 & 0.63 & 0.07 & 0.50 & 19.75 & 5210 \\
& Natural Gas & $-10.2 \%$ & -9.24 & $-7.3 \%$ & 0.94 & -1.66 & 0.30 & 0.15 & -1.61 & 9.72 & 4394 \\
\hline \multirow{5}{*}{ Grains } & Corn & $-2.3 \%$ & -8.20 & $-1.9 \%$ & 0.94 & -0.25 & 0.22 & 0.04 & -0.07 & 9.19 & 5024 \\
& Cotton & $2.6 \%$ & 11.10 & $2.4 \%$ & 0.94 & -0.18 & 0.16 & 0.03 & 0.06 & 7.41 & 4149 \\
& Soybeans & $-0.8 \%$ & -2.06 & $-1.2 \%$ & 0.97 & -0.19 & 0.46 & 0.05 & 3.01 & 24.48 & 5011 \\
& Soybean Meal & $0.0 \%$ & 0.06 & $-0.6 \%$ & 0.96 & -0.16 & 0.34 & 0.05 & 2.20 & 13.61 & 3621 \\
& Soybean Oil & $-1.0 \%$ & -3.50 & $-0.9 \%$ & 0.96 & -0.14 & 0.25 & 0.04 & 1.46 & 12.46 & 3667 \\
& Sugar & $-2.6 \%$ & -5.78 & $-2.3 \%$ & 0.94 & -0.65 & 0.25 & 0.06 & -0.99 & 12.31 & 5225 \\
& Wheat & $-0.7 \%$ & -2.53 & $-1.1 \%$ & 0.94 & -0.22 & 0.26 & 0.04 & 0.88 & 8.82 & 4340 \\
\hline \multirow{2}{*}{ Livestock } & Lean Hogs & $-1.2 \%$ & -3.01 & $-1.1 \%$ & 0.94 & -0.30 & 0.27 & 0.05 & 0.15 & 8.40 & 3231 \\
& Live Cattle & $-1.0 \%$ & -11.06 & $-0.8 \%$ & 0.93 & -0.11 & 0.05 & 0.01 & -0.46 & 5.99 & 4642 \\
\hline \multirow{3}{*}{ Metals } & Copper & $-2.4 \%$ & -3.55 & $-1.9 \%$ & 0.97 & -0.53 & 0.62 & 0.08 & 1.79 & 24.21 & 4220 \\
& Gold & $-1.0 \%$ & -4.41 & $-0.9 \%$ & 0.97 & -0.16 & 0.13 & 0.03 & 0.33 & 10.96 & 3631 \\
& Silver & $-0.2 \%$ & -0.83 & $0.2 \%$ & 0.98 & -0.29 & 0.13 & 0.03 & -1.40 & 14.82 & 5150 \\
\hline \multirow{5}{*}{ Tropical } & Cocoa & $-3.0 \%$ & -8.48 & $-3.1 \%$ & 0.94 & -0.23 & 0.16 & 0.05 & 0.27 & 4.72 & 4004 \\
& Colombian Coffee & $-1.7 \%$ & -0.73 & $-3.2 \%$ & 0.97 & -0.51 & 1.04 & 0.17 & 3.01 & 16.51 & 1794 \\
& Oats & $-6.2 \%$ & -7.68 & $-6.2 \%$ & 0.95 & -0.52 & 0.41 & 0.07 & 0.52 & 9.40 & 2095 \\
& Orange Juice & $-2.3 \%$ & -3.31 & $-2.3 \%$ & 0.97 & -0.53 & 0.30 & 0.08 & -0.33 & 10.43 & 3303 \\
& Rough Rice & $-3.0 \%$ & -8.28 & $-2.7 \%$ & 0.92 & -0.30 & 0.20 & 0.04 & -0.11 & 6.67 & 2835 \\
\hline Wood & Lumber & $-3.5 \%$ & -10.36 & $-3.0 \%$ & 0.95 & -0.22 & 0.13 & 0.04 & -0.86 & 5.51 & 3660 \\
\hline \hline
\end{tabular}

Panel B: 90 Day Variance risk premia

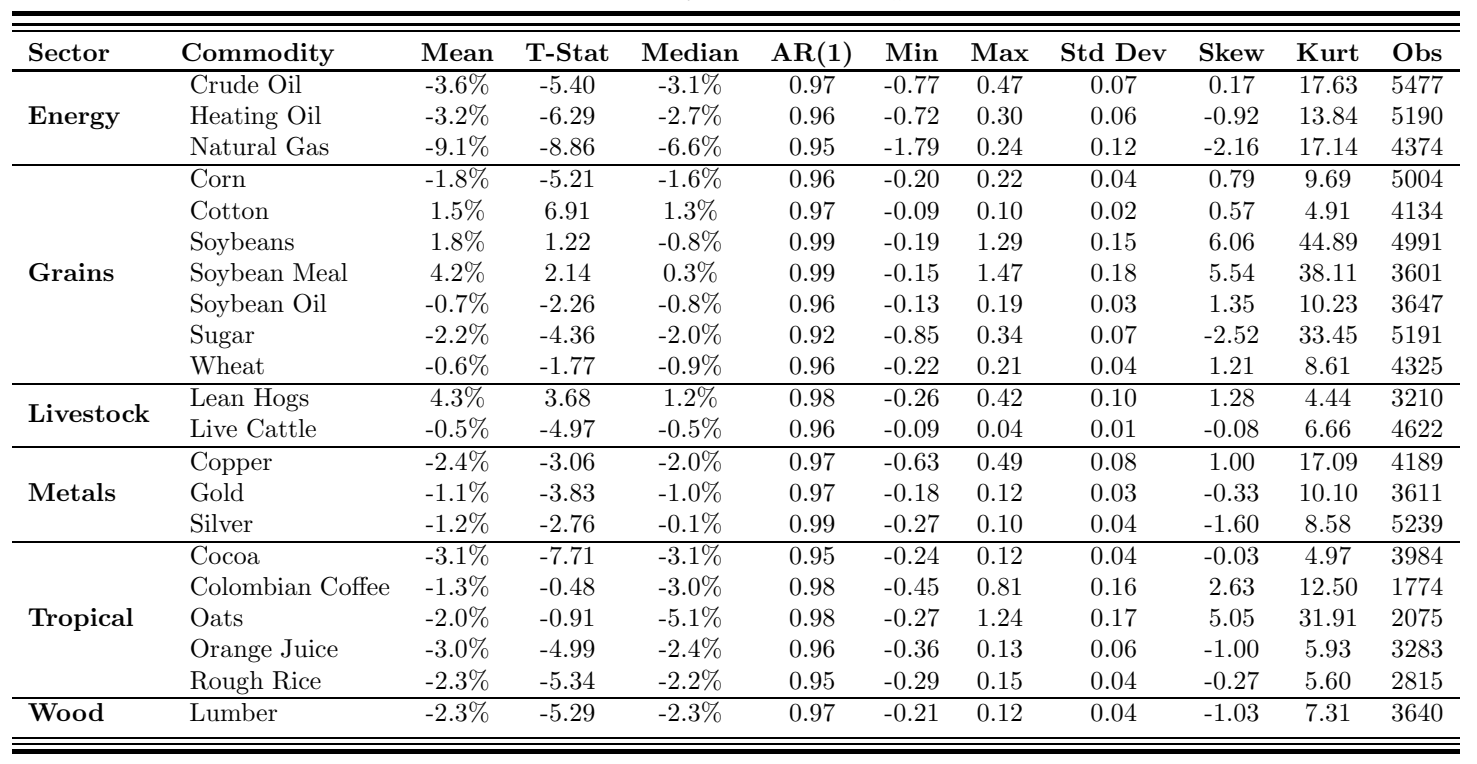




\section{Table 4: Log Variance Risk Premia}

This table presents summary statistics of the estimated log variance risk premia. Columns entitled Mean, T-Stat, Median, AR(1), Min and Max report the average, Newey-West corrected $t$-statistic (same lag length as the maturity of variance swaps), median, first order auto-correlation, minimum and maximum values of log variance risk premia. The last five columns report the standard deviation, skewness, kurtosis, Newey-West adjusted Sharpe ratios (annualized) and number of observations, respectively. Panel A presents the results for a horizon of 60 days, Panel $B$ for a horizon of 90 days.

Panel A: 60 Day Log Variance Risk Premia

\begin{tabular}{|c|c|c|c|c|c|c|c|c|c|c|c|c|}
\hline Energy & Heating Oil & $-29.5 \%$ & -10.04 & $-32.1 \%$ & 0.95 & -1.80 & 2.01 & 0.42 & 0.41 & 4.40 & $34.1 \%$ & 5210 \\
\hline \multirow{5}{*}{ Grains } & Corn & $-44.2 \%$ & -12.66 & $-44.0 \%$ & 0.95 & -2.17 & 1.22 & 0.47 & 0.00 & 3.00 & $43.7 \%$ & 5024 \\
\hline & Cotton & $66.9 \%$ & 16.68 & $69.9 \%$ & 0.91 & -1.30 & 5.52 & 0.57 & 0.14 & 5.20 & $63.4 \%$ & 4149 \\
\hline & Soybeans & $-25.6 \%$ & -6.55 & $-29.9 \%$ & 0.97 & -1.65 & 1.82 & 0.53 & 0.50 & 3.62 & $22.7 \%$ & 5011 \\
\hline & Sugar & $-22.8 \%$ & -7.20 & $-24.1 \%$ & 0.95 & -1.95 & 1.27 & 0.43 & 0.31 & 3.28 & $24.4 \%$ & 5225 \\
\hline & Wheat & $-16.1 \%$ & -4.94 & $-18.7 \%$ & 0.93 & -2.19 & 4.99 & 0.47 & 0.43 & 7.10 & $18.4 \%$ & 4340 \\
\hline \multirow{2}{*}{ Livestock } & Lean Hogs & $-18.3 \%$ & -4.04 & $-18.3 \%$ & 0.95 & -1.92 & 1.44 & 0.50 & 0.04 & 3.23 & $17.4 \%$ & 3231 \\
\hline & Live Cattle & $-46.0 \%$ & -13.95 & $-49.5 \%$ & 0.95 & -1.95 & 1.45 & 0.46 & 0.42 & 3.61 & $50.2 \%$ & 4642 \\
\hline \multirow[b]{2}{*}{ Metals } & Copper & $-29.9 \%$ & -7.65 & $-32.5 \%$ & 0.94 & -1.73 & 4.66 & 0.50 & 0.75 & 6.37 & $28.8 \%$ & $\overline{4220}$ \\
\hline & Gold & $-34.6 \%$ & -8.32 & $-37.9 \%$ & 0.96 & -1.79 & 2.09 & 0.54 & 0.50 & 3.88 & $33.8 \%$ & 3631 \\
\hline \multirow{2}{*}{ Tropical } & Orange Juice & $-23.3 \%$ & -4.39 & $-27.7 \%$ & 0.96 & -2.54 & 2.46 & 0.61 & 0.40 & 4.79 & $18.7 \%$ & 3303 \\
\hline & Rough Rice & $-45.3 \%$ & -9.41 & $-47.1 \%$ & 0.93 & -1.92 & 1.85 & 0.53 & 0.31 & 3.25 & $43.3 \%$ & 2835 \\
\hline Wood & Lumber & $-37.0 \%$ & -13.58 & $-38.6 \%$ & 0.95 & -1.93 & 1.20 & 0.36 & 0.20 & 3.75 & $55.0 \%$ & 3660 \\
\hline
\end{tabular}

Panel B: 90 Day Log Variance Risk Premia

\begin{tabular}{|c|c|c|c|c|c|c|c|c|c|c|c|c|}
\hline Sector & Commodity & Mean & T-Stat & Median & $\operatorname{AR}(1)$ & Min & Max & Std Dev & Skew & Kurt & SR & Obs \\
\hline \multirow{3}{*}{ Energy } & Crude Oil & $-39.3 \%$ & -9.31 & $-42.0 \%$ & 0.98 & -1.52 & 1.71 & 0.45 & 0.61 & 3.83 & $25.2 \%$ & 5477 \\
\hline & Heating Oil & $-32.2 \%$ & -8.17 & $-31.6 \%$ & 0.97 & -1.65 & 1.74 & 0.43 & 0.55 & 4.76 & $22.7 \%$ & 5190 \\
\hline & Natural Gas & $-43.6 \%$ & -11.55 & $-44.1 \%$ & 0.97 & -2.04 & 1.48 & 0.45 & -0.11 & 3.05 & $34.9 \%$ & 4374 \\
\hline \multirow{7}{*}{ Grains } & Corn & $-37.4 \%$ & -9.08 & $-38.0 \%$ & 0.96 & -1.88 & 1.13 & 0.46 & 0.19 & 3.30 & $25.7 \%$ & 5004 \\
\hline & Cotton & $31.4 \%$ & 7.94 & $31.3 \%$ & 0.97 & -0.88 & 1.51 & 0.39 & -0.06 & 2.70 & $24.7 \%$ & 4134 \\
\hline & Soybeans & $-12.0 \%$ & -1.99 & $-20.6 \%$ & 0.98 & -1.82 & 3.06 & 0.63 & 1.22 & 5.94 & $5.6 \%$ & 4991 \\
\hline & Soybean Meal & $13.4 \%$ & 2.26 & $6.1 \%$ & 0.97 & -1.37 & 2.40 & 0.59 & 0.92 & 4.44 & $7.5 \%$ & 3601 \\
\hline & Soybean Oil & $-15.4 \%$ & -3.67 & $-17.0 \%$ & 0.96 & -1.73 & 1.29 & 0.44 & 0.18 & 3.39 & $12.1 \%$ & 3647 \\
\hline & Sugar & $-19.8 \%$ & -5.17 & $-23.1 \%$ & 0.92 & -2.40 & 3.03 & 0.47 & 0.64 & 5.14 & $14.3 \%$ & 5191 \\
\hline & Wheat & $-15.1 \%$ & -3.82 & $-18.5 \%$ & 0.97 & -1.41 & 1.24 & 0.41 & 0.34 & 3.36 & $11.6 \%$ & 4325 \\
\hline \multirow{2}{*}{ Livestock } & Lean Hogs & $28.1 \%$ & 3.34 & $18.5 \%$ & 0.98 & -1.11 & 4.46 & 0.71 & 0.70 & 3.47 & $11.8 \%$ & 3210 \\
\hline & Live Cattle & $-22.9 \%$ & -6.65 & $-28.0 \%$ & 0.97 & -1.32 & 1.38 & 0.41 & 0.67 & 3.73 & $19.6 \%$ & 4622 \\
\hline \multirow{3}{*}{ Metals } & Copper & $-29.3 \%$ & -6.41 & $-32.7 \%$ & 0.96 & -1.55 & 1.85 & 0.49 & 0.81 & 4.68 & $19.8 \%$ & 4189 \\
\hline & Gold & $-34.7 \%$ & -6.67 & $-37.5 \%$ & 0.97 & -1.86 & 1.67 & 0.53 & 0.33 & 3.48 & $22.2 \%$ & 3611 \\
\hline & Silver & $9.8 \%$ & 0.72 & $-9.1 \%$ & 0.98 & -2.86 & 3.80 & 1.12 & 0.56 & 2.83 & $2.0 \%$ & 5239 \\
\hline \multirow{5}{*}{ Tropical } & Cocoa & $-31.9 \%$ & -8.91 & $-33.2 \%$ & 0.96 & -1.35 & 1.05 & 0.38 & 0.39 & 3.67 & $28.2 \%$ & 3984 \\
\hline & Colombian Cofee & $-18.6 \%$ & -1.70 & $-28.8 \%$ & 0.98 & -1.54 & 2.68 & 0.68 & 1.63 & 7.04 & $8.1 \%$ & 1774 \\
\hline & Oats & $-65.5 \%$ & -5.73 & $-73.2 \%$ & 0.98 & -2.19 & 2.43 & 0.78 & 1.29 & 5.79 & $25.2 \%$ & 2075 \\
\hline & Orange Juice & $-26.5 \%$ & -4.55 & $-31.5 \%$ & 0.97 & -2.39 & 1.43 & 0.55 & -0.09 & 3.74 & $15.9 \%$ & 3283 \\
\hline & Rough Rice & $-35.4 \%$ & -6.37 & $-37.4 \%$ & 0.96 & -1.65 & 1.62 & 0.52 & 0.08 & 2.84 & $24.0 \%$ & 2815 \\
\hline Wood & Lumber & $-25.8 \%$ & -7.32 & $-29.3 \%$ & 0.97 & -1.50 & 1.25 & 0.40 & 0.26 & 3.31 & $24.3 \%$ & 3640 \\
\hline
\end{tabular}




\section{Table 5: Time Variation in Variance Risk Premia}

This table reports results from the regressions of realized variance on model-free implied variance. $\alpha_{I V}$ reports slope estimates and the corresponding t-statistics (in brackets) under the null that $\alpha_{I V}=0 . \quad \beta_{I V}$ reports the slope estimate and the corresponding $t$-statistic (in brackets) under the null that $\beta_{I V}=1$. Columns $\alpha_{L I V}$ and $\beta_{L I V}$ present the analogous regression results for log variance risk premia. Standard errors are adjusted following the method of Newey-West with lag length equal to the maturity of the variance swap.

Panel A: 60 Day Variance Risk Premia

\begin{tabular}{|c|c|c|c|c|c|c|c|c|c|c|c|}
\hline Sector & Commodity & \multicolumn{2}{|c|}{$\alpha_{I V}$} & \multicolumn{2}{|r|}{$\beta_{I V}$} & Adj $R^{2}$ & \multicolumn{2}{|c|}{$\alpha_{L I V}$} & \multicolumn{2}{|c|}{$\beta_{L I V}$} & $\operatorname{Adj} R^{2}$ \\
\hline \multirow{3}{*}{ Energy } & Crude Oil & -0.01 & $(-0.58)$ & 0.81 & $(-2.25)$ & $60.7 \%$ & -0.54 & $(-4.12)$ & 0.90 & $(-1.68)$ & $61.5 \%$ \\
\hline & Heating Oil & 0.01 & $(1.16)$ & 0.69 & $(-3.74)$ & $49.1 \%$ & -0.73 & $(-6.35)$ & 0.80 & $(-3.93)$ & $60.6 \%$ \\
\hline & Natural Gas & 0.07 & $(6.04)$ & 0.42 & $(-13.22)$ & $40.7 \%$ & -0.77 & $(-9.48)$ & 0.75 & $(-4.58)$ & $51.6 \%$ \\
\hline \multirow{7}{*}{ Grains } & Corn & 0.00 & $(0.23)$ & 0.72 & $(-3.33)$ & $57.2 \%$ & -0.20 & $(-1.33)$ & 1.09 & $(1.64)$ & $69.4 \%$ \\
\hline & Cotton & 0.04 & $(8.76)$ & 0.70 & $(-2.29)$ & $27.5 \%$ & -1.17 & $(-5.91)$ & 0.50 & $(-9.38)$ & $37.3 \%$ \\
\hline & Soybeans & 0.00 & $(0.4)$ & 0.85 & $(-1.19)$ & $41.7 \%$ & -0.43 & $(-2.15)$ & 0.94 & $(-0.9)$ & $54.8 \%$ \\
\hline & Soybean Meal & 0.00 & $(0.19)$ & 0.98 & $(-0.12)$ & $46.6 \%$ & -0.54 & $(-2.38)$ & 0.83 & $(-2.11)$ & $49.6 \%$ \\
\hline & Soybean Oil & 0.01 & $(1.29)$ & 0.71 & $(-2.03)$ & $37.0 \%$ & -1.06 & $(-3.83)$ & 0.70 & $(-3.25)$ & $36.4 \%$ \\
\hline & Sugar & 0.04 & $(4.88)$ & 0.54 & $(-8.35)$ & $42.4 \%$ & -0.64 & $(-6.06)$ & 0.81 & $(-3.68)$ & $54.8 \%$ \\
\hline & Wheat & 0.01 & $(1.21)$ & 0.83 & $(-2.01)$ & $54.5 \%$ & -0.51 & $(-3.03)$ & 0.87 & $(-2.14)$ & $56.3 \%$ \\
\hline \multirow{2}{*}{ Livestock } & Lean Hogs & 0.03 & $(5.91)$ & 0.51 & $(-7)$ & $29.1 \%$ & -1.24 & $(-5.49)$ & 0.60 & $(-5.08)$ & $29.5 \%$ \\
\hline & Live Cattle & 0.01 & $(3.59)$ & 0.45 & $(-8.44)$ & $33.6 \%$ & -1.57 & $(-6.36)$ & 0.70 & $(-4.55)$ & $40.4 \%$ \\
\hline \multirow{3}{*}{ Metals } & Copper & 0.02 & $(2.55)$ & 0.59 & $(-3.7)$ & $37.9 \%$ & -0.88 & $(-4.69)$ & 0.77 & $(-3.44)$ & $52.0 \%$ \\
\hline & Gold & 0.01 & $(3.53)$ & 0.60 & $(-6)$ & $46.2 \%$ & -1.03 & $(-4.18)$ & 0.80 & $(-2.97)$ & $46.4 \%$ \\
\hline & Silver & 0.01 & $(7.57)$ & 0.44 & $(-8.87)$ & $40.0 \%$ & -2.38 & $(-11.7)$ & 0.37 & $(-12.94)$ & $35.6 \%$ \\
\hline \multirow{5}{*}{ Tropical } & Cocoa & 0.02 & $(3.06)$ & 0.59 & $(-7.2)$ & $34.3 \%$ & -0.66 & $(-5.04)$ & 0.84 & $(-2.63)$ & $42.9 \%$ \\
\hline & Colombian Coffee & 0.14 & $(2.93)$ & 0.09 & $(-4.74)$ & $0.2 \%$ & -1.37 & $(-4.81)$ & 0.40 & $(-3.55)$ & $10.2 \%$ \\
\hline & Oats & 0.03 & $(3.43)$ & 0.24 & $(-11.55)$ & $5.5 \%$ & -1.58 & $(-5.3)$ & 0.67 & $(-2.5)$ & $12.6 \%$ \\
\hline & Orange Juice & 0.06 & $(4.92)$ & 0.31 & $(-6.93)$ & $12.5 \%$ & -1.31 & $(-6.85)$ & 0.52 & $(-5.66)$ & $22.7 \%$ \\
\hline & Rough Rice & 0.03 & $(4.85)$ & 0.38 & $(-13.15)$ & $25.3 \%$ & -1.11 & $(-5.61)$ & 0.74 & $(-3.09)$ & $37.6 \%$ \\
\hline Wood & Lumber & 0.03 & (5) & 0.44 & $(-10.43)$ & $39.6 \%$ & -0.94 & $(-7.66)$ & 0.75 & $(-4.72)$ & $54.4 \%$ \\
\hline
\end{tabular}

Panel B: 90 Day Variance Risk Premia

\begin{tabular}{|c|c|c|c|c|c|c|c|c|c|c|c|}
\hline \multirow{4}{*}{$\begin{array}{l}\text { Sector } \\
\text { Energy }\end{array}$} & \multirow{4}{*}{$\begin{array}{l}\text { Commodity } \\
\text { Crude Oil } \\
\text { Heating Oil } \\
\text { Natural Gas } \\
\end{array}$} & \multicolumn{2}{|c|}{$\overline{\bar{\alpha} \alpha_{I V}}$} & \multicolumn{2}{|c|}{$\overline{\beta_{I V}}$} & \multirow{2}{*}{$\frac{\mathrm{Adj} R^{2}}{60.1 \%}$} & \multicolumn{2}{|c|}{$\alpha_{L I V}$} & \multicolumn{2}{|c|}{$\overline{\beta_{L I V}}$} & \multirow{2}{*}{$\frac{\overline{\mathrm{Adj} R^{2}}}{62.0 \%}$} \\
\hline & & 0.00 & $(0.67)$ & 0.70 & $(-3.99)$ & & -0.62 & $(-3.76)$ & 0.90 & $(-1.46)$ & \\
\hline & & 0.01 & $(2.08)$ & 0.63 & $(-5.22)$ & $56.3 \%$ & -0.79 & $(-5.11)$ & 0.80 & $(-3.1)$ & $56.7 \%$ \\
\hline & & 0.06 & $(5.65)$ & 0.44 & $(-13.01)$ & $43.2 \%$ & -0.75 & $(-6.97)$ & 0.79 & $(-3.14)$ & $54.2 \%$ \\
\hline \multirow{7}{*}{ Grains } & Corn & 0.00 & $(-0.02)$ & 0.79 & $(-2.14)$ & $55.8 \%$ & -0.13 & $(-0.79)$ & 1.09 & $(1.39)$ & $69.4 \%$ \\
\hline & Cotton & 0.02 & $(3.74)$ & 0.96 & $(-0.36)$ & $48.8 \%$ & -0.48 & $(-1.87)$ & 0.77 & $(-3)$ & $51.7 \%$ \\
\hline & Soybeans & -0.02 & $(-0.95)$ & 1.53 & $(1.21)$ & $21.0 \%$ & 0.03 & $(0.1)$ & 1.05 & $(0.56)$ & $51.0 \%$ \\
\hline & Soybean Meal & -0.06 & $(-1.22)$ & 2.32 & $(1.58)$ & $29.5 \%$ & 0.17 & $(0.44)$ & 1.01 & $(0.1)$ & $48.4 \%$ \\
\hline & Soybean Oil & 0.01 & $(1.62)$ & 0.73 & $(-1.95)$ & $39.2 \%$ & -1.06 & $(-3.29)$ & 0.68 & $(-3.04)$ & $37.9 \%$ \\
\hline & Sugar & 0.04 & $(4.42)$ & 0.48 & $(-6.54)$ & $37.9 \%$ & -0.75 & $(-5.69)$ & 0.75 & $(-3.88)$ & $51.5 \%$ \\
\hline & Wheat & 0.01 & $(0.82)$ & 0.86 & $(-1.41)$ & $57.3 \%$ & -0.20 & $(-1.13)$ & 0.98 & $(-0.27)$ & $63.7 \%$ \\
\hline \multirow{2}{*}{ Livestock } & Lean Hogs & 0.07 & $(3.83)$ & 0.63 & $(-1.6)$ & $8.4 \%$ & -1.01 & $(-2.46)$ & 0.51 & $(-3.08)$ & $11.9 \%$ \\
\hline & Live Cattle & 0.01 & $(2.42)$ & 0.61 & $(-3.83)$ & $39.2 \%$ & -1.05 & $(-3.42)$ & 0.78 & $(-2.65)$ & $45.1 \%$ \\
\hline \multirow{3}{*}{ Metals } & Copper & 0.02 & $(2.77)$ & 0.55 & $(-3.79)$ & $35.7 \%$ & -0.88 & $(-4.04)$ & 0.76 & $(-2.95)$ & $52.8 \%$ \\
\hline & Gold & 0.01 & $(3.52)$ & 0.54 & $(-5.46)$ & $41.1 \%$ & -1.16 & $(-3.71)$ & 0.76 & $(-2.78)$ & $44.0 \%$ \\
\hline & Silver & 0.01 & $(6.45)$ & 0.33 & $(-12.07)$ & $40.1 \%$ & -2.43 & $(-10.26)$ & 0.38 & $(-9.79)$ & $35.8 \%$ \\
\hline \multirow{5}{*}{ Tropical } & Cocoa & 0.03 & $(3.02)$ & 0.54 & $(-6.71)$ & $35.7 \%$ & -0.72 & $(-4.39)$ & 0.81 & $(-2.47)$ & $44.6 \%$ \\
\hline & Colombian Coffee & 0.15 & $(2.62)$ & 0.02 & $(-4.4)$ & $0.0 \%$ & -1.48 & $(-4.17)$ & 0.33 & $(-3.11)$ & $7.8 \%$ \\
\hline & Oats & 0.01 & $(0.32)$ & 0.76 & $(-0.77)$ & $3.5 \%$ & -0.63 & $(-1.38)$ & 1.01 & $(0.05)$ & $16.2 \%$ \\
\hline & Orange Juice & 0.05 & $(5.93)$ & 0.32 & $(-9.03)$ & $22.2 \%$ & -1.45 & $(-7.43)$ & 0.47 & $(-6.19)$ & $25.1 \%$ \\
\hline & Rough Rice & 0.03 & $(3.92)$ & 0.43 & $(-7.4)$ & $23.2 \%$ & -1.05 & $(-4.39)$ & 0.73 & $(-2.92)$ & $35.7 \%$ \\
\hline Wood & Lumber & 0.04 & $(5.17)$ & 0.40 & $(-8.36)$ & $30.3 \%$ & -1.01 & $(-5.74)$ & 0.69 & $(-4.29)$ & $46.2 \%$ \\
\hline
\end{tabular}




\section{Table 6: Seasonality Tests}

This table presents average 60 day variance risk premia for each month. Columns 1 and 2 list the commodity sector and the commodity, respectively. Columns 3 to 14 report average variance risk premia for each month. More specifically, the "Jan" column refers to pay-offs of variance swap investments that are initiated in January. The numbers in brackets indicate Newey-West corrected t-statistics.

\begin{tabular}{|c|c|c|c|c|c|c|c|c|c|c|c|c|c|}
\hline Sector & Commodity & Jan & Feb & Mar & Apr & May & Jun & Jul & Aug & Sep & Oct & Nov & Dec \\
\hline \multirow{3}{*}{ Energy } & Crude Oil & $\begin{array}{c}-6.5 \% \\
(-4.73)\end{array}$ & $\begin{array}{c}-3.5 \% \\
(-3.99)\end{array}$ & $\begin{array}{l}-5.5 \% \\
(-3.75)\end{array}$ & $\begin{array}{c}-3.7 \% \\
(-3.77)\end{array}$ & $\begin{array}{c}-2.8 \% \\
(-4.68)\end{array}$ & $\begin{array}{c}-3.4 \% \\
(-3.46)\end{array}$ & $\begin{array}{l}-2.9 \% \\
(-2.27)\end{array}$ & $\begin{array}{l}-1.7 \% \\
(-1.77)\end{array}$ & $\begin{array}{l}-2.0 \% \\
(-1.15)\end{array}$ & $\begin{array}{l}-2.8 \% \\
(-1.98)\end{array}$ & $\begin{array}{c}-1.5 \% \\
(-1.09)\end{array}$ & $\begin{array}{c}-4.4 \% \\
(-2.09)\end{array}$ \\
\hline & Heating Oil & $\begin{array}{l}-5.2 \% \\
(-5.83)\end{array}$ & $\begin{array}{l}-3.1 \% \\
(-3.03)\end{array}$ & $\begin{array}{l}-4.0 \% \\
(-3.99)\end{array}$ & $\begin{array}{l}-2.5 \% \\
(-2.92)\end{array}$ & $\begin{array}{l}-1.5 \% \\
(-2.73)\end{array}$ & $\begin{array}{l}-2.7 \% \\
(-4.12)\end{array}$ & $\begin{array}{l}-1.9 \% \\
(-1.08)\end{array}$ & $\begin{array}{l}-1.4 \% \\
(-1.61)\end{array}$ & $\begin{array}{l}-3.6 \% \\
(-4.02)\end{array}$ & $\begin{array}{l}-4.2 \% \\
(-4.52)\end{array}$ & $\begin{array}{l}-3.6 \% \\
(-5.94)\end{array}$ & $\begin{array}{l}-2.7 \% \\
(-1.05)\end{array}$ \\
\hline & Natural Gas & $\begin{array}{c}-11.9 \% \\
(-5.21)\end{array}$ & $\begin{array}{c}-5.4 \% \\
(-3.18)\end{array}$ & $\begin{array}{c}-4.3 \% \\
(-5.6)\end{array}$ & $\begin{array}{l}-3.4 \% \\
(-4.49)\end{array}$ & $\begin{array}{l}-4.3 \% \\
(-3.79) \\
\end{array}$ & $\begin{array}{l}-6.1 \% \\
(-3.12)\end{array}$ & $\begin{array}{c}-10.5 \% \\
(-3.22) \\
\end{array}$ & $\begin{array}{r}-17.1 \% \\
(-4.06) \\
\end{array}$ & $\begin{array}{c}-20.5 \% \\
(-8.8) \\
\end{array}$ & $\begin{array}{r}-15.2 \% \\
(-7.05) \\
\end{array}$ & $\begin{array}{l}-8.3 \% \\
(-3.12)\end{array}$ & $\begin{array}{r}-17.9 \% \\
(-4.48)\end{array}$ \\
\hline \multirow{7}{*}{ Grains } & Corn & $\begin{array}{l}-2.4 \% \\
(-3.36)\end{array}$ & $\begin{array}{l}-1.3 \% \\
(-2.93)\end{array}$ & $\begin{array}{l}-2.6 \% \\
(-3.38)\end{array}$ & $\begin{array}{c}-2.9 \% \\
(-3.34)\end{array}$ & $\begin{array}{l}-2.3 \% \\
(-4.88)\end{array}$ & $\begin{array}{l}-3.6 \% \\
(-4.75)\end{array}$ & $\begin{array}{l}-2.7 \% \\
(-4.51)\end{array}$ & $\begin{array}{l}-1.7 \% \\
(-2.14)\end{array}$ & $\begin{array}{c}-0.7 \% \\
(-0.51)\end{array}$ & $\begin{array}{l}-1.9 \% \\
(-4.14)\end{array}$ & $\begin{array}{c}-2.1 \% \\
(-6.29)\end{array}$ & $\begin{array}{l}-2.6 \% \\
(-3.14)\end{array}$ \\
\hline & Cotton & $\begin{array}{l}3.5 \% \\
(5.66)\end{array}$ & $\begin{array}{c}2.1 \% \\
(6.73)\end{array}$ & $\begin{array}{l}2.9 \% \\
(7.83)\end{array}$ & $\begin{array}{l}3.1 \% \\
(4.51)\end{array}$ & $\begin{array}{c}4.6 \% \\
(9.03)\end{array}$ & $\begin{array}{l}2.2 \% \\
(2.74)\end{array}$ & $\begin{array}{l}2.2 \% \\
(4.26)\end{array}$ & $\begin{array}{l}3.0 \% \\
(4.15)\end{array}$ & $\begin{array}{c}2.0 \% \\
(3.99)\end{array}$ & $\begin{array}{l}2.7 \% \\
(3.2)\end{array}$ & $\begin{array}{c}0.9 \% \\
(1.19)\end{array}$ & $\begin{array}{l}2.3 \% \\
(6.41)\end{array}$ \\
\hline & Soybeans & $\begin{array}{l}-1.4 \% \\
(-2.76)\end{array}$ & $\begin{array}{l}-0.2 \% \\
(-0.72)\end{array}$ & $\begin{array}{l}-1.5 \% \\
(-2.83)\end{array}$ & $\begin{array}{l}-1.7 \% \\
(-1.76)\end{array}$ & $\begin{array}{l}-0.4 \% \\
(-0.32)\end{array}$ & $\begin{array}{c}0.7 \% \\
(0.37)\end{array}$ & $\begin{array}{l}-0.3 \% \\
(-0.21)\end{array}$ & $\begin{array}{l}-0.6 \% \\
(-1.39)\end{array}$ & $\begin{array}{l}-0.4 \% \\
(-0.62)\end{array}$ & $\begin{array}{l}-1.1 \% \\
(-4.06)\end{array}$ & $\begin{array}{l}-1.5 \% \\
(-3.63)\end{array}$ & $\begin{array}{l}-1.7 \% \\
(-3.26)\end{array}$ \\
\hline & Soybean Meal & $\begin{array}{l}-1.3 \% \\
(-2.05)\end{array}$ & $\begin{array}{c}0.7 \% \\
(1.59)\end{array}$ & $\begin{array}{l}-0.5 \% \\
(-1.22)\end{array}$ & $\begin{array}{l}-0.5 \% \\
(-0.75)\end{array}$ & $\begin{array}{l}0.8 \% \\
(0.9)\end{array}$ & $\begin{array}{c}0.4 \% \\
(0.44)\end{array}$ & $\begin{array}{l}0.5 \% \\
(0.35)\end{array}$ & $\begin{array}{l}1.9 \% \\
(0.95)\end{array}$ & $\begin{array}{c}0.9 \% \\
(1.03)\end{array}$ & $\begin{array}{l}-0.8 \% \\
(-1.28)\end{array}$ & $\begin{array}{l}-1.0 \% \\
(-1.92)\end{array}$ & $\begin{array}{l}-1.2 \% \\
(-2.99)\end{array}$ \\
\hline & Soybean Oil & $\begin{array}{l}-0.1 \% \\
(-0.23)\end{array}$ & $\begin{array}{l}-0.1 \% \\
(-0.59)\end{array}$ & $\begin{array}{l}-1.2 \% \\
(-3.29)\end{array}$ & $\begin{array}{l}-1.4 \% \\
(-1.81)\end{array}$ & $\begin{array}{l}-1.4 \% \\
(-2.02)\end{array}$ & $\begin{array}{l}-2.8 \% \\
(-4.61)\end{array}$ & $\begin{array}{l}-1.7 \% \\
(-2.48)\end{array}$ & $\begin{array}{l}0.0 \% \\
(0.01)\end{array}$ & $\begin{array}{c}2.0 \% \\
(1.25)\end{array}$ & $\begin{array}{c}-0.3 \% \\
(-0.6)\end{array}$ & $\begin{array}{l}-1.4 \% \\
(-4.94)\end{array}$ & $\begin{array}{l}-1.3 \% \\
(-5.48)\end{array}$ \\
\hline & Sugar & $\begin{array}{l}-2.8 \% \\
(-3.28)\end{array}$ & $\begin{array}{l}-3.1 \% \\
(-3.08)\end{array}$ & $\begin{array}{l}-3.3 \% \\
(-4.07)\end{array}$ & $\begin{array}{l}-4.2 \% \\
(-3.7)\end{array}$ & $\begin{array}{l}-1.3 \% \\
(-1.2)\end{array}$ & $\begin{array}{l}-1.4 \% \\
(-2.09)\end{array}$ & $\begin{array}{l}-4.7 \% \\
(-3.77)\end{array}$ & $\begin{array}{c}0.0 \% \\
(-0.05)\end{array}$ & $\begin{array}{l}0.8 \% \\
(0.8)\end{array}$ & $\begin{array}{c}-2.7 \% \\
(-3)\end{array}$ & $\begin{array}{l}-3.7 \% \\
(-3.89)\end{array}$ & $\begin{array}{l}-4.3 \% \\
(-3.18)\end{array}$ \\
\hline & Wheat & $\begin{array}{l}-0.9 \% \\
(-1.85)\end{array}$ & $\begin{array}{c}-0.7 \% \\
(-1.48) \\
\end{array}$ & $\begin{array}{l}-1.0 \% \\
(-1.34) \\
\end{array}$ & $\begin{array}{c}-2.3 \% \\
(-3.56) \\
\end{array}$ & $\begin{array}{c}-0.8 \% \\
(-2.19) \\
\end{array}$ & $\begin{array}{c}0.5 \% \\
(0.54) \\
\end{array}$ & $\begin{array}{l}0.2 \% \\
(0.24) \\
\end{array}$ & $\begin{array}{c}-0.4 \% \\
(-0.5) \\
\end{array}$ & $\begin{array}{c}0.1 \% \\
(0.09) \\
\end{array}$ & $\begin{array}{c}-0.9 \% \\
(-1.36)\end{array}$ & $\begin{array}{l}-0.8 \% \\
(-1.31) \\
\end{array}$ & $\begin{array}{l}-1.6 \% \\
(-1.94)\end{array}$ \\
\hline \multirow{2}{*}{ Livestock } & Lean Hogs & $\begin{array}{l}-1.0 \% \\
(-2.03)\end{array}$ & $\begin{array}{c}-0.1 \% \\
(-0.1)\end{array}$ & $\begin{array}{c}1.6 \% \\
(1.47)\end{array}$ & $\begin{array}{l}-1.3 \% \\
(-1.14)\end{array}$ & $\begin{array}{c}0.9 \% \\
(1.87)\end{array}$ & $\begin{array}{c}0.8 \% \\
(0.96)\end{array}$ & $\begin{array}{c}-0.3 \% \\
(-0.61)\end{array}$ & $\begin{array}{c}-4.6 \% \\
(-5.32)\end{array}$ & $\begin{array}{l}-2.3 \% \\
(-4.85)\end{array}$ & $\begin{array}{l}-3.2 \% \\
(-2.88)\end{array}$ & $\begin{array}{l}-1.0 \% \\
(-0.73)\end{array}$ & $\begin{array}{c}-4.1 \% \\
(-7.54)\end{array}$ \\
\hline & Live Cattle & $\begin{array}{l}-1.0 \% \\
(-5.04)\end{array}$ & $\begin{array}{l}-0.9 \% \\
(-4.11)\end{array}$ & $\begin{array}{l}-0.8 \% \\
(-3.74)\end{array}$ & $\begin{array}{l}-2.0 \% \\
(-6.73)\end{array}$ & $\begin{array}{l}-1.0 \% \\
(-5.6)\end{array}$ & $\begin{array}{l}-1.2 \% \\
(-3.18)\end{array}$ & $\begin{array}{l}-1.0 \% \\
(-2.65)\end{array}$ & $\begin{array}{l}-1.1 \% \\
(-3.64)\end{array}$ & $\begin{array}{l}-0.6 \% \\
(-3.12)\end{array}$ & $\begin{array}{l}-0.9 \% \\
(-7.61)\end{array}$ & $\begin{array}{l}-0.7 \% \\
(-4.64)\end{array}$ & $\begin{array}{l}-1.3 \% \\
(-5.85)\end{array}$ \\
\hline \multirow{3}{*}{ Metals } & Copper & $\begin{array}{c}-1.7 \% \\
(-3.89)\end{array}$ & $\begin{array}{c}-2.0 \% \\
(-3.89)\end{array}$ & $\begin{array}{c}-2.5 \% \\
(-1.8)\end{array}$ & $\begin{array}{c}-0.9 \% \\
(-0.68)\end{array}$ & $\begin{array}{c}-3.7 \% \\
(-1.98)\end{array}$ & $\begin{array}{c}-5.3 \% \\
(-2.79)\end{array}$ & $\begin{array}{l}-4.4 \% \\
(-4.5)\end{array}$ & $\begin{array}{l}-1.4 \% \\
(-2.17)\end{array}$ & $\begin{array}{c}1.1 \% \\
(0.52)\end{array}$ & $\begin{array}{c}-2.0 \% \\
(-1.59)\end{array}$ & $\begin{array}{c}-3.7 \% \\
(-2.38)\end{array}$ & $\begin{array}{l}-1.5 \% \\
(-1.75)\end{array}$ \\
\hline & Gold & $\begin{array}{l}-0.9 \% \\
(-2.3)\end{array}$ & $\begin{array}{l}-1.7 \% \\
(-4.29)\end{array}$ & $\begin{array}{l}-1.5 \% \\
(-2.65)\end{array}$ & $\begin{array}{l}-0.7 \% \\
(-1.1)\end{array}$ & $\begin{array}{l}-0.6 \% \\
(-1.42)\end{array}$ & $\begin{array}{l}-0.9 \% \\
(-2.76)\end{array}$ & $\begin{array}{l}-0.5 \% \\
(-1.01)\end{array}$ & $\begin{array}{l}0.2 \% \\
(0.3)\end{array}$ & $\begin{array}{l}-0.9 \% \\
(-1.73)\end{array}$ & $\begin{array}{l}-2.0 \% \\
(-4.68)\end{array}$ & $\begin{array}{l}-1.6 \% \\
(-2.86)\end{array}$ & $\begin{array}{l}-1.2 \% \\
(-1.77)\end{array}$ \\
\hline & Silver & $\begin{array}{l}0.1 \% \\
(0.12) \\
\end{array}$ & $\begin{array}{c}-0.1 \% \\
(-0.28) \\
\end{array}$ & $\begin{array}{l}-0.6 \% \\
(-1.07)\end{array}$ & $\begin{array}{c}-0.5 \% \\
(-0.75) \\
\end{array}$ & $\begin{array}{l}-0.7 \% \\
(-0.81)\end{array}$ & $\begin{array}{l}-0.3 \% \\
(-0.47)\end{array}$ & $\begin{array}{l}0.3 \% \\
(0.6) \\
\end{array}$ & $\begin{array}{c}1.0 \% \\
(1.62) \\
\end{array}$ & $\begin{array}{c}0.4 \% \\
(0.53) \\
\end{array}$ & $\begin{array}{l}-0.4 \% \\
(-0.59) \\
\end{array}$ & $\begin{array}{l}-1.0 \% \\
(-1.03) \\
\end{array}$ & $\begin{array}{c}-0.9 \% \\
(-0.79) \\
\end{array}$ \\
\hline \multirow{5}{*}{ Tropical } & Cocoa & $\begin{array}{c}-3.4 \% \\
(-5.06)\end{array}$ & $\begin{array}{l}-2.7 \% \\
(-3.01)\end{array}$ & $\begin{array}{l}-3.9 \% \\
(-6.46)\end{array}$ & $\begin{array}{c}-3.9 \% \\
(-3.58)\end{array}$ & $\begin{array}{l}-2.1 \% \\
(-2.15)\end{array}$ & $\begin{array}{l}-2.2 \% \\
(-2.76)\end{array}$ & $\begin{array}{c}-2.6 \% \\
(-3.19)\end{array}$ & $\begin{array}{c}-2.6 \% \\
(-3)\end{array}$ & $\begin{array}{l}-2.8 \% \\
(-3.55)\end{array}$ & $\begin{array}{l}-2.1 \% \\
(-2.29)\end{array}$ & $\begin{array}{l}-3.8 \% \\
(-6.2)\end{array}$ & $\begin{array}{c}-4.4 \% \\
(-5.44)\end{array}$ \\
\hline & Colombian Coffee & $\begin{array}{c}-3.9 \% \\
(-1)\end{array}$ & $\begin{array}{l}-4.1 \% \\
(-3.54)\end{array}$ & $\begin{array}{l}-0.8 \% \\
(-0.28)\end{array}$ & $\begin{array}{l}8.5 \% \\
(0.95)\end{array}$ & $\begin{array}{l}-5.6 \% \\
(-1.27)\end{array}$ & $\begin{array}{l}-6.3 \% \\
(-1.36)\end{array}$ & $\begin{array}{l}-5.3 \% \\
-1.94)\end{array}$ & $\begin{array}{l}-0.6 \% \\
(-0.43)\end{array}$ & $\begin{array}{l}4.6 \% \\
(0.92)\end{array}$ & $\begin{array}{l}-0.2 \% \\
(-0.05)\end{array}$ & $\begin{array}{l}-5.9 \% \\
(-3.79)\end{array}$ & $\begin{array}{l}-4.6 \% \\
(-1.03)\end{array}$ \\
\hline & Oats & $\begin{array}{c}-5.6 \% \\
(-10)\end{array}$ & $\begin{array}{l}-5.5 \% \\
(-9.88)\end{array}$ & $\begin{array}{l}-6.3 \% \\
(-4.27)\end{array}$ & $\begin{array}{l}-7.3 \% \\
-3.78)\end{array}$ & $\begin{array}{l}-4.8 \% \\
(-2.95)\end{array}$ & $\begin{array}{l}-9.6 \% \\
(-5.61)\end{array}$ & $\begin{array}{l}-5.8 \% \\
(-3.88)\end{array}$ & $\begin{array}{l}-5.6 \% \\
(-6.6)\end{array}$ & $\begin{array}{c}-6.1 \% \\
(-9.9)\end{array}$ & $\begin{array}{l}-5.0 \% \\
(-5.06)\end{array}$ & $\begin{array}{c}-6.5 \% \\
(-19.02)\end{array}$ & $\begin{array}{c}-7.4 \% \\
(-14.56)\end{array}$ \\
\hline & Orange Juice & $\begin{array}{l}-4.5 \% \\
(-3.82)\end{array}$ & $\begin{array}{l}-1.8 \% \\
(-1.37)\end{array}$ & $\begin{array}{l}0.3 \% \\
(0.27)\end{array}$ & $\begin{array}{l}0.3 \% \\
(0.37)\end{array}$ & $\begin{array}{c}0.1 \% \\
(0.13)\end{array}$ & $\begin{array}{l}-0.9 \% \\
(-0.9)\end{array}$ & $\begin{array}{l}-1.7 \% \\
(-1.89)\end{array}$ & $\begin{array}{l}-0.2 \% \\
(-0.11)\end{array}$ & $\begin{array}{l}-0.8 \% \\
(-0.41)\end{array}$ & $\begin{array}{l}-6.2 \% \\
(-2.43)\end{array}$ & $\begin{array}{l}-4.6 \% \\
(-4.48)\end{array}$ & $\begin{array}{l}-8.6 \% \\
(-5.6)\end{array}$ \\
\hline & Rough Rice & $\begin{array}{l}-2.8 \% \\
(-1.85)\end{array}$ & $\begin{array}{l}-1.7 \% \\
(-1.98)\end{array}$ & $\begin{array}{l}-1.6 \% \\
(-2.67)\end{array}$ & $\begin{array}{l}-2.7 \% \\
(-3.23)\end{array}$ & $\begin{array}{l}-2.2 \% \\
(-3.68)\end{array}$ & $\begin{array}{l}-4.4 \% \\
(-8.75)\end{array}$ & $\begin{array}{l}-2.3 \% \\
(-5.37)\end{array}$ & $\begin{array}{l}-3.1 \% \\
(-3.21)\end{array}$ & $\begin{array}{l}-2.1 \% \\
(-2.34)\end{array}$ & $\begin{array}{l}-3.7 \% \\
(-4.71)\end{array}$ & $\begin{array}{l}-5.2 \% \\
(-5.22)\end{array}$ & $\begin{array}{l}-3.9 \% \\
(-3.75)\end{array}$ \\
\hline Wood & Lumber & $\begin{array}{l}-4.4 \% \\
(-4.87)\end{array}$ & $\begin{array}{l}-5.1 \% \\
(-6.05)\end{array}$ & $\begin{array}{l}-3.7 \% \\
(-8.91)\end{array}$ & $\begin{array}{l}-2.6 \% \\
(-2.77)\end{array}$ & $\begin{array}{c}-1.8 \% \\
(-1.86)\end{array}$ & $\begin{array}{c}-3.0 \% \\
(-7.73)\end{array}$ & $\begin{array}{l}-3.1 \% \\
(-6.17)\end{array}$ & $\begin{array}{l}-2.4 \% \\
(-7.16)\end{array}$ & $\begin{array}{c}-3.2 \% \\
(-4.02)\end{array}$ & $\begin{array}{c}-4.2 \% \\
(-7.87)\end{array}$ & $\begin{array}{c}-4.9 \% \\
(-8.71)\end{array}$ & $\begin{array}{l}-4.0 \% \\
(-4.65)\end{array}$ \\
\hline
\end{tabular}




\section{Table 7: Macroconomic Expectations and Variance Risk Premia}

This table presents results from univariate regressions of variance risk premia on macroeconomic forecasts. RGDP, CPI and IP refer to the median forecasts of real GDP, CPI and industrial production, respectively. Each variable corresponds to the monthly median forecasts of the current calendar year. DFSPD and TSPD denote the default spread (BAA-AAA) and term spread (10Y-2Y), respectively. Newey-West adjusted t-statistics are reported in brackets. All variables are standardized.

Panel A: 60 Day Variance Risk Premia

\begin{tabular}{|c|c|c|c|c|c|c|c|c|c|c|c|c|c|c|c|c|c|}
\hline \multirow{2}{*}{ Sector } & \multirow{2}{*}{ Commodity } & \multicolumn{3}{|c|}{ RGDP } & \multicolumn{3}{|c|}{ CPI } & \multicolumn{3}{|c|}{ IP } & \multicolumn{3}{|c|}{ DFSPD } & \multicolumn{3}{|c|}{ TSPD } & \multirow[b]{2}{*}{ Nobs } \\
\hline & & $\beta$ & T-Stat & $\operatorname{Adj} R^{2}$ & $\beta$ & T-Stat & $\operatorname{Adj} R^{2}$ & $\beta$ & T-Stat & Adj $R^{2}$ & $\beta$ & T-Stat & Adj $R^{2}$ & $\beta$ & T-Stat & $\operatorname{Adj} R^{2}$ & \\
\hline \multirow{3}{*}{ Energy } & Crude Oil & 0.18 & $(2.21)$ & $3.4 \%$ & 0.45 & $(5.06)$ & $20.4 \%$ & 0.24 & $(3.1)$ & $5.6 \%$ & \begin{tabular}{|l|}
-0.20 \\
\end{tabular} & $(-1.25)$ & $4.0 \%$ & -0.13 & $(-1.64)$ & $1.6 \%$ & 257 \\
\hline & Heating Oil & 0.17 & (1.8) & $2.8 \%$ & 0.41 & $(5.37)$ & $16.8 \%$ & 0.24 & $(3.25)$ & $5.7 \%$ & -0.19 & $(-1.85)$ & $3.5 \%$ & -0.07 & $(-0.96)$ & $0.5 \%$ & 260 \\
\hline & Natural Gas & 0.10 & (1.18) & $1.0 \%$ & 0.07 & $(0.79)$ & $0.4 \%$ & 0.15 & $(1.91)$ & $2.4 \%$ & -0.03 & $(-0.48)$ & $0.1 \%$ & 0.07 & $(0.85)$ & $0.5 \%$ & 222 \\
\hline \multirow{7}{*}{ Grains } & Corn & 0.10 & $(1.05)$ & $1.1 \%$ & 0.24 & $(2.38)$ & $5.5 \%$ & 0.08 & $(0.75)$ & $0.6 \%$ & \begin{tabular}{|l|}
-0.10 \\
\end{tabular} & $(-0.58)$ & $1.0 \%$ & 0.01 & $(0.13)$ & $0.0 \%$ & 264 \\
\hline & Cotton & -0.03 & $(-0.32)$ & $0.1 \%$ & -0.14 & $(-2.74)$ & $2.0 \%$ & -0.11 & $(-1.35)$ & $1.2 \%$ & 0.10 & $(1.42)$ & $1.0 \%$ & 0.25 & $(3.58)$ & $6.2 \%$ & 208 \\
\hline & Soybeans & 0.21 & $(2.61)$ & $4.2 \%$ & 0.20 & $(3.35)$ & $3.8 \%$ & 0.18 & $(2.71)$ & $3.3 \%$ & -0.21 & $(-3.07)$ & $4.6 \%$ & -0.10 & $(-1.39)$ & $1.0 \%$ & 269 \\
\hline & Soybean Meal & 0.03 & $(0.22)$ & $0.1 \%$ & -0.03 & $(-0.29)$ & $0.1 \%$ & -0.01 & $(-0.1)$ & $0.0 \%$ & -0.13 & $(-1.92)$ & $1.6 \%$ & 0.09 & (1.13) & $0.8 \%$ & 240 \\
\hline & Soybean Oil & -0.04 & $(-0.54)$ & $0.2 \%$ & 0.20 & $(1.98)$ & $4.2 \%$ & -0.01 & $(-0.13)$ & $0.0 \%$ & 0.06 & $(0.45)$ & $0.4 \%$ & 0.10 & $(0.45)$ & $1.0 \%$ & 226 \\
\hline & Sugar & 0.12 & $(1.52)$ & $1.4 \%$ & 0.24 & $(3.35)$ & $6.0 \%$ & 0.17 & $(2.33)$ & $2.9 \%$ & -0.15 & $(-2.96)$ & $2.4 \%$ & -0.18 & $(-2.41)$ & $3.3 \%$ & 257 \\
\hline & Wheat & 0.07 & $(0.74)$ & $0.4 \%$ & 0.15 & $(1.69)$ & $2.2 \%$ & 0.10 & (1.13) & $0.9 \%$ & -0.10 & $(-0.82)$ & $1.0 \%$ & 0.09 & (1.17) & $0.8 \%$ & 259 \\
\hline \multirow{2}{*}{ Livestock } & Lean Hogs & \begin{tabular}{|l|}
-0.06 \\
\end{tabular} & $(-0.43)$ & $0.4 \%$ & -0.06 & $(-0.44)$ & $0.3 \%$ & -0.02 & $(-0.16)$ & $0.1 \%$ & \begin{tabular}{|l|}
0.12 \\
\end{tabular} & $(1.25)$ & $1.4 \%$ & -0.08 & $(-0.89)$ & $0.6 \%$ & 167 \\
\hline & Live Cattle & 0.10 & $(1.28)$ & $1.0 \%$ & 0.19 & $(2.74)$ & $3.6 \%$ & 0.10 & $(1.29)$ & $1.1 \%$ & -0.22 & $(-2.7)$ & $4.9 \%$ & -0.08 & $(-1.1)$ & $0.7 \%$ & 275 \\
\hline \multirow{3}{*}{ Metals } & Copper & 0.24 & $(2)$ & $5.9 \%$ & 0.34 & $(2.81)$ & $11.7 \%$ & 0.26 & $(2.15)$ & $6.9 \%$ & \begin{tabular}{|l|}
-0.12 \\
\end{tabular} & $(-0.79)$ & $1.5 \%$ & -0.01 & $(-0.16)$ & $0.0 \%$ & 244 \\
\hline & Gold & 0.24 & $(2.63)$ & $5.9 \%$ & 0.30 & $(3.51)$ & $8.8 \%$ & 0.26 & $(3.15)$ & $7.0 \%$ & -0.43 & $(-6.03)$ & $18.5 \%$ & -0.25 & $(-3.44)$ & $6.3 \%$ & 222 \\
\hline & Silver & 0.11 & $(1.1)$ & $1.2 \%$ & 0.33 & (5) & $11.0 \%$ & 0.11 & $(1.13)$ & $1.2 \%$ & -0.34 & $(-3.83)$ & $11.3 \%$ & -0.32 & $(-3.81)$ & $10.5 \%$ & 268 \\
\hline \multirow{5}{*}{ Tropical } & Cocoa & 0.14 & $(1.76)$ & $2.1 \%$ & 0.20 & $(2.56)$ & $3.8 \%$ & 0.14 & $(1.93)$ & $2.0 \%$ & \begin{tabular}{|l|l|}
-0.17 & \\
\end{tabular} & $(-2.1)$ & $2.8 \%$ & -0.11 & $(-1.24)$ & $1.1 \%$ & 230 \\
\hline & Colombian Coffee' & 0.14 & $(0.98)$ & $1.9 \%$ & 0.06 & $(0.69)$ & $0.3 \%$ & 0.23 & $(1.87)$ & $5.1 \%$ & -0.25 & $(-2.46)$ & $6.4 \%$ & -0.17 & $(-0.94)$ & $3.0 \%$ & 100 \\
\hline & Oats & 0.13 & $(1.72)$ & $1.7 \%$ & 0.19 & $(2.32)$ & $3.8 \%$ & 0.14 & $(2.04)$ & $1.9 \%$ & -0.08 & $(-0.86)$ & $0.6 \%$ & -0.04 & $(-0.4)$ & $0.1 \%$ & 146 \\
\hline & Orange Juice & -0.03 & $(-0.29)$ & $0.1 \%$ & 0.07 & $(0.74)$ & $0.5 \%$ & 0.01 & $(0.11)$ & $0.0 \%$ & -0.16 & $(-1.97)$ & $2.5 \%$ & -0.13 & $(-1.62)$ & $1.8 \%$ & 165 \\
\hline & Rough Rice & -0.01 & $(-0.2)$ & $0.0 \%$ & 0.00 & $(0.03)$ & $0.0 \%$ & 0.12 & $(1.37)$ & $1.3 \%$ & -0.03 & $(-0.28)$ & $0.1 \%$ & -0.09 & $(-0.88)$ & $0.9 \%$ & 168 \\
\hline Wood & Lumber & 0.07 & $(0.67)$ & $0.5 \%$ & 0.30 & $(3.22)$ & $9.1 \%$ & 0.09 & $(0.92)$ & $0.8 \%$ & \begin{tabular}{|l|}
0.00 \\
\end{tabular} & $(0.03)$ & $0.0 \%$ & -0.18 & $(-2.2)$ & $3.4 \%$ & 153 \\
\hline
\end{tabular}

Panel B: 90 Day Variance Risk Premia

\begin{tabular}{|c|c|c|c|c|c|c|c|c|c|c|c|c|c|c|c|c|c|}
\hline \multirow{2}{*}{ Sector } & \multirow{2}{*}{ Commodity } & \multicolumn{3}{|c|}{ RGDP } & \multicolumn{3}{|c|}{ CPI } & \multicolumn{3}{|c|}{ IP } & \multicolumn{3}{|c|}{ DFSPD } & \multicolumn{3}{|c|}{ TSPD } & \multirow{2}{*}{ Nobs } \\
\hline & & $\beta$ & T-Stat & $\operatorname{Adj} R^{2}$ & $\beta$ & T-Stat & $\operatorname{Adj} R^{2}$ & $\beta$ & T-Stat & $\operatorname{Adj} R^{2}$ & $\beta$ & T-Stat & Adj $R^{2}$ & $\beta$ & T-Stat & $\operatorname{Adj} R^{2}$ & \\
\hline \multirow{3}{*}{ Energy } & Crude Oil & 0.22 & $(2.25)$ & $5.0 \%$ & 0.45 & $(4.14)$ & $20.1 \%$ & 0.28 & $(3.19)$ & $7.8 \%$ & \begin{tabular}{|l|}
-0.26 \\
\end{tabular} & $(-1.54)$ & $6.6 \%$ & -0.12 & $(-1.49)$ & $1.5 \%$ & 268 \\
\hline & Heating Oil & 0.26 & $(2.4)$ & $6.5 \%$ & 0.37 & $(3.25)$ & $13.7 \%$ & 0.30 & $(3.85)$ & $9.3 \%$ & -0.25 & $(-2.08)$ & $6.4 \%$ & -0.09 & $(-1.12)$ & $0.8 \%$ & 259 \\
\hline & Natural Gas & 0.08 & $(0.83)$ & $0.7 \%$ & 0.08 & $(0.87)$ & $0.7 \%$ & 0.16 & $(1.76)$ & $2.5 \%$ & -0.05 & $(-0.81)$ & $0.3 \%$ & 0.06 & $(0.62)$ & $0.3 \%$ & 221 \\
\hline \multirow{7}{*}{ Grains } & Corn & 0.12 & $(1.03)$ & $1.4 \%$ & 0.27 & $(2.59)$ & $7.5 \%$ & 0.13 & $(1.13)$ & $1.6 \%$ & \begin{tabular}{|c|c|}
-0.22 \\
\end{tabular} & $(-1.39)$ & $5.0 \%$ & -0.06 & $(-0.9)$ & $0.4 \%$ & 264 \\
\hline & Cotton & -0.02 & $(-0.17)$ & $0.0 \%$ & -0.24 & $(-3.02)$ & $5.7 \%$ & -0.14 & $(-1.59)$ & $2.0 \%$ & 0.15 & $(1.9)$ & $2.2 \%$ & 0.34 & $(3.41)$ & $11.8 \%$ & 207 \\
\hline & Soybeans & 0.15 & $(1.89)$ & $2.3 \%$ & 0.04 & $(0.96)$ & $0.1 \%$ & 0.12 & $(1.75)$ & $1.4 \%$ & -0.14 & $(-1.74)$ & $1.9 \%$ & -0.05 & $(-0.66)$ & $0.3 \%$ & 269 \\
\hline & Soybean Meal & -0.21 & $(-0.88)$ & $4.2 \%$ & -0.27 & $(-1.38)$ & $7.5 \%$ & -0.28 & $(-1.16)$ & $8.1 \%$ & 0.08 & $(0.53)$ & $0.6 \%$ & 0.18 & $(1.45)$ & $3.2 \%$ & 239 \\
\hline & Soybean Oil & 0.03 & $(0.3)$ & $0.1 \%$ & 0.24 & $(2.4)$ & $5.7 \%$ & 0.06 & $(0.77)$ & $0.3 \%$ & -0.01 & $(-0.05)$ & $0.0 \%$ & 0.08 & $(1.09)$ & $0.7 \%$ & 225 \\
\hline & Sugar & 0.12 & $(1.59)$ & $1.5 \%$ & 0.22 & $(3.15)$ & $4.8 \%$ & 0.15 & $(2.07)$ & $2.3 \%$ & -0.15 & $(-2.95)$ & $2.2 \%$ & -0.24 & $(-3.27)$ & $5.9 \%$ & 256 \\
\hline & Wheat & 0.10 & $(0.94)$ & $1.0 \%$ & 0.18 & $(1.8)$ & $3.2 \%$ & 0.14 & (1.4) & $1.9 \%$ & -0.16 & $(-1.28)$ & $2.6 \%$ & 0.10 & $(1.13)$ & $0.9 \%$ & 258 \\
\hline \multirow{2}{*}{ Livestock } & Lean Hogs & -0.22 & $(-1.17)$ & $5.0 \%$ & -0.34 & $(-1.98)$ & $11.4 \%$ & -0.20 & $(-1.02)$ & $4.0 \%$ & 0.33 & $(1.91)$ & $10.7 \%$ & 0.16 & $(1.35)$ & $2.5 \%$ & 166 \\
\hline & Live Cattle & 0.13 & $(1.74)$ & $1.8 \%$ & 0.11 & $(1.33)$ & $1.1 \%$ & 0.10 & $(1.36)$ & $1.0 \%$ & -0.13 & $(-1.5)$ & $1.7 \%$ & -0.04 & $(-0.42)$ & $0.1 \%$ & 274 \\
\hline \multirow{3}{*}{ Metals } & Copper & 0.24 & $(1.81)$ & $5.9 \%$ & 0.36 & $(2.72)$ & $13.2 \%$ & 0.26 & $(1.96)$ & $6.9 \%$ & -0.16 & $(-1.02)$ & $2.4 \%$ & -0.02 & $(-0.22)$ & $0.0 \%$ & 244 \\
\hline & Gold & 0.30 & $(2.51)$ & $8.8 \%$ & 0.32 & $(2.92)$ & $10.0 \%$ & 0.31 & $(2.85)$ & $9.7 \%$ & -0.48 & $(-5.55)$ & $23.1 \%$ & -0.27 & $(-2.99)$ & $7.2 \%$ & 222 \\
\hline & Silver & 0.16 & $(1.24)$ & $2.6 \%$ & 0.38 & $(4.63)$ & $14.3 \%$ & 0.17 & $(1.39)$ & $3.0 \%$ & -0.47 & $(-6.63)$ & $22.0 \%$ & -0.35 & $(-3.34)$ & $12.6 \%$ & 268 \\
\hline \multirow{5}{*}{ Tropical } & Cocoa & 0.16 & $(1.66)$ & $2.6 \%$ & 0.25 & $(2.68)$ & $6.4 \%$ & 0.17 & $(2.03)$ & $2.9 \%$ & \begin{tabular}{|l|l|}
-0.17 \\
\end{tabular} & $(-1.71)$ & $2.9 \%$ & -0.13 & $(-1.3)$ & $1.6 \%$ & 229 \\
\hline & Colombian Coffee & 0.14 & $(0.96)$ & $1.9 \%$ & 0.06 & $(0.75)$ & $0.4 \%$ & 0.24 & $(1.78)$ & $5.8 \%$ & -0.28 & $(1.78)$ & $8.1 \%$ & -0.16 & $(-0.91)$ & $2.5 \%$ & 99 \\
\hline & Oats & 0.10 & $(1.11)$ & $0.9 \%$ & 0.07 & $(1.23)$ & $0.5 \%$ & 0.08 & $(1.01)$ & $0.6 \%$ & -0.05 & $(-0.57)$ & $0.3 \%$ & -0.03 & $(-0.3)$ & $0.1 \%$ & 145 \\
\hline & Orange Juice & 0.03 & $(0.31)$ & $0.1 \%$ & 0.07 & $(0.78)$ & $0.5 \%$ & 0.07 & $(0.86)$ & $0.5 \%$ & -0.13 & $(-1.18)$ & $1.7 \%$ & -0.19 & $(-2.01)$ & $3.5 \%$ & 164 \\
\hline & Rough Rice & 0.07 & $(0.94)$ & $0.5 \%$ & 0.02 & $(0.28)$ & $0.0 \%$ & 0.16 & $(1.92)$ & $2.6 \%$ & -0.08 & $(-0.89)$ & $0.6 \%$ & -0.06 & $(-0.53)$ & $0.3 \%$ & 166 \\
\hline Wood & Lumber & -0.07 & $(-0.91)$ & $0.5 \%$ & 0.16 & $(1.58)$ & $2.6 \%$ & \begin{tabular}{|c|}
-0.08 \\
\end{tabular} & $(-0.87)$ & $0.6 \%$ & 0.25 & $(1.82)$ & $6.2 \%$ & -0.06 & $(-0.6)$ & $0.3 \%$ & 151 \\
\hline
\end{tabular}




\section{Table 8: Macroconomic Uncertainty and Variance Risk Premia}

This table presents results from univariate regressions of variance risk premia on macroeconomic uncertainty factors. URGDP, UCPI, UIP refer to uncertainty about real GDP, CPI and industrial production, respectively. Each uncertainty factor corresponds to the first principal component of the time series of cross-sectional standards deviation of professional forecasts for the current and next year. DFSPD and TSPD denote the default spread (BAA-AAA) and term spread $(10 Y-2 Y)$, respectively. Newey-West adjusted t-statistics are reported in brackets. All variables are standardized.

Panel A: 60 Day Variance Risk Premia

\begin{tabular}{|c|c|c|c|c|c|c|c|c|c|c|c|c|c|c|c|c|c|}
\hline \multirow{2}{*}{ Sector } & \multirow{2}{*}{ Commodity } & \multicolumn{3}{|c|}{ URGDP } & \multicolumn{3}{|c|}{ UCPI } & \multicolumn{3}{|c|}{ UIP } & \multicolumn{3}{|c|}{ DFSPD } & \multicolumn{3}{|c|}{ TSPD } & \multirow[t]{2}{*}{ Nobs } \\
\hline & & $\beta$ & T-Stat & $\operatorname{Adj} R^{2}$ & $\beta$ & T-Stat & $\operatorname{Adj} R^{2}$ & $\beta$ & T-Stat & $\operatorname{Adj} R^{2}$ & $\beta$ & T-Stat & $\operatorname{Adj} R^{2}$ & $\beta$ & T-Stat & $\operatorname{Adj} R^{2}$ & \\
\hline \multirow{3}{*}{ Energy } & Crude Oil & 0.08 & $(0.9)$ & $0.6 \%$ & -0.03 & $(-0.2)$ & $0.1 \%$ & 0.21 & $(2.6)$ & $4.5 \%$ & -0.20 & $(-1.1)$ & $4.0 \%$ & -0.11 & $(-1.7)$ & $1.3 \%$ & 252 \\
\hline & Heating Oil & 0.07 & $(0.8)$ & $0.5 \%$ & 0.04 & $(0.3)$ & $0.1 \%$ & 0.21 & (3) & $4.4 \%$ & -0.19 & $(-1.9)$ & $3.6 \%$ & -0.06 & $(-1.1)$ & $0.3 \%$ & 255 \\
\hline & Natural Gas & 0.04 & $(0.5)$ & $0.2 \%$ & 0.06 & (1) & $0.4 \%$ & 0.11 & (1.3) & $1.1 \%$ & -0.02 & $(-0.5)$ & $0.1 \%$ & 0.08 & (1) & $0.7 \%$ & 221 \\
\hline \multirow{7}{*}{ Grains } & Corn & 0.08 & $(1.2)$ & $0.6 \%$ & -0.01 & $(-0.1)$ & $0.0 \%$ & 0.08 & $(1.3)$ & $0.7 \%$ & -0.10 & $(-0.6)$ & $1.0 \%$ & 0.02 & $(0.3)$ & $0.0 \%$ & 253 \\
\hline & Cotton & -0.01 & $(-0.2)$ & $0.0 \%$ & -0.06 & $(-1)$ & $0.3 \%$ & -0.12 & $(-1.7)$ & $1.4 \%$ & 0.10 & (1.7) & $1.0 \%$ & 0.24 & (3.3) & $5.9 \%$ & 207 \\
\hline & Soybeans & 0.03 & $(0.7)$ & $0.1 \%$ & 0.10 & (1.4) & $1.0 \%$ & 0.12 & $(1.8)$ & $1.4 \%$ & -0.22 & $(-3.3)$ & $4.6 \%$ & -0.09 & $(-1.4)$ & $0.7 \%$ & 257 \\
\hline & Soybean Meal & -0.10 & $(-1.5)$ & $1.0 \%$ & -0.04 & $(-0.5)$ & $0.2 \%$ & -0.12 & $(-1.4)$ & $1.4 \%$ & -0.13 & $(-2.2)$ & $1.6 \%$ & 0.09 & $(1.2)$ & $0.8 \%$ & 232 \\
\hline & Soybean Oil & -0.10 & $(-1.6)$ & $0.9 \%$ & -0.17 & $(-1.4)$ & $2.8 \%$ & -0.03 & $(-0.4)$ & $0.1 \%$ & 0.06 & $(0.5)$ & $0.4 \%$ & 0.09 & (1.6) & $0.9 \%$ & 224 \\
\hline & Sugar & 0.19 & $(2.9)$ & $3.5 \%$ & 0.10 & (2) & $1.0 \%$ & 0.16 & $(2.5)$ & $2.7 \%$ & -0.16 & $(-3)$ & $2.5 \%$ & -0.19 & $(-3.3)$ & $3.6 \%$ & 256 \\
\hline & Wheat & 0.06 & (1) & $0.4 \%$ & 0.05 & $(0.4)$ & $0.2 \%$ & 0.11 & (1.7) & $1.3 \%$ & -0.10 & $(-0.9)$ & $1.1 \%$ & 0.07 & (1) & $0.5 \%$ & 248 \\
\hline \multirow{2}{*}{ Livestock } & Lean Hogs & -0.05 & $(-0.5)$ & $0.2 \%$ & -0.07 & $(-1.1)$ & $0.5 \%$ & -0.06 & $(-0.7)$ & $0.4 \%$ & 0.12 & $(1.7)$ & $1.3 \%$ & -0.08 & $(-1.2)$ & $0.6 \%$ & 166 \\
\hline & Live Cattle & 0.02 & $(0.5)$ & $0.1 \%$ & 0.11 & $(1.5)$ & $1.2 \%$ & 0.10 & (1.9) & $1.1 \%$ & -0.24 & $(-3.6)$ & $5.7 \%$ & -0.08 & $(-1.2)$ & $0.6 \%$ & 241 \\
\hline \multirow{3}{*}{ Metals } & Copper & 0.02 & $(0.3)$ & $0.0 \%$ & 0.04 & $(0.3)$ & $0.1 \%$ & 0.21 & $(2)$ & $4.4 \%$ & -0.12 & $(-0.8)$ & $1.5 \%$ & -0.01 & $(-0.2)$ & $0.0 \%$ & 242 \\
\hline & Gold & 0.04 & $(0.4)$ & $0.2 \%$ & 0.26 & (2) & $6.7 \%$ & 0.26 & (3.3) & $6.7 \%$ & -0.43 & $(-5.3)$ & $18.6 \%$ & -0.25 & $(-3.8)$ & $6.0 \%$ & 210 \\
\hline & Silver & -0.25 & $(-3.3)$ & $6.2 \%$ & 0.15 & $(1.1)$ & $2.3 \%$ & 0.05 & $(0.8)$ & $0.2 \%$ & -0.34 & $(-4)$ & $11.4 \%$ & -0.31 & $(-4.3)$ & $9.6 \%$ & 257 \\
\hline \multirow{5}{*}{ Tropical } & Cocoa & 0.10 & $(1.3)$ & $1.0 \%$ & 0.12 & $(2.1)$ & $1.4 \%$ & 0.21 & $(4.2)$ & $4.3 \%$ & -0.17 & $(-2.8)$ & $2.8 \%$ & -0.11 & $(-1.6)$ & $1.1 \%$ & 230 \\
\hline & Colombian Coffee & -0.08 & $(-0.7)$ & $0.6 \%$ & -0.05 & $(-0.6)$ & $0.3 \%$ & 0.09 & (1.1) & $0.8 \%$ & -0.26 & $(-2.3)$ & $6.6 \%$ & -0.19 & $(-1)$ & $3.5 \%$ & 99 \\
\hline & Oats & 0.15 & (2) & $2.3 \%$ & -0.03 & $(-0.4)$ & $0.1 \%$ & 0.23 & (3.3) & $5.2 \%$ & -0.08 & $(-1)$ & $0.6 \%$ & -0.04 & $(-0.6)$ & $0.1 \%$ & 146 \\
\hline & Orange Juice & 0.17 & (1.5) & $3.0 \%$ & 0.20 & $(3.1)$ & $4.1 \%$ & 0.07 & $(0.8)$ & $0.5 \%$ & -0.16 & $(-2.3)$ & $2.5 \%$ & -0.13 & $(-1.7)$ & $1.8 \%$ & 165 \\
\hline & Rough Rice & 0.16 & $(1.9)$ & $2.5 \%$ & -0.05 & $(-0.6)$ & $0.2 \%$ & 0.19 & $(2.4)$ & $3.5 \%$ & -0.03 & $(-0.3)$ & $0.1 \%$ & -0.09 & $(-1.1)$ & $0.9 \%$ & 168 \\
\hline Wood & Lumber & -0.03 & $(-0.3)$ & $0.1 \%$ & -0.08 & $(-0.7)$ & $0.6 \%$ & 0.06 & $(0.9)$ & $0.4 \%$ & 0.00 & $(0)$ & $0.0 \%$ & \begin{tabular}{|l|}
-0.17 \\
\end{tabular} & $(-2.4)$ & $2.8 \%$ & 148 \\
\hline
\end{tabular}

Panel B: 90 Day Variance Risk Premia

\begin{tabular}{|c|c|c|c|c|c|c|c|c|c|c|c|c|c|c|c|c|c|}
\hline \multirow{2}{*}{ Sector } & \multirow{2}{*}{ Commodity } & \multicolumn{3}{|c|}{ URGDP } & \multicolumn{3}{|c|}{ UCPI } & \multicolumn{3}{|c|}{ UIP } & \multicolumn{3}{|c|}{ DFSPD } & \multicolumn{3}{|c|}{ TSPD } & \multirow[t]{2}{*}{ Nobs } \\
\hline & & $\beta$ & T-Stat & $\operatorname{Adj} R^{2}$ & $\beta$ & T-Stat & $\operatorname{Adj} R^{2}$ & $\beta$ & T-Stat & $\operatorname{Adj} R^{2}$ & $\beta$ & T-Stat & $\operatorname{Adj} R^{2}$ & $\beta$ & T-Stat & $\operatorname{Adj} R^{2}$ & \\
\hline \multirow{3}{*}{ Energy } & Crude Oil & 0.14 & $(1.46)$ & $1.9 \%$ & \begin{tabular}{|l|l|}
0.07 & \\
\end{tabular} & $(0.34)$ & $0.5 \%$ & 0.25 & $(2.77)$ & $6.1 \%$ & -0.26 & $(-1.42)$ & $6.6 \%$ & \begin{tabular}{|l|}
-0.11 \\
\end{tabular} & $(-1.59)$ & $1.3 \%$ & 256 \\
\hline & Heating Oil & 0.16 & $(1.61)$ & $2.6 \%$ & 0.12 & $(0.84)$ & $1.4 \%$ & 0.28 & $(2.94)$ & $8.0 \%$ & -0.26 & $(-1.98)$ & $6.7 \%$ & -0.07 & $(-1.34)$ & $0.5 \%$ & 254 \\
\hline & Natural Gas & 0.04 & $(0.72)$ & $0.2 \%$ & 0.06 & $(1.21)$ & $0.4 \%$ & 0.10 & (1.53) & $1.0 \%$ & -0.05 & $(-1.17)$ & $0.3 \%$ & 0.07 & $(0.86)$ & $0.4 \%$ & 220 \\
\hline \multirow{7}{*}{ Grains } & Corn & 0.06 & $(0.83)$ & $0.4 \%$ & \begin{tabular}{|l|l|}
0.13 \\
\end{tabular} & $(0.76)$ & $1.6 \%$ & 0.12 & $(1.6)$ & $1.5 \%$ & -0.22 & $(-1.38)$ & $5.0 \%$ & \begin{tabular}{|l|}
-0.06 \\
\end{tabular} & $(-1.19)$ & $0.4 \%$ & 253 \\
\hline & Cotton & -0.02 & $(-0.27)$ & $0.0 \%$ & -0.04 & $(-0.82)$ & $0.2 \%$ & -0.15 & $(-2.35)$ & $2.1 \%$ & 0.15 & $(2.37)$ & $2.2 \%$ & 0.34 & $(3.49)$ & $11.5 \%$ & 206 \\
\hline & Soybeans & 0.08 & $(1.31)$ & $0.7 \%$ & 0.11 & $(1.34)$ & $1.2 \%$ & 0.11 & $(1.28)$ & $1.2 \%$ & -0.14 & $(-1.74)$ & $1.9 \%$ & -0.05 & $(-0.69)$ & $0.3 \%$ & 257 \\
\hline & Soybean Meal & -0.11 & $(-0.98)$ & $1.1 \%$ & -0.11 & $(-0.91)$ & $1.2 \%$ & -0.27 & $(-1.3)$ & $7.1 \%$ & 0.08 & $(0.64)$ & $0.6 \%$ & 0.18 & $(1.65)$ & $3.1 \%$ & 231 \\
\hline & Soybean Oil & -0.07 & $(1.46)$ & $0.4 \%$ & -0.11 & $(-1.04)$ & $1.3 \%$ & 0.02 & $(0.37)$ & $0.0 \%$ & -0.01 & $(-0.06)$ & $0.0 \%$ & 0.08 & $(1.84)$ & $0.6 \%$ & 223 \\
\hline & Sugar & 0.11 & $(2.48)$ & $1.2 \%$ & 0.08 & $(1.67)$ & $0.6 \%$ & 0.12 & $(2.35)$ & $1.5 \%$ & -0.15 & $(-3.07)$ & $2.3 \%$ & -0.25 & $(-4.06)$ & $6.4 \%$ & 255 \\
\hline & Wheat & 0.09 & $(1.68)$ & $0.9 \%$ & 0.10 & $(0.82)$ & $1.0 \%$ & 0.16 & $(2.11)$ & $2.6 \%$ & -0.16 & $(-1.28)$ & $2.7 \%$ & 0.08 & $(1.05)$ & $0.6 \%$ & 247 \\
\hline \multirow{2}{*}{ Livestock } & Lean Hogs & -0.11 & $(-0.8)$ & $1.1 \%$ & \begin{tabular}{|l|}
-0.17 \\
\end{tabular} & $(-1.17)$ & $2.8 \%$ & -0.22 & $(-1.4)$ & $5.0 \%$ & 0.33 & $(2.09)$ & $10.6 \%$ & \begin{tabular}{|l|l|}
0.15 \\
\end{tabular} & $(1.7)$ & $2.3 \%$ & 165 \\
\hline & Live Cattle & 0.08 & (1.38) & $0.6 \%$ & 0.06 & $(0.93)$ & $0.4 \%$ & 0.11 & $(1.86)$ & $1.3 \%$ & -0.14 & $(-2.26)$ & $2.0 \%$ & -0.04 & $(-0.52)$ & $0.1 \%$ & 240 \\
\hline \multirow{3}{*}{ Metals } & Copper & 0.00 & $(0.02)$ & $0.0 \%$ & 0.06 & $(0.42)$ & $0.4 \%$ & 0.21 & $(2.02)$ & $4.2 \%$ & -0.16 & $(-1.06)$ & $2.4 \%$ & \begin{tabular}{|l|}
-0.02 \\
-1
\end{tabular} & $(-0.32)$ & $0.0 \%$ & 242 \\
\hline & Gold & 0.08 & $(0.93)$ & $0.6 \%$ & 0.31 & $(1.95)$ & $9.6 \%$ & 0.31 & $(3.24)$ & $9.6 \%$ & -0.48 & $(-4.24)$ & $23.2 \%$ & -0.27 & $(-3.65)$ & $7.2 \%$ & 210 \\
\hline & Silver & -0.25 & $(1.46)$ & $6.1 \%$ & 0.27 & $(1.98)$ & $7.0 \%$ & 0.07 & $(0.92)$ & $0.5 \%$ & -0.47 & $(-8.57)$ & $22.3 \%$ & -0.33 & $(-4.59)$ & $11.1 \%$ & 257 \\
\hline \multirow{5}{*}{ Tropical } & Cocoa & 0.10 & $(1.12)$ & $1.0 \%$ & \begin{tabular}{|l|l|}
0.13 & \\
\end{tabular} & $(2.01)$ & $1.6 \%$ & 0.25 & $(4.4)$ & $6.0 \%$ & -0.17 & $(-2.43)$ & $2.9 \%$ & \begin{tabular}{|l|}
-0.13 \\
\end{tabular} & $(-1.93)$ & $1.6 \%$ & 229 \\
\hline & Colombian Coffee & -0.07 & $(-0.69)$ & $0.4 \%$ & -0.05 & $(-0.68)$ & $0.3 \%$ & 0.13 & $(1.31)$ & $1.8 \%$ & -0.29 & $(-2.1)$ & $8.2 \%$ & -0.17 & $(-1.02)$ & $2.8 \%$ & 98 \\
\hline & Oats & 0.11 & $(1.53)$ & $1.3 \%$ & 0.03 & $(0.34)$ & $0.1 \%$ & 0.12 & $(1.36)$ & $1.4 \%$ & -0.05 & $(-0.54)$ & $0.3 \%$ & -0.03 & $(-0.42)$ & $0.1 \%$ & 145 \\
\hline & Orange Juice & 0.21 & $(1.87)$ & $4.6 \%$ & 0.21 & $(2.44)$ & $4.5 \%$ & 0.17 & (1.79) & $2.8 \%$ & -0.13 & $(-1.78)$ & $1.7 \%$ & -0.19 & $(-2.04)$ & $3.5 \%$ & 164 \\
\hline & Rough Rice & 0.13 & $(1.46)$ & $1.6 \%$ & -0.05 & $(-0.55)$ & $0.2 \%$ & 0.17 & $(2.21)$ & $3.1 \%$ & -0.08 & $(-0.98)$ & $0.6 \%$ & -0.06 & $(-0.69)$ & $0.3 \%$ & 166 \\
\hline Wood & Lumber & -0.13 & $(-1.44)$ & $1.7 \%$ & \begin{tabular}{|l|}
-0.27 \\
\end{tabular} & $(-2.54)$ & $7.4 \%$ & -0.10 & $(-1.26)$ & $1.1 \%$ & 0.25 & $(1.92)$ & $6.3 \%$ & \begin{tabular}{|l|}
-0.05 \\
\end{tabular} & $(-0.51)$ & $0.2 \%$ & 146 \\
\hline
\end{tabular}




\section{Table 9: Commodity Specific Drivers of Variance Risk Premia}

This table presents results from univariate regressions of variance risk premia on commodity specific variables. BAS, HP and OI denote the basis, hedging pressure and open interest, respectively. We report Newey-West corrected $t$-statistics in brackets. All variables are standardized. All regressions are estimated with intercepts but we report only slope estimates.

Panel A: 60 Day Variance Risk Premia

\begin{tabular}{|c|c|c|c|c|c|c|c|c|c|c|c|}
\hline \multirow{2}{*}{ Sector } & \multirow{2}{*}{ Commodity } & \multicolumn{3}{|c|}{ BAS } & \multicolumn{3}{|c|}{ HP } & \multicolumn{3}{|c|}{ OI } & \multirow{2}{*}{ Nobs } \\
\hline & & $\beta$ & T-Stat & $\operatorname{Adj} R^{2}$ & $\beta$ & T-Stat & $\operatorname{Adj} R^{2}$ & $\beta$ & T-Stat & $\operatorname{Adj} R^{2}$ & \\
\hline \multirow{3}{*}{ Energy } & Crude Oil & -0.04 & $(-0.43)$ & $0.1 \%$ & $\begin{array}{c}-0.09 \\
\end{array}$ & $(-1.49)$ & $0.9 \%$ & 0.03 & $(0.54)$ & $0.1 \%$ & 257 \\
\hline & Heating Oil & 0.15 & $(1.59)$ & $2.1 \%$ & 0.04 & $(0.67)$ & $0.1 \%$ & 0.11 & $(2.06)$ & $1.3 \%$ & 260 \\
\hline & Natural Gas & -0.23 & $(-2.14)$ & $5.2 \%$ & 0.02 & $(0.25)$ & $0.0 \%$ & -0.04 & $(-0.63)$ & $0.1 \%$ & 222 \\
\hline \multirow{7}{*}{ Grains } & Corn & 0.27 & $(2.33)$ & $7.3 \%$ & -0.03 & $(-0.71)$ & $0.1 \%$ & -0.07 & $(-1.14)$ & $0.4 \%$ & 264 \\
\hline & Cotton & -0.06 & $(-0.36)$ & $0.3 \%$ & 0.06 & $(0.63)$ & $0.3 \%$ & -0.03 & $(-0.35)$ & $0.1 \%$ & 208 \\
\hline & Soybeans & -0.34 & $(-2.43)$ & $11.5 \%$ & -0.02 & $(-0.36)$ & $0.0 \%$ & 0.07 & $(1.07)$ & $0.5 \%$ & 269 \\
\hline & Soybean Meal & -0.23 & $(-2.05)$ & $5.3 \%$ & -0.06 & $(-1.05)$ & $0.3 \%$ & 0.06 & $(0.99)$ & $0.3 \%$ & 240 \\
\hline & Soybean Oil & 0.00 & (0) & $0.0 \%$ & -0.17 & $(-2.2)$ & $2.9 \%$ & 0.04 & $(0.69)$ & $0.2 \%$ & 226 \\
\hline & Sugar & 0.15 & $(1.81)$ & $2.3 \%$ & -0.03 & $(-0.37)$ & $0.1 \%$ & 0.13 & (1.39) & $1.6 \%$ & 257 \\
\hline & Wheat & -0.01 & $(-0.13)$ & $0.0 \%$ & 0.03 & $(0.4)$ & $0.1 \%$ & 0.00 & $(-0.04)$ & $0.0 \%$ & 259 \\
\hline \multirow{2}{*}{ Livestock } & Lean Hogs & 0.15 & $(1.64)$ & $2.4 \%$ & -0.05 & $(-0.56)$ & $0.3 \%$ & $\begin{array}{c}-0.04 \\
\end{array}$ & $(-0.69)$ & $0.2 \%$ & 167 \\
\hline & Live Cattle & -0.14 & $(-1.74)$ & $1.9 \%$ & 0.08 & $(1.08)$ & $0.6 \%$ & -0.14 & $(-2.22)$ & $2.0 \%$ & 275 \\
\hline \multirow{3}{*}{ Metals } & Copper & 0.00 & $(-0.06)$ & $0.0 \%$ & 0.09 & $(0.94)$ & $0.9 \%$ & 0.06 & $(0.95)$ & $0.3 \%$ & 244 \\
\hline & Gold & 0.19 & $(2.33)$ & $3.5 \%$ & -0.22 & $(-3.03)$ & $4.7 \%$ & -0.06 & $(-0.67)$ & $0.4 \%$ & 222 \\
\hline & Silver & 0.34 & $(4.2)$ & $11.7 \%$ & 0.11 & $(1.16)$ & $1.3 \%$ & -0.13 & $(-2.12)$ & $1.7 \%$ & 268 \\
\hline \multirow{5}{*}{ Tropical } & Cocoa & 0.01 & $(0.13)$ & $0.0 \%$ & -0.12 & $(-1.34)$ & $1.5 \%$ & $\begin{array}{c}-0.04 \\
\end{array}$ & $(-0.69)$ & $0.1 \%$ & 230 \\
\hline & Colombian Coffee & -0.17 & $(-2.29)$ & $2.8 \%$ & -0.03 & $(-0.17)$ & $0.1 \%$ & -0.02 & $(-0.19)$ & $0.0 \%$ & 100 \\
\hline & Oats & 0.29 & $(2.4)$ & $8.7 \%$ & 0.13 & $(1.6)$ & $1.7 \%$ & -0.09 & $(-1.08)$ & $0.8 \%$ & 146 \\
\hline & Orange Juice & -0.13 & $(-1.28)$ & $1.6 \%$ & -0.17 & $(-2.4)$ & $3.0 \%$ & -0.03 & $(-0.33)$ & $0.1 \%$ & 165 \\
\hline & Rough Rice & -0.03 & $(-0.3)$ & $0.1 \%$ & -0.12 & $(-1.31)$ & $1.4 \%$ & 0.02 & $(0.22)$ & $0.0 \%$ & 168 \\
\hline Wood & Lumber & 0.16 & $(2.04)$ & $2.7 \%$ & -0.06 & $(-0.47)$ & $0.4 \%$ & -0.07 & $(-0.99)$ & $0.4 \%$ & 153 \\
\hline
\end{tabular}

Panel B: 90 Day Variance Risk Premia

\begin{tabular}{|c|c|c|c|c|c|c|c|c|c|c|c|}
\hline \multirow{2}{*}{ Sector } & \multirow{2}{*}{ Commodity } & \multicolumn{3}{|c|}{ BAS } & \multicolumn{3}{|c|}{ HP } & \multicolumn{3}{|c|}{ OI } & \multirow{2}{*}{ Nobs } \\
\hline & & $\beta$ & T-Stat & $\operatorname{Adj} R^{2}$ & $\beta$ & T-Stat & $\operatorname{Adj} R^{2}$ & $\beta$ & T-Stat & $\operatorname{Adj} R^{2}$ & \\
\hline \multirow{3}{*}{ Energy } & Crude Oil & -0.06 & $(-0.46)$ & $0.3 \%$ & -0.10 & $(-1.35)$ & $0.9 \%$ & 0.06 & $(0.92)$ & $0.3 \%$ & 268 \\
\hline & Heating Oil & 0.06 & $(0.56)$ & $0.4 \%$ & 0.04 & $(0.57)$ & $0.1 \%$ & 0.11 & $(2.76)$ & $1.1 \%$ & 259 \\
\hline & Natural Gas & -0.16 & $(-1.7)$ & $2.6 \%$ & 0.04 & $(0.43)$ & $0.1 \%$ & -0.03 & $(-0.5)$ & $0.1 \%$ & 221 \\
\hline \multirow{7}{*}{ Grains } & Corn & -0.16 & $(-1.63)$ & $2.6 \%$ & -0.06 & $(-1.15)$ & $0.4 \%$ & $\begin{array}{c}-0.04 \\
\end{array}$ & $(-0.94)$ & $0.2 \%$ & 264 \\
\hline & Cotton & 0.07 & $(0.81)$ & $0.5 \%$ & 0.10 & $(0.91)$ & $1.0 \%$ & 0.01 & $(0.08)$ & $0.0 \%$ & 207 \\
\hline & Soybeans & -0.59 & $(-3.65)$ & $35.1 \%$ & -0.01 & $(-0.09)$ & $0.0 \%$ & 0.05 & $(0.9)$ & $0.3 \%$ & 269 \\
\hline & Soybean Meal & -0.49 & $(-3.29)$ & $24.4 \%$ & 0.07 & $(1.1)$ & $0.5 \%$ & -0.02 & $(-0.39)$ & $0.0 \%$ & 239 \\
\hline & Soybean Oil & -0.14 & $(-2.55)$ & $2.0 \%$ & -0.14 & $(-1.95)$ & $2.0 \%$ & 0.04 & $(0.61)$ & $0.1 \%$ & 225 \\
\hline & Sugar & 0.11 & $(1.2)$ & $1.2 \%$ & -0.16 & $(-1.85)$ & $2.5 \%$ & 0.13 & $(1.14)$ & $1.6 \%$ & 256 \\
\hline & Wheat & -0.15 & $(-2.64)$ & $2.2 \%$ & 0.00 & $(0.04)$ & $0.0 \%$ & -0.02 & $(-0.43)$ & $0.1 \%$ & 258 \\
\hline \multirow{2}{*}{ Livestock } & Lean Hogs & 0.21 & $(1.89)$ & $4.6 \%$ & -0.13 & $(-1.13)$ & $1.6 \%$ & -0.08 & $(-1.34)$ & $0.7 \%$ & 166 \\
\hline & Live Cattle & -0.25 & $(-3.2)$ & $6.2 \%$ & 0.05 & $(0.62)$ & $0.2 \%$ & -0.03 & $(-0.55)$ & $0.1 \%$ & 274 \\
\hline \multirow{3}{*}{ Metals } & Copper & 0.00 & $(0.02)$ & $0.0 \%$ & 0.11 & $(1.09)$ & $1.3 \%$ & 0.04 & $(0.76)$ & $0.2 \%$ & 244 \\
\hline & Gold & 0.21 & $(2.12)$ & $4.2 \%$ & -0.21 & $(-2.49)$ & $4.3 \%$ & -0.04 & $(-0.48)$ & $0.1 \%$ & 222 \\
\hline & Silver & 0.40 & $(4.16)$ & $15.6 \%$ & 0.06 & $(0.61)$ & $0.4 \%$ & -0.10 & $(-1.59)$ & $0.9 \%$ & 268 \\
\hline \multirow{5}{*}{ Tropical } & Cocoa & 0.02 & $(0.19)$ & $0.0 \%$ & -0.16 & $(-1.57)$ & $2.4 \%$ & -0.02 & $(-0.41)$ & $0.0 \%$ & 229 \\
\hline & Colombian Coffee & -0.14 & $(-1.73)$ & $1.9 \%$ & 0.04 & $(0.2)$ & $0.2 \%$ & 0.01 & $(0.17)$ & $0.0 \%$ & 99 \\
\hline & Oats & -0.03 & $(-0.21)$ & $0.1 \%$ & 0.11 & $(1.5)$ & $1.3 \%$ & -0.08 & $(-1.1)$ & $0.7 \%$ & 145 \\
\hline & Orange Juice & -0.20 & $(-2.03)$ & $4.0 \%$ & -0.23 & $(-2.88)$ & $5.3 \%$ & -0.01 & $(-0.06)$ & $0.0 \%$ & 164 \\
\hline & Rough Rice & -0.30 & $(-3.78)$ & $8.9 \%$ & -0.09 & $(-0.92)$ & $0.8 \%$ & 0.03 & $(0.32)$ & $0.1 \%$ & 166 \\
\hline Wood & Lumber & 0.18 & $(1.98)$ & $3.1 \%$ & -0.15 & $(-1.05)$ & $2.3 \%$ & $\begin{array}{c}-0.04 \\
\end{array}$ & $(-0.66)$ & $0.2 \%$ & 151 \\
\hline
\end{tabular}


Table 10: Joint Effects of Commodity and Macroeconomic Factors on Variance Risk Premia

This table presents results from regressions of variance risk premia on commodity and macroeconomic variables. CPI, IP refer to median forecasts of consumer price index and industrial production, respectively. Each uncertainty factor corresponds to the first principal component of the time series of cross-sectional deviation of forecasts for the current and next year. DFSPD and TSPD denote default spread (BAA-AAA) and term spread $(10 Y-2 Y)$, respectively. BAS, HP and OI denote basis, hedging pressure and open interest, respectively. All variables are standardized. Newey-West adjusted t-statistics are reported in brackets. Marg $R^{2}$ denotes the ratio of the $R^{2}$ with commodity factors only over the $R^{2}$ with both macroeconomic and commodity factors.

Panel A: 60 Day Variance Risk Premia

\begin{tabular}{|c|c|c|c|c|c|c|c|c|c|c|c|c|c|c|c|c|c|c|}
\hline \multirow{5}{*}{$\begin{array}{l}\text { Sector } \\
\text { Energy }\end{array}$} & \multirow{5}{*}{$\begin{array}{l}\text { Commodity } \\
\text { Crude Oil } \\
\text { Heating Oil } \\
\text { Natural Gas }\end{array}$} & \multirow{2}{*}{\multicolumn{8}{|c|}{$\begin{array}{l}\text { Macroconomic Variables } \\
\text { IP }\end{array}$}} & \multicolumn{6}{|c|}{ Commodity Factors } & \multirow{5}{*}{\begin{tabular}{|l} 
Adj $R^{2}$ \\
$22.0 \%$ \\
$22.3 \%$ \\
$6.4 \%$
\end{tabular}} & \multirow{2}{*}{\multicolumn{2}{|c|}{ Marg $R^{2} \mid$ Nobs }} \\
\hline & & CPI & & & \multirow{2}{*}{\multicolumn{2}{|c|}{ DFSPD }} & \multirow{2}{*}{\multicolumn{2}{|c|}{ TSPD }} & \multicolumn{2}{|c|}{$\begin{array}{ll}\mathrm{C} \\
\mathrm{BAS}\end{array}$} & \multicolumn{2}{|c|}{ HP } & \multicolumn{2}{|c|}{ OI } & & & \\
\hline & & 0.50 & $(3.84)$ & 0.02 & $(0.24)$ & & & & & 0.17 & $(2.32)$ & 0.04 & $(0.71)$ & -0.02 & $(-0.41)$ & & \multirow{2}{*}{$\begin{array}{l}5.3 \% \\
12.9 \%\end{array}$} & \multirow{2}{*}{$\begin{array}{l}257 \\
260\end{array}$} \\
\hline & & 0.42 & & 0.11 & & -0.06 & $(-0.76)$ & 0.11 & & 0.20 & & 0.05 & & 0.08 & & & & \\
\hline & & & $(-0.42)$ & 0.21 & $(1.75)$ & 0.06 & $(0.66)$ & 0.14 & (1.55) & -0.20 & $(-1.76)$ & 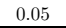 & $(0.63)$ & -0.08 & & & $66.2 \%$ & 222 \\
\hline \multirow{7}{*}{ Grain } & Corn & 0.32 & $(2.76)$ & \begin{tabular}{c|c|}
-0.07 \\
\end{tabular} & $(-0.78)$ & $\begin{array}{c}-0.16 \\
\end{array}$ & $(-0.93)$ & 0.18 & $(2.54)$ & 0.31 & $(2.89)$ & \begin{tabular}{c|c|c|}
-0.06 \\
\end{tabular} & $(-1.11)$ & \begin{tabular}{c|c|}
-0.06 \\
\end{tabular} & $e_{(-1}$ & $15.3 \%$ & $39.9 \%$ & 264 \\
\hline & & -0 & $(-3.09)$ & -0.06 & $(-0)$. & 0.04 & $(0.44)$ & 0.20 & (2) & -0.14 & $(-0.85)$ & 0.01 & $(0.13)$ & -0.02 & $(-1)$ & $6.9 \%$ & & 208 \\
\hline & & & $(3.2)$ & 0.02 & $(0.2$ & -0.14 & $(-2.28)$ & -0.05 & $(-0.57)$ & -0.42 & $(-3.26)$ & -0.02 & $(-0.29)$ & 0.07 & (1. & $21.8 \%$ & $5.2 \%$ & 269 \\
\hline & & & $(0$. & -0.09 & $(-0.6$ & -0.24 & $(-2.67)$ & 0.14 & $(1.78)$ & -0.22 & $(-2.19)$ & -0.11 & $(-2.16)$ & 0.04 & $(0$. & & $\%$ & 40 \\
\hline & & & (1. & -0.6 & $(-0.1$ & 0.04 & & 0.16 & & -0.02 & $(-0.34)$ & -0.16 & $(-2$. & & & & & 226 \\
\hline & & & (2. & 0.04 & & -0.08 & & -0.07 & $(-0)$ & 16 & & & $(-0)$ & 0.11 & & & & 257 \\
\hline & $\mathrm{Wl}$ & & $(2$. & 0.6 & $(0$. & -0.12 & $(-0$ & 0.22 & $(2.57)$ & 0.07 & $(0.87)$ & 0 & $(-0.07)$ & -0.01 & & & $4.1 \%$ & 59 \\
\hline \multirow[t]{2}{*}{ Livestock } & & & & 0.1 & & & & & & 0.12 & & & & & & & & 167 \\
\hline & $\mathrm{Li}$ & & $(2$. & -0 & & -0.24 & & 0.03 & & -0.08 & $(-0.95)$ & & & -0.09 & & & & 275 \\
\hline \multirow{3}{*}{ Metals } & & & & & & & & & & & & & & & & & & 14 \\
\hline & & & $(2$ & -0 & & & & & & & & & & & & & & 22 \\
\hline & & & & & & & & & & & & & & & & & & \\
\hline \multirow{5}{*}{ Tropical } & & & & & & & & & & & & & & & & & & 0 \\
\hline & & & $(0$. & & & & & & & & & & & & & & & \\
\hline & & & $(1.0$ & & $(0$. & & & & & & & & & 09 & & & & 46 \\
\hline & & & $(-0$. & & $(-0$ & & & -0.06 & & -0.07 & $(-0$ & & $(-1$ & 0.00 & & & & 65 \\
\hline & & -0.11 & $(-0.75)$ & 0.22 & $(1$. & 0.09 & $(0$. & -0.07 & $(-0.62)$ & -0.01 & $(-0.09)$ & .09 & $(-0.93)$ & 0.02 & & $\%$ & & 68 \\
\hline od & $\begin{array}{l}\text { Luml } \\
\end{array}$ & 34 & $(3.13)$ & $\begin{array}{c}-0.03 \\
\end{array}$ & $(-0.23)$ & 0.10 & $(0.82)$ & -0.10 & $(-0.89)$ & & $\frac{(1.95)}{\left(\frac{1}{2}\right)}$ & $\overline{0.4}$ & (0.8. & -0.11 & & $.5 \%$ & $\overline{0.6 \%}$ & 153 \\
\hline
\end{tabular}

Panel B: 90 Day Variance Risk Premia

\begin{tabular}{|c|c|c|c|c|c|c|c|c|c|c|c|c|c|c|c|c|c|c|}
\hline \multirow{3}{*}{ Sector } & \multirow{3}{*}{$\begin{array}{l}\text { Commodity } \\
\text { Crude Oil }\end{array}$} & \multicolumn{8}{|c|}{ Macroeconomic Variables } & \multirow{2}{*}{\multicolumn{6}{|c|}{ Commodity Factors }} & \multirow{2}{*}{ Adj $R^{2}$} & \multirow{2}{*}{\multicolumn{2}{|c|}{\begin{tabular}{|l|l|l|}
$\operatorname{Narg} R^{2}$ & Nobs \\
\end{tabular}}} \\
\hline & & & PI & & IP & & SPD & & SPD & & & & & & $\mathrm{OI}$ & & & \\
\hline & & 0.50 & $(3.42)$ & 0.05 & $\begin{array}{l}(0.64) \\
\end{array}$ & \begin{tabular}{c|c|c|} 
\\
\end{tabular} & $(-1.28)$ & 0.12 & & \begin{tabular}{|l|}
0.18 \\
\end{tabular} & $(2.35)$ & 0.05 & $(0.71)$ & & $(0.18)$ & & & \\
\hline \multirow[t]{2}{*}{ Energy } & Heating Oil & 0.33 & $(2.87)$ & 0.17 & $(2.35)$ & -0.10 & $(-1.1)$ & 0.11 & $(1.95)$ & 0.12 & (1.17) & 0.07 & (1.2) & 0.09 & $(2.77)$ & $19.4 \%$ & & 259 \\
\hline & Natural Gas & -0.01 & $(-0.08)$ & 0.19 & $(1.61)$ & 0.04 & $(0.36)$ & 0.14 & $(1.46)$ & -0.13 & $(-1.26)$ & 0.06 & $(0.64)$ & -0.06 & $(-1.26)$ & $3.5 \%$ & $49.7 \%$ & 221 \\
\hline \multirow{7}{*}{ Grains } & Corn & 0.27 & $(2.18)$ & -0.07 & $(-0.87)$ & -0.21 & $(-1.3)$ & 0.10 & $(1.27)$ & \begin{tabular}{|l|l|l|}
-0.11 &
\end{tabular} & $(-1.05)$ & -0.09 & $(-1.66)$ & -0.04 & $(-0.96)$ & $11.4 \%$ & $24.6 \%$ & 264 \\
\hline & & -0.24 & $(-3.96)$ & -0.08 & $(-0.63)$ & 0.00 & $(0)$ & 0.29 & $(2.7)$ & $\mid-0.02$ & $(-0.24)$ & 0.05 & $(0.5)^{\prime}$ & 0.04 & $(0.61)$ & & & 207 \\
\hline & Soybear & 0.11 & $(2.25)$ & 0.04 & $(0.77)$ & -0.05 & $(-1.37)$ & -0.14 & $(-1.51)$ & $\mid-0.66$ & $(-4.2)$ & 0.04 & $(0.55)$ & 0.07 & $(1.5)$ & $40.0 \%$ & $86.2 \%$ & 269 \\
\hline & Soybean Meal & -0.12 & $(-1.15)$ & -0.23 & $(-1.06)$ & -0.14 & $(-1.25)$ & 0.03 & $(0.56)$ & $\mid-0.42$ & $(-4.12)$ & -0.04 & $(-1.34)$ & -0.01 & $(-0.39)$ & $28.0 \%$ & $81.4 \%$ & 239 \\
\hline & & 0.28 & $(2.09)$ & 0.00 & (0) & -0.01 & $(-0.09)$ & 0.15 & $(1.77)$ & $\mid-0.17$ & $(-2.8)$ & -0.18 & $(-2.55)$ & 0.02 & & & & 225 \\
\hline & & 0.14 & $(2.06)$ & 0.04 & $(0.51)$ & -0.05 & $(-0.53)$ & -0.15 & $(-2.02)$ & \begin{tabular}{|l|} 
\\
\end{tabular} & $(1.28)$ & -0.15 & $(-2.01)$ & 0.11 & & & & 256 \\
\hline & & 0.21 & $\begin{array}{l}(2.03) \\
\end{array}$ & 0.04 & $(0.34)$ & -0.18 & $(-1.47)$ & 0.24 & $(2.68)$ & \begin{tabular}{|l|} 
\\
\end{tabular} & $(-0.7)$ & -0.06 & & -0.04 & $(-0.68)$ & & & 258 \\
\hline \multirow{2}{*}{ Livestock } & & $\begin{array}{l}-0.34 \\
-0.84\end{array}$ & $(-3.07)$ & 0.26 & & 0.36 & & -0.05 & & \begin{tabular}{|l|l|}
0.09 \\
\end{tabular} & $(1.02)$ & & & -0.07 & & & & 166 \\
\hline & Live & 0.08 & $(0.74)$ & -0.01 & $(-0.13)$ & $\begin{array}{l}-0.11 \\
\end{array}$ & $(-1.24)$ & 0.02 & $(0.24)$ & \begin{tabular}{|l|l|}
--0.23 \\
\end{tabular} & $(-2.8)$ & -0.04 & $(-0.45)$ & $\begin{array}{r}-0.02 \\
\end{array}$ & $(-0.47)$ & & & 274 \\
\hline \multirow{3}{*}{ Metals } & & 0.46 & $(3.1$ & 0.10 & $\begin{array}{l}(1.17) \\
\end{array}$ & 0.02 & & 0.08 & & \begin{tabular}{|l|}
0.21 \\
\end{tabular} & $(2.74)$ & & & $\begin{array}{c}-0.03 \\
\end{array}$ & & & & 244 \\
\hline & & 0.32 & $(2.34)$ & & $(-1.07)$ & -0.46 & $(-4.42)$ & -0.25 & $(-1.9)$ & $\mid-0.31$ & $(-1.95)$ & 0.03 & $(0.32)$ & -0.02 & $(-0$ & & & 222 \\
\hline & Sil & 0.23 & $(2.47)$ & -0.28 & $(-2.61)$ & -0.49 & $(-5.11)$ & -0.10 & $(-0.96)$ & \begin{tabular}{|l}
0.16 \\
\end{tabular} & $\begin{array}{l}(1.61) \\
\end{array}$ & 0.12 & $(1$. & -0.06 & $(-1.49)$ & & & 268 \\
\hline \multirow{5}{*}{ Tropical } & & 0.24 & & 0.01 & $(0.08)$ & -0.11 & & -0.04 & $(-0.40)$ & \begin{tabular}{|l|l|}
-0.07 \\
\end{tabular} & & -0.14 & & -0.04 & & & & 229 \\
\hline & $\mathrm{C}$ & 0.00 & $(-0.01)$ & 0.12 & $(0.84)$ & -0.20 & $(-1.43)$ & -0.10 & $(-0.52)$ & \begin{tabular}{|l|} 
\\
\end{tabular} & $(-1.34)$ & -0.03 & $(-0.17)$ & 0.11 & & & & 9 \\
\hline & & 0.03 & $(0.32)$ & 0.04 & $(0$. & 0.05 & $(0.93)$ & 0.00 & $(0.03)$ & \begin{tabular}{|l|}
-0.02 \\
\end{tabular} & $(-0.18)$ & 0.11 & (1.61) & $\begin{array}{l}-0.09 \\
0.02\end{array}$ & $(-1$. & & & 145 \\
\hline & & -0.10 & $(-0.81)$ & 0.02 & $(0.14$ & -0.08 & $(-0.64)$ & -0.13 & $\begin{array}{l}(-1.2) \\
(0.2)\end{array}$ & -0.14 & $(-1.34)$ & -0.21 & $(-2$. & 0.03 & $(0$ & & & 164 \\
\hline & Rol & -0.10 & $\begin{array}{l}(-0.8) \\
\end{array}$ & 0.24 & $(2.22)$ & 0.06 & $(0.52)$ & $\begin{array}{r}-0.01 \\
\end{array}$ & $\begin{array}{l}(-0.15) \\
\end{array}$ & \begin{tabular}{|c|}
-0.28 \\
0.12
\end{tabular} & $(-3.61)$ & $\begin{aligned}-0.05 \\
0.02\end{aligned}$ & $(-0.44)$ & 0.01 & $(0.16)$ & 3.20 & $\frac{\%}{\%}$ & 166 \\
\hline wood & Lumber & 0.26 & $(2.21)$ & 0.00 & $(-0.03)$ & 0.32 & $(2.46)$ & -0.06 & $(-0.48$ & \begin{tabular}{|l|l|} 
\\
\end{tabular} .13 & (1.46) & 0.02 & $(0.11)$ & -0.09 & $(-1.42)$ & $11.3 \%$ & $34.2 \%$ & 151 \\
\hline
\end{tabular}




\section{Table 11: Information Content of Gold's Variance Risk Premium: Univariate Regressions}

This table presents results from regressions of multi-period excess returns (3, 6, 9 and 12 months) on gold's 90 day variance risk premium. We obtain forecasts of realized variance through a simple EWMA model with smoothing constant $\lambda$ equal to 0.94. We consider one variance swap position per quarter, effectively creating non-overlapping time series. All variables are standardized. All regressions are estimated with intercepts but we report only slope estimates. The numbers in brackets show the Newey-West t-statistics computed with $h+1$ lags where, $h$ refers to the number of periods.

\begin{tabular}{|c|c|c|c|c|c|c|c|c|c|c|c|c|c|c|}
\hline \multirow{2}{*}{ Sector } & \multirow{2}{*}{ Commodity } & \multicolumn{3}{|c|}{3 Month } & \multicolumn{3}{|c|}{6 Month } & \multicolumn{3}{|c|}{9 Month } & \multicolumn{3}{|c|}{12 Month } & \multirow{2}{*}{ Nobs } \\
\hline & & & $\mathbf{R P}$ & $\operatorname{Adj} R^{2}$ & & $\overline{\mathbf{R P}}$ & $\operatorname{Adj} R^{2}$ & & $\overline{R P}$ & $\operatorname{Adj} R^{2}$ & & $\overline{\mathbf{R P}}$ & $\operatorname{Adj} R^{2}$ & \\
\hline \multirow{3}{*}{ Energy } & Crude Oil & -0.13 & $(-1.04)$ & $0.4 \%$ & -0.19 & $(-1.18)$ & $2.5 \%$ & $\begin{array}{l}-0.21 \\
\end{array}$ & $(-1.31)$ & $3.1 \%$ & $\begin{array}{l}-0.13 \\
\end{array}$ & $(-0.72)$ & $0.4 \%$ & 80 \\
\hline & Heating Oil & -0.11 & $(-0.75)$ & $-0.1 \%$ & -0.14 & $(-0.96)$ & $0.8 \%$ & -0.17 & $(-1.12)$ & $1.5 \%$ & -0.13 & $(-0.86)$ & $0.5 \%$ & 80 \\
\hline & Natural Gas & -0.05 & $(-0.48)$ & $-1.1 \%$ & -0.07 & $(-0.77)$ & $-0.9 \%$ & 0.01 & $(0.11)$ & $-1.4 \%$ & 0.03 & $(0.33)$ & $-1.3 \%$ & 74 \\
\hline \multirow{7}{*}{ Grains } & Corn & -0.20 & $(-1.94)$ & $2.9 \%$ & -0.21 & $(-1.51)$ & $3.4 \%$ & $\begin{array}{c}-0.18 \\
-0.0\end{array}$ & $(-1.47)$ & $2.1 \%$ & -0.16 & $(-1.73)$ & $1.4 \%$ & 80 \\
\hline & Cotton & -0.21 & $(-1.6)$ & $3.2 \%$ & -0.24 & $(-2.04)$ & $4.6 \%$ & -0.23 & $(-1.83)$ & $3.9 \%$ & -0.17 & $(-1.47)$ & $1.6 \%$ & 80 \\
\hline & Soybeans & -0.26 & $(-2.56)$ & $5.6 \%$ & -0.22 & $(-1.96)$ & $3.6 \%$ & -0.21 & $(-1.87)$ & $3.4 \%$ & -0.15 & $(-1.7)$ & $0.9 \%$ & 80 \\
\hline & Soybean Meal & -0.16 & $(-1.99)$ & $1.3 \%$ & -0.13 & $(-1.25)$ & $0.5 \%$ & -0.16 & $(-1.54)$ & $1.4 \%$ & -0.07 & $(-0.83)$ & $-0.8 \%$ & 80 \\
\hline & Soybean Oil & -0.29 & $(-2.41)$ & $7.0 \%$ & -0.30 & $(-2.67)$ & $8.0 \%$ & -0.20 & $(-1.77)$ & $3.0 \%$ & -0.19 & $(-2.15)$ & $2.5 \%$ & 80 \\
\hline & Sugar & -0.23 & $(-2.5)$ & $4.0 \%$ & -0.21 & $(-3.03)$ & $3.1 \%$ & -0.16 & $(-1.92)$ & $1.4 \%$ & -0.05 & $(-0.49)$ & $-1.1 \%$ & 80 \\
\hline & Wheat & -0.14 & $(-1.21)$ & $0.6 \%$ & -0.10 & $(-1.18)$ & $-0.2 \%$ & -0.10 & $(-1.6)$ & $-0.3 \%$ & 0.00 & $(0.02)$ & $-1.3 \%$ & 80 \\
\hline \multirow{2}{*}{ Livestock } & Lean Hogs & 0.00 & $(-0.01)$ & $-1.8 \%$ & -0.17 & $(-1.03)$ & $1.0 \%$ & -0.12 & $(-0.48)$ & $-0.2 \%$ & -0.12 & $(-0.56)$ & $-0.3 \%$ & 58 \\
\hline & Live Cattle & -0.05 & $(-0.59)$ & $-1.0 \%$ & -0.16 & $(-1.98)$ & $1.3 \%$ & -0.24 & $(-1.93)$ & $4.5 \%$ & -0.32 & $(-3.15)$ & $9.3 \%$ & 79 \\
\hline \multirow{3}{*}{ Metals } & Copper & -0.30 & $(-2.39)$ & $7.5 \%$ & -0.29 & $(-1.8)$ & $6.9 \%$ & -0.34 & $(-2.24)$ & $10.6 \%$ & -0.28 & $(-1.69)$ & $6.3 \%$ & 76 \\
\hline & Gold & -0.40 & $(-4.32)$ & $14.6 \%$ & -0.24 & $(-2.69)$ & $4.6 \%$ & -0.28 & $(-4.09)$ & $6.5 \%$ & -0.28 & $(-3.14)$ & $6.7 \%$ & 80 \\
\hline & Silver & -0.25 & $(-2.14)$ & $4.9 \%$ & -0.14 & $(-0.98)$ & $0.6 \%$ & -0.24 & $(-2.09)$ & $4.7 \%$ & -0.20 & $(-1.95)$ & $2.6 \%$ & 80 \\
\hline \multirow{5}{*}{ Tropical } & Cocoa & -0.17 & $(-1.52)$ & $1.7 \%$ & -0.23 & $(-2.33)$ & $4.1 \%$ & $\begin{array}{l}-0.19 \\
\end{array}$ & $(-2.04)$ & $2.5 \%$ & $\begin{array}{c}-0.11 \\
\end{array}$ & $(-1.5)$ & $-0.1 \%$ & 80 \\
\hline & Colombian Coffee & 0.13 & $(1.14)$ & $0.4 \%$ & -0.02 & $(-0.16)$ & $-1.3 \%$ & -0.06 & $(-0.66)$ & $-1.0 \%$ & -0.12 & $(-1.36)$ & $0.1 \%$ & 80 \\
\hline & Oats & -0.10 & $(-0.95)$ & $-0.3 \%$ & -0.10 & $(-0.92)$ & $-0.3 \%$ & -0.03 & $(-0.28)$ & $-1.2 \%$ & -0.12 & $(-1.17)$ & $0.2 \%$ & 80 \\
\hline & Orange Juice & -0.09 & $(-0.75)$ & $-0.5 \%$ & -0.17 & $(-1.39)$ & $1.7 \%$ & -0.22 & $(-2.28)$ & $3.8 \%$ & -0.16 & $(-1.55)$ & $1.3 \%$ & 80 \\
\hline & Rough Rice & -0.29 & $(-2.17)$ & $6.6 \%$ & -0.29 & $(-2.07)$ & $6.7 \%$ & -0.24 & $(-2.02)$ & $4.4 \%$ & -0.22 & $(-1.87)$ & $3.2 \%$ & 60 \\
\hline Wood & Lumber & -0.05 & $(-0.46)$ & $-1.0 \%$ & -0.16 & $(-1.12)$ & $1.2 \%$ & -0.26 & $(-1.85)$ & $5.6 \%$ & -0.28 & $(-2.63)$ & $6.5 \%$ & 78 \\
\hline
\end{tabular}


Table 12: Information Content of Gold's Variance Risk Premium: Multivariate Regressions

This table reports results from multi-periods regressions of commodity excess returns (3, 6, 9 and 12 months) on gold's non-overlapping variance risk premium (90 day). We forecast realized variance using a simple EWMA model with smoothing parameter $\lambda$ equal to 0.94, obtaining an ex-ante forecast of variance risk premia. To enhance comparability, we standardize all variables. All regressions are estimated with intercepts. We present only slope estimates and their corresponding test statistics. We report in brackets the Newey-West $t$-statistics computed with $h+1$ lags where $h$ refers to the number of periods. VRP, BAS and OI denote the variance risk premium, basis and open interest, respectively. Adj $R_{1}^{2}$ and Adj $R_{2}^{2}$ report the adjusted $R^{2}$ once VRP is included and excluded from the regression, respectively.

\begin{tabular}{|c|c|c|c|c|c|c|c|c|c|c|c|c|c|c|c|c|c|c|c|c|c|c|c|c|c|c|c|c|c|c|c|c|c|c|}
\hline \multirow{4}{*}{$\begin{array}{l}\text { Sector } \\
\text { Energy }\end{array}$} & \multirow{4}{*}{$\begin{array}{l}\text { Commodity } \\
\text { Crude Oil } \\
\text { Heating Oil } \\
\text { Natural Gas } \\
\end{array}$} & \multirow{2}{*}{\multicolumn{8}{|c|}{$\begin{array}{r}\text { 3 Month } \\
\mathrm{O}\end{array}$}} & \multirow{2}{*}{\multicolumn{8}{|c|}{$\begin{array}{r}6 \text { Month } \\
\end{array}$}} & \multirow{2}{*}{\multicolumn{8}{|c|}{$\begin{array}{l}9 \text { Month } \\
\end{array}$}} & \multirow{2}{*}{\multicolumn{8}{|c|}{12 Month }} & \multirow{2}{*}{ Nobs } \\
\hline & & & & & & & & & & & & & & & & & & & & & & & & & & & & & & & & & & \\
\hline & & \begin{tabular}{|c|}
-0.09 \\
-0.07
\end{tabular} & $(-0.69)$ & 0.13 & $\begin{array}{l}\quad(1.39) \\
(1.39)\end{array}$ & 0.12 & $(0.9)$ & $\begin{array}{l}1.3 \% \\
1.3 \%\end{array}$ & $\begin{array}{l}-2.4 \% \\
1.7 \%\end{array}$ & $\begin{array}{l}-0.16 \\
-0.14 \\
-0.14\end{array}$ & $\begin{array}{l}(-1.96) \\
(-0.96)\end{array}$ & 0.01 & $\begin{array}{l}(1.1) \\
(0.13)\end{array}$ & $\begin{array}{l}0.19 \\
0.15\end{array}$ & $\begin{array}{l}(3.29) \\
(1.04)\end{array}$ & $\begin{array}{l}5.9 \% \% \\
0.5 \%\end{array}$ & 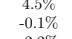 & $\mid \begin{array}{l}-0.18 \\
-0.17\end{array}$ & $\begin{array}{l}(-1.1) \\
(-1.13)\end{array}$ & $\begin{array}{l}0.03 \\
-0.03 \\
-0.03\end{array}$ & $\begin{array}{l}(2.16) \\
(-0.3)\end{array}$ & $\begin{array}{l}0.17 \\
0.10\end{array}$ & $\begin{array}{l}(2.08) \\
(0.67)\end{array}$ & $\begin{array}{l}5.9 \% \% \\
-0.1 \%\end{array}$ & 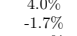 & $\mid \begin{array}{l}-0.09 \\
-0.14\end{array}$ & $\begin{array}{l}(-0.54) \\
(-0.88)\end{array}$ & $\begin{array}{l}0.17 \\
-0.04\end{array}$ & 4 & $\begin{array}{l}0.16 \\
0.04\end{array}$ & $\begin{array}{l}(2.44) \\
(0.28)\end{array}$ & $\begin{array}{l}3.3 \% \\
-1.9 \% \\
\end{array}$ & $\begin{array}{l}3.7 \% \text {. } \\
-2.5 \%\end{array}$ & $\begin{array}{l}80 \\
80\end{array}$ \\
\hline & & & & & & & & & & & & & & & & $\begin{array}{l}-2.9 \% \\
20 \%\end{array}$ & $-2.2 \%$ & & $(0.11)$ & & & & & $-2.2 \%$ & $-0.8 \%$ & & $(0.31)$ & & $(0.83)$ & -0.04 & $(-0.46)$ & $\begin{array}{l}-3.1 \% \\
\end{array}$ & $-1.7 \%$ & 74 \\
\hline & $\begin{array}{l}\text { Corn } \\
\text { Corts }\end{array}$ & $\mid-0.21$ & $(-2.01)$ & 0.19 & (2.24) & 0.06 & $(0.93)$ & $\begin{array}{l}4.7 \% \\
.7 \%\end{array}$ & 1.5 & -0.22 & $(-1.62)$ & 0.16 & $(1.79)$ & 0.03 & (0.42) & $\begin{array}{l}3.7 \% \\
\end{array}$ & $0.1 \%$ & \begin{tabular}{|c|}
-0.19 \\
\end{tabular} & (-1.64) & 0.23 & $(2.27)$ & -0.06 & $(-0.83)$ & $5.2 \%$ & $2.7 \%$ & $\mid-0.18$ & $(-1.94)$ & 0.26 & $\delta \quad(2.57)$ & 0.15 & $(-2.53)$ & $7.3 \%$ & $\%$ & 80 \\
\hline & & & $(-2.2$ & $\begin{array}{l}0.14 \\
0.53\end{array}$ & (4.66) & $\begin{array}{l}0.02 \\
0.07\end{array}$ & $\begin{array}{l}(0.22) \\
(1.07)\end{array}$ & $7 \%$ & $25.8 \%$ & $\begin{array}{l}-0.24 \\
-0.23\end{array}$ & $\left.\begin{array}{l}(-2.02) \\
(-2.22)\end{array}\right)$ & ${ }_{0.35}^{0.08}$ & 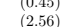 & 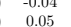 & $\begin{array}{l}(-0.8) \\
(0.71)\end{array}$ & $13.9 \%$ & $\begin{array}{l}-1.9 \% \\
9.6 \%\end{array}$ & $\mid \begin{array}{l}-0.23 \\
-0.22\end{array}$ & $(-2.03)$ & $\begin{array}{l}0.16 \\
0.29\end{array}$ & 13) & 07 & $\begin{array}{l}(-0.79) \\
(1.16)\end{array}$ & $5 \%$ & & $\mid \begin{array}{l}-0.17 \\
-0.15\end{array}$ & & 19 & & & & & & 80 \\
\hline Grains & Soybean Meal & $\mid-0.22$ & $(-2.53)$ & 0.55 & $(3.41)$ & -0.12 & $(-2.12)$ & $31.1 \%$ & $27.2 \%$ & -0.18 & $(-2.05)$ & 0.50 & (3.84) & -0.08 & $(-1.12)$ & $23.7 \%$ & $21.5 \%$ & \begin{tabular}{|c|}
-0.19 \\
-0.19
\end{tabular} & $(-2.08)$ & 0.46 & $(4.04)$ & 0.03 & $(0.4)$ & $20.8 \%$ & $18.2 \%$ & $\mid-0.11$ & $(-1.46)$ & 0.43 & $(3.78)$ & -0.06 & $(-0.83)$ & $15.9 \%$ & $15.8 \%$ & 80 \\
\hline & & & & 0.17 & (1.96) & & $(0.61)$ & $\begin{array}{l}8.2 \% \\
-7.9 \%\end{array}$ & $1.3 \%$ & $\begin{array}{l}-0.30 \\
-0.308\end{array}$ & $\begin{array}{l}(-2.71) \\
\end{array}$ & $\begin{array}{l}0.12 \\
0.023\end{array}$ & (1.08) & $\begin{array}{l}-0.03 \\
-0.04\end{array}$ & $=(-0.26)$ & & $\begin{array}{l}-1.1 .1 \% \\
\end{array}$ & $\left.\right|^{-0.21}$ & (2) & 0.12 & (1.1.18) & ${ }_{0}^{02}$ & $\begin{array}{l}(-0.24) \\
(0.24)\end{array}$ & & $\begin{array}{l}-1.0 \% \\
6.1 \%\end{array}$ & ${ }^{20}$ & 21) & 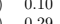 & 19) & . 1.12 & (8) & $3 \%$ & $\begin{array}{l}-0.6 \% \\
0.8 \%\end{array}$ & 80 \\
\hline & & $\begin{array}{l}-0.28 \\
-0.13\end{array}$ & $(-1.17)$ & $\begin{array}{l}0.25 \\
0.18\end{array}$ & $\begin{array}{l}(2.202) \\
(2.33)\end{array}$ & $\begin{array}{l}0.00 \\
-0.02\end{array}$ & $(-0.24)$ & $1.5 \%$ & $\begin{array}{l}1.1 .0 \% \\
1.0 \%\end{array}$ & $\begin{array}{l}-0.28 \\
-0.10\end{array}$ & $\begin{array}{l}(-3.94) \\
(-1.2)\end{array}$ & $\begin{array}{l}0.243 \\
0.24\end{array}$ & $(2.98)$ & $\begin{array}{l}-0.04 \\
-0.05\end{array}$ & $\begin{array}{l}(-0.01) \\
(-0.49)\end{array}$ & $\begin{array}{l}31.9 \% \\
3.7 \%\end{array}$ & $\begin{array}{l}4.8 \% \\
4.0 \%\end{array}$ & $\mid \begin{array}{l}-0.24 \\
-0.10\end{array}$ & 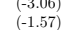 & $\begin{array}{l}0.34 \\
0.28\end{array}$ & $\begin{array}{l}(2.87) \\
(3.2)\end{array}$ & $\begin{array}{l}0.04 \\
-0.08\end{array}$ & $\begin{array}{l}(0.44) \\
(-0.87)\end{array}$ & $3 \%$ & $\begin{array}{l}6.1 \% \\
6.4 \%\end{array}$ & $\mid \begin{array}{c}-0.11 \\
0.00\end{array}$ & $\begin{array}{l}(-1.12) \\
(-0.02)\end{array}$ & 0.19 & $\left\{\begin{array}{l}2.822 \\
(1.57)\end{array}\right.$ & $\begin{array}{l}0.03 \\
-0.10\end{array}$ & $(-0.82)$ & $\begin{array}{l}4.8 \% \\
1.1 \%\end{array}$ & $\begin{array}{l}4.8 \% \\
2.3 \%\end{array}$ & 80 \\
\hline Livestock & $\begin{array}{l}\text { Lean Hogs } \\
\end{array}$ & 0.02 & $\begin{array}{l}0.18) \\
(0.36)\end{array}$ & 0.55 & $(4.92)$ & 0.18 & $\begin{array}{l}1.98) \\
(1.16)\end{array}$ & $32.0 \%$ & $33.2 \%$ & -0.16 & $\begin{array}{l}(-0.98) \\
(-0.96)\end{array}$ & 0.29 & $(2.45)$ & 0.06 & $(0.41)$ & $7.1 \%$ & $6.2 \%$ & -0.12 & $(-0.47)$ & 0.14 & (1.55) & 0.07 & $(0.61)$ & $-1.2 \%$ & $-0.9 \%$ & \begin{tabular}{|l|l|}
-0.12 \\
\end{tabular} & $(-0.55)$ & 0.18 & $3 .(2.38)$ & 0.09 & $(0.76)$ & $0.5 \%$ & $1.0 \%$ & 58 \\
\hline & & $\begin{array}{l}-10.03 \\
-0.29\end{array}$ & $\frac{(-2.30)}{(-2.35)}$ & $\frac{0.48}{0.08}$ & 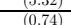 & $\frac{-0.10}{0.04}$ & (-1.46) & $\frac{21.40}{5.76}$ & $\frac{28.3 \%}{-1.5 \%}$ & $\begin{array}{l}-0.148 \\
-0.28\end{array}$ & $\frac{(-1.90)}{(-1.8)}$ & $\frac{0.23}{0.03}$ & $\frac{(2.84)}{(0.31)}$ & $\frac{0.03}{-0.03}$ & & $\frac{1.2 \%}{4.5 \%}$ & $\frac{6.6 \% \%}{-2.4 \%}$ & \begin{tabular}{|l|l|}
-0.22 \\
-0.34 \\
\end{tabular} & $\frac{(-1.91)}{(-2.22)}$ & $\frac{0.20}{0.08}$ & $\frac{91)}{56)}$ & $\frac{33}{00}$ & (0.32) & $6.1 \%$ & & \begin{tabular}{|l|l|l|}
-0.32 \\
-0.27 \\
\end{tabular} & (-3.1.67) & 0.11 & (04) & $\begin{array}{l}-\frac{-0.03}{0.01} \\
0.01\end{array}$ & $\frac{(-0.47)}{(0.09)}$ & & & \\
\hline Metals & & -0.33 & $(-3.31)$ & -0.30 & $(-2.99)$ & 0.14 & (1.4) & \% & 15 & -0.17 & $(-1.75)$ & -0.37 & $(-3.08)$ & 0.20 & $(2.32)$ & $9 \%$ & $16.3 \%$ & $\mid-0.19$ & $(-2.23)$ & 40 & $\begin{array}{l}(-2.98) \\
(-.98)\end{array}$ & 15 & $(2.49)$ & $0 \%$ & $.7 \%$ & $\mid-0.17$ & 46) & -0.49 & $\begin{array}{l}9 \\
(-4.01)\end{array}$ & .13 & .18) & $.4 \%$ & $26.7 \%$ & 80 \\
\hline & & & & -0.06 & & & & & & -0.10 & & $-\frac{0.21}{0.17}$ & & 0.6 & & & & $\mid-0.20$ & & & & & & & & & & & & & & & & \\
\hline & & & 63) & $\begin{array}{l}0.15 \\
-0.01\end{array}$ & 13) & 0.005 & & & & $\begin{array}{l}-0.24 \\
-0.04\end{array}$ & & 0.14 & & & & & & $\begin{array}{l}-0.19 \\
-0.09 \\
-0.09\end{array}$ & & & & & & & & & & & & & & & & 80 \\
\hline opica & & & & -0.01 & fis & 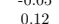 & & & & $\mid \begin{array}{l}-0.010 \\
-0.10\end{array}$ & & 0.14 & $\begin{array}{l}(1.24) \\
(049)\end{array}$ & -0.05 & & & & 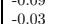 & & & & & & & & & & & & & & & & 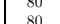 \\
\hline & & -0.0 & $0.77)$ & 0.34 & (2.28) & - 0.128 & $\begin{array}{l}(-1.0) \\
(-0.8)\end{array}$ & $4 \%$ & $8.9 \%$ & -0.16 & 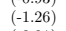 & 0.27 & $\begin{array}{l}(1.84) \\
(1.87\end{array}$ & 然. & (2) & & $x$ & \begin{tabular}{|c|c|}
-0.21 \\
\end{tabular} & 0 & 0.31 & & 0.04 & & & & $\begin{array}{r}-0.15 \\
-0.15\end{array}$ & & & & & & & & 80 \\
\hline & $\frac{\text { Rough }}{\text { Lumbe }}$ & \begin{tabular}{|l|}
-0.25 \\
0.00
\end{tabular} & $\frac{(-2.4)}{-0.04)}$ & $\frac{0.53}{0.29}$ & $\frac{(8.36)}{(2.69)}$ & $\frac{-0.12}{-0.1212}$ & $\frac{-1.32)}{-1.111)}$ & $\frac{35.0 \%}{5.0 \%}$ & $\frac{30}{6 .}$ & $\frac{-0.26}{-0.111}$ & $(-2.21)$ & $\frac{0.39}{0.37}$ & (4.72) & $\frac{-0.1}{0.22}$ & 33) & $\frac{23.3 \%}{15.8 \%}$ & $\frac{17.6 \%}{158 \%}$ & \begin{tabular}{|l|}
-0.22 \\
-0.23
\end{tabular} & $\begin{array}{l}-2.26) \\
-178)\end{array}$ & 0.35 & $(3.7)$ & $\frac{-0.14}{-0.25}$ & $(-1.63)$ & $17.0 \%$ & $13.4 \%$ & $\frac{-0.20}{-0.220}$ & $\frac{(-1.93)}{-1-2.44)}$ & 0.33 & (2.5) & $\frac{-0.10}{-0.15}$ & .41) & $\frac{13.3 \%}{13.6 \%}$ & $\frac{10.9 \%}{9.5 \%}$ & \\
\hline
\end{tabular}




\section{Table 13: Non-Overlapping Variance Risk Premia}

This table displays summary statistics for non-overlapping variance risk premia. Columns under Mean, T-Stat, Median, AR(1), Min and Max report the average, Newey-West corrected t-statistics (6 lags), median, first order auto-correlation, minimum and maximum values. Std Dev, Skew and Kurt refer to standard deviation, skewness and kurtosis. The last column reports the number of observations.

Panel A: 60 Day Variance Risk Premia

\begin{tabular}{|c|c|c|c|c|c|c|c|c|c|c|c|}
\hline Sector & Commodity & Mean & T-Stat & Median & $\operatorname{AR}(1)$ & Min & $\operatorname{Max}$ & Std Dev & Skew & Kurt & Obs \\
\hline \multirow{3}{*}{ Energy } & Crude Oil & $-2.8 \%$ & -3.55 & $-2.9 \%$ & 0.17 & -0.29 & 0.54 & 0.09 & 2.17 & 18.26 & 135 \\
\hline & Heating Oil & $-2.7 \%$ & -4.56 & $-2.4 \%$ & -0.17 & -0.46 & 0.34 & 0.07 & -0.23 & 16.40 & 132 \\
\hline & Natural Gas & $-9.1 \%$ & -8.18 & $-6.7 \%$ & -0.04 & -0.46 & 0.25 & 0.13 & -0.62 & 3.81 & 112 \\
\hline \multirow{7}{*}{ Grains } & Corn & $-2.7 \%$ & -9.51 & $-2.2 \%$ & -0.20 & -0.15 & 0.16 & 0.04 & 0.18 & 6.85 & 134 \\
\hline & Cotton & $2.8 \%$ & 8.32 & $2.6 \%$ & 0.13 & -0.09 & 0.14 & 0.03 & 0.42 & 6.19 & 106 \\
\hline & Soybeans & $-1.4 \%$ & -2.95 & $-1.4 \%$ & 0.02 & -0.17 & 0.35 & 0.05 & 2.94 & 23.49 & 135 \\
\hline & Soybean Meal & $0.1 \%$ & 0.15 & $-0.5 \%$ & -0.11 & -0.10 & 0.25 & 0.05 & 1.84 & 9.45 & 129 \\
\hline & Soybean Oil & $-0.9 \%$ & -2.69 & $-1.0 \%$ & 0.07 & -0.08 & 0.18 & 0.03 & 1.42 & 10.69 & 126 \\
\hline & Sugar & $-2.5 \%$ & -4.04 & $-2.4 \%$ & 0.12 & -0.22 & 0.15 & 0.06 & 0.02 & 4.86 & 128 \\
\hline & Wheat & $-1.0 \%$ & -3.47 & $-1.2 \%$ & -0.10 & -0.13 & 0.16 & 0.04 & 0.47 & 6.16 & 132 \\
\hline \multirow{2}{*}{ Livestock } & Lean Hogs & $-0.3 \%$ & -0.69 & $-0.9 \%$ & 0.11 & -0.10 & 0.18 & 0.04 & 1.35 & 7.83 & 84 \\
\hline & Live Cattle & $-1.0 \%$ & -6.23 & $-0.7 \%$ & 0.02 & -0.10 & 0.03 & 0.02 & -1.60 & 11.14 & 142 \\
\hline \multirow{3}{*}{ Metals } & Copper & $-1.7 \%$ & -2.46 & $-1.5 \%$ & 0.01 & -0.33 & 0.57 & 0.08 & 2.01 & 24.44 & 128 \\
\hline & Gold & $-0.8 \%$ & -3.41 & $-0.7 \%$ & 0.21 & -0.14 & 0.12 & 0.03 & 0.17 & 13.45 & 118 \\
\hline & Silver & $-0.3 \%$ & -0.58 & $0.3 \%$ & 0.19 & -0.25 & 0.12 & 0.04 & -2.42 & 19.44 & 134 \\
\hline \multirow{5}{*}{ Tropical } & Cocoa & $-2.5 \%$ & -4.85 & $-2.2 \%$ & 0.30 & -0.22 & 0.12 & 0.05 & -0.05 & 4.75 & 123 \\
\hline & Colombian Coffee & $-0.2 \%$ & -0.05 & $-3.5 \%$ & 0.36 & -0.22 & 1.04 & 0.21 & 3.02 & 14.40 & 51 \\
\hline & Oats & $-5.9 \%$ & -5.55 & $-6.4 \%$ & 0.21 & -0.24 & 0.22 & 0.07 & 1.27 & 6.43 & 90 \\
\hline & Orange Juice & $-2.7 \%$ & -3.51 & $-2.5 \%$ & 0.08 & -0.25 & 0.29 & 0.07 & 0.61 & 7.58 & 112 \\
\hline & Rough Rice & $-2.8 \%$ & -6.22 & $-2.6 \%$ & 0.10 & -0.17 & 0.07 & 0.04 & -0.42 & 4.06 & 101 \\
\hline Wood & Lumber & $-2.6 \%$ & -5.88 & $-2.5 \%$ & 0.05 & -0.21 & 0.07 & 0.04 & -1.21 & 7.74 & 122 \\
\hline
\end{tabular}

Panel B: 90 Day Variance Risk Premia

\begin{tabular}{lllllllllccc}
\hline \hline Sector & Commodity & Mean & T-Stat & Median & AR(1) & Min & Max & Std Dev & Skew & Kurt & Obs \\
\hline \multirow{2}{*}{ Energy } & Crude Oil & $-3.3 \%$ & -4.05 & $-2.8 \%$ & 0.00 & -0.28 & 0.32 & 0.07 & 0.90 & 12.01 & 89 \\
& Heating Oil & $-2.5 \%$ & -4.29 & $-2.3 \%$ & -0.10 & -0.16 & 0.28 & 0.05 & 1.64 & 14.66 & 88 \\
& Natural Gas & $-9.0 \%$ & -6.35 & $-6.7 \%$ & -0.04 & -0.51 & 0.12 & 0.11 & -1.33 & 5.72 & 74 \\
\hline \multirow{5}{*}{ Grains } & Corn & $-1.5 \%$ & -3.67 & $-1.6 \%$ & -0.21 & -0.15 & 0.16 & 0.04 & 0.75 & 7.33 & 89 \\
& Cotton & $1.3 \%$ & 5.35 & $1.1 \%$ & -0.07 & -0.04 & 0.08 & 0.02 & 0.93 & 5.20 & 70 \\
& Soybeans & $1.2 \%$ & 0.79 & $-0.7 \%$ & -0.01 & -0.10 & 1.15 & 0.14 & 6.61 & 51.85 & 89 \\
& Soybean Meal & $3.3 \%$ & 1.89 & $0.2 \%$ & -0.05 & -0.11 & 1.28 & 0.16 & 6.37 & 49.61 & 86 \\
& Soybean Oil & $-0.9 \%$ & -2.52 & $-0.8 \%$ & 0.16 & -0.10 & 0.16 & 0.03 & 1.25 & 10.04 & 84 \\
& Sugar & $-4.2 \%$ & -4.82 & $-3.7 \%$ & 0.12 & -0.21 & 0.17 & 0.06 & 0.08 & 4.49 & 85 \\
& Wheat & $-0.5 \%$ & -1.67 & $-0.8 \%$ & 0.09 & -0.09 & 0.16 & 0.03 & 1.68 & 10.46 & 88 \\
\hline \multirow{2}{*}{ Livestock } & Lean Hogs & $5.5 \%$ & 5.12 & $2.2 \%$ & -0.35 & -0.11 & 0.31 & 0.10 & 0.98 & 3.03 \\
& Live Cattle & $-0.5 \%$ & -5.72 & $-0.5 \%$ & -0.08 & -0.03 & 0.03 & 0.01 & 0.32 & 4.35 & 94 \\
\hline \multirow{2}{*}{ Metals } & Copper & $-2.3 \%$ & -3.12 & $-1.5 \%$ & 0.15 & -0.25 & 0.26 & 0.06 & -0.20 & 10.14 & 85 \\
& Gold & $-0.8 \%$ & -2.83 & $-0.8 \%$ & 0.00 & -0.14 & 0.10 & 0.03 & -0.74 & 13.42 & 78 \\
& Silver & $-1.2 \%$ & -1.53 & $-0.1 \%$ & 0.49 & -0.19 & 0.10 & 0.04 & -1.57 & 7.69 & 89 \\
\hline \multirow{5}{*}{ Tropical } & Cocoa & $-3.0 \%$ & -6.11 & $-2.8 \%$ & 0.06 & -0.14 & 0.08 & 0.04 & 0.05 & 3.42 & 82 \\
& Colombian Coffee & $-2.2 \%$ & -0.65 & $-2.3 \%$ & 0.23 & -0.45 & 0.51 & 0.16 & 0.91 & 7.39 & 33 \\
& Oats & $-1.1 \%$ & -0.47 & $-5.0 \%$ & -0.02 & -0.13 & 0.87 & 0.16 & 3.91 & 19.64 & 60 \\
& Orange Juice & $-2.3 \%$ & -3.71 & $-2.0 \%$ & 0.04 & -0.15 & 0.09 & 0.05 & -0.37 & 2.85 & 74 \\
& Rough Rice & $-1.7 \%$ & -4.04 & $-1.8 \%$ & 0.02 & -0.13 & 0.11 & 0.04 & 0.31 & 4.27 & 67 \\
\hline Wood & Lumber & $-2.0 \%$ & -3.55 & $-2.2 \%$ & 0.11 & -0.17 & 0.09 & 0.04 & -0.33 & 4.67 & 81 \\
\hline \hline
\end{tabular}




\section{Table 14: Subsample Analysis}

This table reports mean variance risk premia, t-statistics and number of observations over each subsample. We report Newey-West corrected t-statistics, with lag length equal to the maturity of variance swaps, in brackets. The first subsample covers the period prior to November 2000. The second period extends from December 2000 to November 2006. Finally, the third period runs from December 2006 onward.

Panel A: 60 Day Variance Risk Premia

\begin{tabular}{ll|ccc|ccc|ccc}
\hline \hline \multirow{2}{*}{ Sector } & \multirow{2}{*}{ Commodity } & \multicolumn{3}{|c}{ Before Nov 2000 } & \multicolumn{2}{c}{ Dec 2000-Nov 2006 } & \multicolumn{3}{c}{ Dec 2006-End } \\
\cline { 3 - 10 } & & Mean & T-Stat & Obs & Mean & T-Stat & Obs & Mean & T-Stat & Obs \\
\hline \multirow{3}{*}{ Energy } & Crude Oil & $-2.3 \%$ & -4.42 & 2364 & $-5.0 \%$ & -5.80 & 1495 & $-3.6 \%$ & -1.95 & 1166 \\
& Heating Oil & $-2.0 \%$ & -4.77 & 2563 & $-3.9 \%$ & -5.16 & 1489 & $-4.2 \%$ & -3.74 & 1158 \\
& Natural Gas & $-7.7 \%$ & -5.17 & 1749 & $-12.3 \%$ & -5.51 & 1492 & $-11.3 \%$ & -5.24 & 1153 \\
\hline \multirow{5}{*}{ Grains } & Corn & $-2.1 \%$ & -8.66 & 2824 & $-2.1 \%$ & -6.46 & 1084 & $-2.8 \%$ & -2.76 & 1116 \\
& Cotton & $2.2 \%$ & 10.28 & 2534 & $3.4 \%$ & 6.67 & 1438 & $1.5 \%$ & 3.73 & 177 \\
& Soybeans & $0.0 \%$ & -0.02 & 2554 & $-0.7 \%$ & -1.45 & 1325 & $-2.7 \%$ & -3.65 & 1132 \\
& Soybean Meal & $0.2 \%$ & 0.51 & 1661 & $-0.5 \%$ & -0.80 & 1055 & $0.4 \%$ & 0.30 & 905 \\
& Soybean Oil & $-0.8 \%$ & -3.04 & 1708 & $-1.7 \%$ & -4.25 & 1042 & $-0.6 \%$ & -0.68 & 917 \\
& Sugar & $-1.8 \%$ & -3.13 & 2586 & $-3.0 \%$ & -3.92 & 1490 & $-3.7 \%$ & -3.32 & 1149 \\
& Wheat & $-0.8 \%$ & -3.02 & 2462 & $-0.8 \%$ & -1.91 & 924 & $-0.4 \%$ & -0.38 & 954 \\
\hline \multirow{2}{*}{ Livestock } & Lean Hogs & $-0.7 \%$ & -0.81 & 950 & $-1.7 \%$ & -3.60 & 1362 & $-1.1 \%$ & -1.25 & 919 \\
& Live Cattle & $-0.7 \%$ & -8.02 & 2666 & $-1.5 \%$ & -7.75 & 1172 & $-1.5 \%$ & -6.49 & 804 \\
\hline \multirow{3}{*}{ Metals } & Copper & $-1.5 \%$ & -5.60 & 1996 & $-2.8 \%$ & -2.48 & 1071 & $-3.5 \%$ & -1.65 & 1153 \\
& Gold & $-0.4 \%$ & -2.72 & 1181 & $-1.0 \%$ & -4.00 & 1301 & $-1.7 \%$ & -2.69 & 1149 \\
& Silver & $1.2 \%$ & 5.69 & 2584 & $-1.0 \%$ & -2.83 & 1413 & $-2.6 \%$ & -3.55 & 1153 \\
\hline \multirow{5}{*}{ Tropical } & Cocoa & $-3.2 \%$ & -5.22 & 1541 & $-2.4 \%$ & -4.91 & 1311 & $-3.6 \%$ & -4.70 & 1152 \\
& Colombian Coffee & $4.2 \%$ & 1.09 & 911 & $-7.8 \%$ & -5.95 & 883 & N/A & N/A & N/A \\
& Oats & $-6.6 \%$ & -5.41 & 769 & $-6.7 \%$ & -4.57 & 781 & $-4.9 \%$ & -3.47 & 545 \\
& Orange Juice & $-2.3 \%$ & -1.69 & 1356 & $-1.6 \%$ & -1.55 & 821 & $-2.8 \%$ & -3.03 & 1126 \\
& Rough Rice & $-3.1 \%$ & -6.03 & 1283 & $-4.0 \%$ & -6.47 & 937 & $-1.3 \%$ & -2.34 & 615 \\
\hline Wood & Lumber & $-3.8 \%$ & -6.27 & 1692 & $-3.7 \%$ & -9.81 & 1259 & $-2.4 \%$ & -3.86 & 709 \\
\hline \hline
\end{tabular}

Panel B: 90 Day Variance Risk Premia

\begin{tabular}{|c|c|c|c|c|c|c|c|c|c|c|}
\hline \multirow{2}{*}{ Sector } & \multirow{2}{*}{ Commodity } & \multicolumn{3}{|c|}{ Before Nov 2000} & \multicolumn{3}{|c|}{ Dec 2000-Nov 2006} & \multicolumn{3}{|c|}{ Dec 2006-End } \\
\hline & & Mean & T-Stat & Obs & Mean & T-Stat & Obs & Mean & T-Stat & Obs \\
\hline \multirow{3}{*}{ Energy } & Crude Oil & $-2.6 \%$ & -4.09 & 2849 & $-5.3 \%$ & -5.59 & 1495 & $-3.8 \%$ & -1.59 & 1133 \\
\hline & Heating Oil & $-2.0 \%$ & -3.68 & 2563 & $-4.2 \%$ & -5.32 & 1489 & $-4.5 \%$ & -3.02 & 1138 \\
\hline & Natural Gas & $-6.9 \%$ & -4.57 & 1749 & $-10.7 \%$ & -5.49 & 1492 & $-10.3 \%$ & -5.30 & 1133 \\
\hline \multirow{7}{*}{ Grains } & Corn & $-1.3 \%$ & -3.38 & 2824 & $-2.0 \%$ & -6.05 & 1084 & $-2.8 \%$ & -2.57 & 1096 \\
\hline & Cotton & $1.1 \%$ & 7.03 & 2537 & $2.1 \%$ & 4.26 & 1438 & $1.3 \%$ & 2.75 & 159 \\
\hline & Soybeans & $2.7 \%$ & 1.09 & 2554 & $3.0 \%$ & 1.08 & 1325 & $-1.6 \%$ & -1.90 & 1112 \\
\hline & Soybean Meal & $2.3 \%$ & 1.91 & 1661 & $2.9 \%$ & 1.42 & 1055 & $9.4 \%$ & 1.34 & 885 \\
\hline & Soybean Oil & $-0.6 \%$ & -1.91 & 1708 & $-1.2 \%$ & -2.56 & 1042 & $-0.5 \%$ & -0.47 & 897 \\
\hline & Sugar & $-1.3 \%$ & -2.09 & 2572 & $-2.7 \%$ & -3.54 & 1490 & $-3.6 \%$ & -2.53 & 1129 \\
\hline & Wheat & $-0.7 \%$ & -2.06 & 2467 & $-0.8 \%$ & -1.78 & 924 & $-0.2 \%$ & -0.14 & 934 \\
\hline \multirow{2}{*}{ Livestock } & Lean Hogs & $2.2 \%$ & 1.44 & 950 & $4.2 \%$ & 2.59 & 1362 & $6.6 \%$ & 2.40 & 898 \\
\hline & Live Cattle & $-0.3 \%$ & -3.50 & 2666 & $-0.5 \%$ & -2.18 & 1172 & $-0.9 \%$ & -4.27 & 784 \\
\hline \multirow{3}{*}{ Metals } & Copper & $-1.5 \%$ & -5.29 & 1985 & $-2.7 \%$ & -2.08 & 1071 & $-3.6 \%$ & -1.43 & 1133 \\
\hline & Gold & $-0.6 \%$ & -2.73 & 1181 & $-1.0 \%$ & -3.42 & 1301 & $-1.8 \%$ & -2.28 & 1129 \\
\hline & Silver & $1.1 \%$ & 4.21 & 2693 & $-2.6 \%$ & -4.13 & 1413 & $-5.1 \%$ & -5.01 & 1133 \\
\hline \multirow{5}{*}{ Tropical } & Cocoa & $-3.2 \%$ & -4.48 & 1541 & $-2.5 \%$ & -5.43 & 1311 & $-3.7 \%$ & -4.16 & 1132 \\
\hline & Colombian Coffee & $4.8 \%$ & 1.10 & 911 & $-7.7 \%$ & -6.81 & 863 & $\mathrm{~N} / \mathrm{A}$ & $\mathrm{N} / \mathrm{A}$ & $\mathrm{N} / \mathrm{A}$ \\
\hline & Oats & $-0.9 \%$ & -0.19 & 769 & $-2.7 \%$ & -0.85 & 781 & $-2.6 \%$ & -1.67 & 525 \\
\hline & Orange Juice & $-3.6 \%$ & -3.65 & 1356 & $-2.3 \%$ & -2.18 & 821 & $-2.9 \%$ & -2.83 & 1106 \\
\hline & Rough Rice & $-2.2 \%$ & -3.48 & 1283 & $-3.1 \%$ & -3.94 & 937 & $-1.1 \%$ & -2.11 & 595 \\
\hline Wood & Lumber & $-3.2 \%$ & -4.16 & 1692 & $-2.1 \%$ & -5.00 & 1259 & $-0.6 \%$ & -0.72 & 689 \\
\hline
\end{tabular}

